\title{
Zur Kenntnis s
}

des

\section{GENERATIONS WECHSELS}

und der

\section{PARTHENOGENESIS}

\section{BEI DEN INSEKTEN.}

Von

Dr. Rud. Leuckart,

Professor der Zoologie und vergleichenden Anatomie in Giessen.

I N H A I T.

Generationswechsel der Aphiden. - Ceschichtliches zur Lehre von der Parthenogenesis. Parthenogenesis der Coceiden und Chermesarten. - Parthenogenesis der Psychiden. Parthenogenesis der Bienen, Hummeln u. a. - Schlussbetrachtungen.

Mit einer lithographirten Tafel.

\section{FRANRFURT a. M.}

VERLAG VON MEIDINGER SOHN \& COMP.

1858.

$$
m \cdot W \text {. }
$$


(c)

Q 4463

$\angle 65$

Q12. Ent.

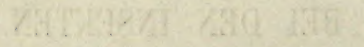

best ac

(254666.

Druek von Aug Osterrieth,
in Frankfort a. M.

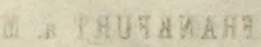

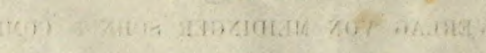


Der Inhalt der nachfolgenden Blätter betrifft eine Erscheinung aus der Fortpflanzungsgeschichte der Thiere, die in vollem Maasse die Aufmerksamkeit und das Interesse verdient, die sie seit Publication der von Siebold'schen Abhandlung über die "wahre Parthenogenesis bei Schmetterlingen und Bienen" (Leipzig 1856) gefunden hat. Es ist aber nicht blos eine Bestätigung der durch v. Siebold und zum Theil schon früher durch mich hierüber publicirten Angaben, die ich in diesen Blättern mittheile; dieselben enthalten auch eine Anzahl neuer Beobachtungen und Thatsachen, die unsere Erfahrungen über Parthenogenesis, wie ich hoffe, nach mehr als einer Richtung hin erweitern werden. Meine Untersuchungen würden übrigens wohl kaum ihren gegenwärtigen Umfang erreicht haben, wenn mir dabei nicht die freundlichste und uneigennützigste Unterstïtzung zahlreicher fachverwandter Forscher und Bienenfreunde zur Seite gestanden hätte. Ich fühle mich gedrungen, denselben hiermit öffentlich meinen wärmsten Dank zu sagen und das Büchlein ihrer nachsichtigen Theilnahme zu empfehlen.

\section{Dr. Leuckart.}




\section{D r u ckfe h ler.}

Seite 8 Zeile 2 von unten lies: "des Gen. Empusa" statt „der Ger. Empusa."

* $20 \pi 3 n$ n 30 nunserer Aphiden statt : nebrerer Aphiden.

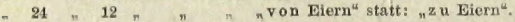

"26 "17" oben " "das mioh" statt: "die mich".

Bei dem Separatdruck dieses Aufsatzes aus Moleschott's Untersuchungen wurde vergessen, folgende Seitenangaben zu verändern:

Seite 38 Zeile, 17 von oben neite $9^{u}$ statt "Seite $335^{a}$.

n $44 n 12 n$ unten ${ }_{n}$ Seite $2^{\text {af }}$ statt ${ }_{n}$ Seite $328^{4}$.

7. 45 n 17 n $n$ Seite $24^{\circ}$ statt "Seite $350^{4}$

" $49 " 8$ " 8 n "Seite $46^{4}$ statt ${ }_{n}$ Seite $372^{*}$.

- 51,8 " oben ${ }_{n}$ Seite $27^{*}$ statt "Seite $953^{4}$.

" 65 " $9{ }^{n}{ }_{n}$ "Seite $46^{*}$ statt "Seite $357^{4}$.

" $64 " 5 \%$ unten "Seite $68^{4}$ atatt "Seite $394^{*}$.

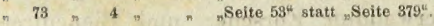




\title{
Zur Kenntniss des Generationswechsels und der Parthenogenesis bei den Insekten.
}

\author{
Von \\ Rud. Leuckart, Professor in Giessen.
}

(Mit 1 Tafel.)

1. Der Generationswechsel der Aphiden.

Die entomologische Literatur hat seit Anfang des vergangenen Jahrhunderts zahlreiche Beobachtungen über „Fortpflanzung ohne vorhergegangene Begattung“ aufzuweisen, oder doch wenigstens Beobachtungen, die in solchem Sinne gedeutet wurden. Viele dieser Fälle sind von v. Siebold in seiner Abhandlung über die „wahre Parthenogenesis bei Schmetterlingen und Bienen* (Leipzig 1856) zusammengestellt; man könnte deren Zahl leicht noch durch Nachträge vermehren, wie das denn auch neuerlich z. B. von Lubbock (Transact. roy. Soc. 1857) geschehen ist.

Unter allen diesen Beobachtungen aber ist keine, die das Interesse der Naturforscher in einem höheren Grade in Anspruch genommen hat, als diejenige, die sich auf die Fortpflanzung der Blattläuse oder Aphiden bezieht. Während es sonst immer nur einzelne seltene Fälle waren, in denen man die von (vermuthlich) unbefruchteten Insektenweibchen abgelegten Eier sich entwickeln sah, schien bei den Blattläusen eine Fortpflanzung ohne vorhergegangene Begattung ganz constant den grössesten Theil des Jahres hindurch stattzufinden. 
Durch die Untersuchungen von $\mathrm{R}$ éa u m ur, Bonnet, de G eer u. A. war zur Genüge nachgewiesen, dass es nur im Spätherbst männliche Blattläuse gebe. Man sah diese Männchen mit den Weibchen in Begattung und beobachtete bald darauf das Eierlegen. Die Eier überwinterten und producirten im nächsten Frühjahr eine Brut von Individuen, die durch ihre Fortpflanzungsfähigkeit den Weibchen glichen, sich aber von diesen nicht selten durch mancherlei äussere Organisationsverhältnisse und weiter auch dadurch unterschieden, dass sie statt Eier eine lebendige Nachkommenschaft hervorbrachten, und das überdies ohne männliches Zuthun. Solche vivipare Blattläuse folgten meist in mehreren Generationen auf einander, bis schliesslich, bei Eintritt der ungünstigen Jahreszeit, wieder eine Generation eierlegender Weibchen und Männchen zum Vorschein $\operatorname{kam} *)$.

Die Richtigkeit dieser Thatsachen konnte nicht bezweifelt werden; sie war auch von Bonnet und anderen, späteren Beobachtern auf experimentellem Wege, durch Isolation und fortgesetzte sorgfältige Ueberwachung der einzelnen Individuen, hinreichend festgestellt. Bonnet sah bei seinen Experimenten neun Generationen von Blattläusen ohne männliche Individuen auf einander folgen (Traité d'insectologie 1745 1. Part.) und Duva u sogar deren eilf (Mém. du Mus. d'hist. natur. P. III. p. 126); ja den Bemühungen von Kyber gelang es, durch Regulirung der Temperatur eine Blattlauscolonie vier Jahre lang**) ohne Männchen, durch mehr als fünfzig Genera-

*) Bei den meisten Aphiden (besonders den sohr zablreichen Arten des Gen. Aphis u. and.) scheint die Zahl der viviparen Zwischengenerationen etwa 12 bis $16 \mathrm{zu}$ betragen, doch giebt es auch Arten, bei denen weniger, selbst Arten, bei denen nur eine einzige oder zwei solcher viviparen Generationen vorkommen. Am abweichendsten verhalten sich die Arten des Gen. Chermes, die sich, wie schon de Geer und Kaltenbach beobachteten, ausschliesslich durch Eier fortpflanzen, und sich dadurch, wie später noch specieller erörtert werden soll, an dio Schildluluse anschliessen.

**) Bei dieser Gelegenheit will ich übrigens bemerken, dass auch im Freien (unter Steinen, Laub, Rinde u. s, w.) mitunter einzelne vivipare Blattliase überwintern. 
tionen hindurch, am Leben zu erhalten (Germar's Magaz. der Entomologie 1812, S. 14).

Je sicherer nun aber diese Beobachtungen waren, desto schwieriger erschien die physiologische Deutung derselben. Es kann nicht meine Absicht sein, die verschiedenen Erklärungsversuche der Forscher hier aufzuzählen und zu prüfen; ich will nur so viel hervorheben, dass man die viviparen Blattläuse sehr allgemein als Weibchen betrachtete, die sich wesentlich in derselben Weise, wie die Weibchen der letzten Herbstgeneration fortpflanzten und von dieser überhaupt nur insofern verschieden seien, als ihre Eier der Befruchtung nicht bedürften und bis zur vollständigen Entwickelung der Embryonen in den Geschlechstorganen verweilten. Diese Ansicht blieb auch dann noch gültig, als durch die Untersuchungen von Siebold's (Froriep's neue Notizen 1839. N. 262) der Nachweis geführt war, dass die viviparen Blattläuse nicht nur der Samentasche entbehrten, die den oviparen Weibchen ganz in gewöhnlicher Weise zukam, sondern auch überdies durch eine besondere Bildung ihrer "Eierstocksröhren" von letzteren verschieden seien,

Erst mit dem Versuche von Steenstrup, die Fortpflanzung der Aphiden dem Gesetze des Generationswechsels unterzuordnen (über den Generationswechsel S. 121), also erst mit dem Jahre 1842 begann eine andere Auffassung sich Bahn zu brechen. Die weibliche Natur der viviparen Blattläuse wurde von S teenstrup in Zweifel gezogen; er erklärte letztere für Ammen, d. h. für Geschöpfe, die niemals geschlechtsreif würden, also auch keine Eier producirten, wohl aber die Fähigkeit einer ungeschlechtlichen Vermehrung besässen und durch diese denn auch schliesslich nach mehrfachen Zwischengenerationen eine geschlechtlich entwickelte Brut hervorbrächten. Die Fortpflanzung der viviparen Blattläuse erschien hierbei natürlich X nicht mehr als eine Entwickelung unbefruchteter Eier, sondern als eine Entwickelung von inneren Knospen oder Keimkörnern, die überhaupt keiner Befruchtung bedurften.

Obwohl Steenstrup den eigentlichen Beweis für die Richtigkeit seiner Behauptung nicht beigebracht hat und den hier vorliegenden 
Fall überhaupt mehr nach der Analogie mit anderen ähnlichen Vorgängen, als nach besonderen, eigenen Beobachtungen und Untersuchungen beurtheilt hatte, fand die Annahme eines Generationswechsels bei den Aphiden doch bald eine allgemeine Verbreitung. Schien es doch, dasa mit dieser Deutung das Räthsel der ganzen Erscheinung in einfacher und naturgemässer Weise erledigt würde und die Unterschiede zwischen den viviparen und oviparen Blattläusen dabei ihre volle Erklärung fänden.

Was Steenstrup unterlassen hatte, suchte V. Carus in seiner Abhandlung über den Generationswechsel (Leipzig 1849 S. 20) nachzuholen, indem er sich die Anfgabe stellte, durch nähere Untersuchung und Vergleichung die Verschiedenheit der bei den viviparen und oviparen Blattläusen gebildeten Keimstoffe nachzuweisen. Man kann jedoch nicht sagen, dass V. Carus seine Aufgabe in glücklicher Weise gelöst und die vorliegende Frage zum Abschlusse gebracht hätte, wenn er die Resultate seiner Untersuchungen in den Satz zusammenfasst, „dass bei den eierlegenden Aphiden eire Zelle mit Kern und Kernkörperchen die Grundlage des jungen Individuums ausmache, während dieses sich bei den lebendig gebärenden Ammen - wie es auch für die Trematodenammen behauptet wurde $\checkmark$ nur aus einer amorphen Körnermasse zusammensetze". Bei der vollkommenen histologischen Uebereinstimmung der von beiderlei Individuen erzeugten Nachkommen musste diese Behauptung von Anfang an höchst unwahrscheinlich sein; sie ist auch in der That eine irrthümliche. Nach den Untersuchungen von Leydig (Oken's Isis 1848. S. 184 und Zeitschrift für wissenschaftliche Zool. II. S. 62) und v o n Burnett (Proceed. americ. assuc. VII Meet. helt 1853. p.203 ff. oder the americ. Journ. of science and arts. 1854. Vol. XVII. p. 62) kann es keinem Zweifel mehr unterliegen, dass sich die Sprösslinge der viviparen Aphiden ganz in derselben Weise, wie die der oviparen Individuen, aus Zellen entwickeln. Durch Leydig haben wir sogar erfahren, dass die Entwickelung derselben ursprünglich an eine einzige Zelle anknüpft, die nach Art der Eizelle in dem obersten blinden Ende der Keimstocksröhren ihren Ursprung nimmt. 
Leider haben die beiden letztgenannten Forscher ihre Untersuchungen ausschliesslich auf die Keimstoffe der viviparen Aphiden beschränkt, die Eier der oviparen Weibchen aber unberïcksichtigt gelassen *). Da nun die Mittheilungen von V. Carus über diese letztern gleichfalls unzureichend sind, so ist es nach den vorliegenden Beobachtungen schwer, wenn nicht unmöglich, die Beziehungen dieser beiderlei Gebilde resp. deren etwaige Verschiedenheiten gehörig abzuschätzen. Es kann uns deshalb auch nicht überraschen, wenn wir in allerneuester Zeit, nachdem die Möglichkeit einer spontanen Entwickelung bekanntlich auch an wirklichen Eiern ausser Zweifel gestellt ist, die viviparen Aphiden bei einer Anzahl von Forschern wieder zu Weibchen werden sehen. So spricht sich $u$.A. de Filippi in der zweiten Auflage seines Werkes über die Fortpflanzung der Thiere (delle funzioni riproduttive degli animali, Milano 1856, p. 77) aus **) und so auch Lubbock in seiner Abhandlung über die Parthenogenesis der Daphnien (1. c.), der letztere mit ausdrücklicher Berufung auf Leydig, dessen primitive Keimzelle geradezu als Ei gedeutet und mit den sogenannten Wintereiern der Daphnien ( agamic egg") zusammengestellt wird. Dazu kommt noch weiter eine höchst auffallende Beobachtung von C. v. Heyden (Stettiner entomol. Zeitung 1857, S. 83), der im Spätherbst einst bei einer grossen, einer Colonie zu Lachnus quercus zugehörigen Blattlaus die Geburt eines Männchens beobachtete und damn weiter fand, dass die übrigen der Mutter dieses Männchens vollkommen gleichen Individuen fast alle eben solche Männchen auf dem Rücken trugen und damit in Begattung begriffen waren, zum Theil auch Eier legten **). C. v.

*) Burnett hat allerdings an dem zuerst citirten Orte nachträglich noch einigo Notizen über die Eierbildung der Aphiden zugefügt, jedoch sind diese so aphoristisch, dass sie keine weitere Berücksichtigung beanspruchen können.

**) "Gli aphidi vivipari sono dunque da considerarsi come vere femini vergini. “ w:*: Schon Kaltenbach hat die Mannchen zu Lachnus quercus und deren Begattung mit den eierlegenden Weibchen gesehen. (Monographie der Pflanzenläuse S. 166.) Kalten bach bemerkt dabei, dass Lachnus quercus die einzige 
Heyden zieht aus dieser Beobachtung den Schluss, dass bei Lachnus quercus dasselbe Individuum eine Zeit lang als Amme lebendige Junge und zwar zuletzt ein Männchen gebäre, gegen den Winter hin aber ein gewöhnliches Weibchen werde und dann nach vorausgegangener Begattung Eier lege. Eine solche Schlussfolgerung liegt allerdings nahe, allein wir dürfen doch nicht übersehen, dass dieselbc eine Voraussetzung in sich einschliesst, die nicht bewiesen ist, die Voraussetzung nämlich, dass die weiblichen Individuen, die v. Heyden in Begattung fand und von denen er das Eierlegen beobachtete, eben so, wie das eine nicht in Begattung gesehene Individuum, vorher lebendige Junge zur Welt gebracht hätten. Durch eine andere, einstweilen freilich eben so wenig bewiesene Voraussetzung, durch die Annahme nämlich, dass die viviparen und oviparen Generationen von Lachnus quercus in Form, Grösse und Ausstattung des Körpers vollkommen unter sich übereinstimmten, wird der hier vorliegende Fall seine ganze scheinbare Bedeutung verlieren und sich den frühern Erfahrungen vollständig anschliessen. So viel ist jedenfalls gewiss, dass die Heyden'sche Beobachtung nicht die Beweiskraft hat, die ihr vielleicht von mancher Seite beigelegt wird.

Wenn ich in Folgendem meine eigenen Untersuchungen über die Fortpflanzung der Aphiden darlege und dabei zu Resultaten komme, die mit der Heyden'schen Annahme einer Umwandlung der viviparen Blattläuse in ovipare Weibchen unvereinbar erscheinen, so ist damit übrigens noch nicht ohne Weiteres die Unrichtigkeit der letzteren nachgewiesen. Für ein solches Unternehmen dürfte es unumgänglich nöthig sein, den Lachnus quercus selbst zu untersuchen, wozu ich bisher noch keine Gelegenheit hatte *).

ihm bekannte über der Erde lebende $\mathrm{Bl}$ attlausart mit flügellosen Munnchen sei. Dass solche Fulle jedoch noch mehr vorkommen, beweist meine Beobachtung über Schizoneura corni, für die ich auf die spätern Blätter verweise.

*) Uebrigens hat schon de Geer für Aphis rosae u. a. sich sehr entschieden gegen die Möglichkeit einer solchen Umwandlung der viviparen Blattlause in ovipare ausgesprochen. Vergl, Abhandlungen zur Geschichte der Insekten, Bd. III, S. $12 \mathrm{ff}$, 
Meine Beobachtungen sind (Ende October vergangenen Jahres) an zwei versehiedenen $\Lambda$ rten angestellt, an der :uf Cormus alba massen-

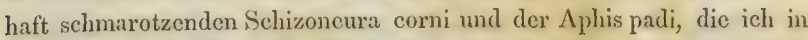
eben so grosser Menge von den Blättern des Prunus padus sammelte. In beiden Fillen konnte ich mit Lecichtigkeit, wie v. Sicbold bei

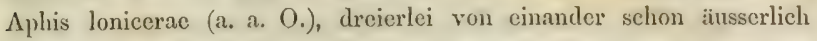
selir abweichend gebildete Formen unterscheiden; bei Schizoneura corni eine gefliigelte Form von ansehnlicher Grösse, die sich bostïndig als vivipar auswies *) und zwei ungefligelte Formen, eine grässere, das Weibehen, und eine kleinere, durch ihren schlanken Kïrper und ihre lïngern Beine und Fühler leicht von den Weibehen zu unterseheiden, das Münnchen *⿻丷木⿰夕㐄巜). Bei Aplis padi war dic Organisation dieser dreierlei Individuen etwas anders; es fanden sich (wic es v. Siebold auch für $\Lambda$. lonicerae angiebt) zwei geflügelte Formon und cine ungeflügelte. Die letztere ergab sich als ovipare Generation, wiilurend die geflïgelten Individuen theils Männchen (dic kleinern und schlankern), theils auch ***) vivipare Ammen (die grössern und plumperen) waren. Die weiblichen Individuen waren dabei in beiden Fillen durch eine hellere, gelbliche Firbung ausgezeichnet und iiberhaupt in einer so charakteristischen Weise von den viviparen Exemplaren verschieden, dass eine Uebertragung der v. Heyden'schen Vermuthung auf die hier vorliegenden Fälle schon von vorn herein als unzulässig erscheinen musste.

Bei Untersuchung der innern Geschlechtsorgane fanden sich dieselben durchgreifenden Verschiedenheiten, wie im Aeussern, nirgends

*) Ob bei Schizoneura corni nicht auch in frïhern Monaten ungetlügelte Ammen vorkommen, wio bei zahlreichen andern Blattliusen, muss ich unentschicden lassen.

**) Den frühern Zoologen, Kaltoubach nicht ausgenommen, ist das Munnchen von Schizoneura corni unbekannt geblieben. Auch die Existenz besonderer oviparer Weibchen haben dieselben nicht gekannt; Kaltenbach giebt an, dass Schizoneura und einige andere Formen sich ausschlicsslich durch vivipare Individuen fortpflanzten.

***) In frühern Monaten gicbt es von $\Lambda$ phis padi auch geflügolte Ammen. 
aber Ucbergänge, wic sic doch nach der $\Lambda$ nnalıme v. Heyden's vorhanden sein naüssten.

Bevor ich diese Behauptung durch cine speciclle Beschreibung der Generationsorgane und Keimstoffe bei den oviparen und viviparen Individuen im Einzelnen nachweise, mögen, wenn auch vielleicht nur der Vollständigkeit halber, einige Bemerkungen über die - bisher nur so selten untersuchton - männlichen Organo hier Platz finden (vergl. Fig. 1).

Die Hoden, die sonst bei den Insekten meist parige Gebilde darstellen, sind in beiden Arten zu einer unpaaren Masse vereinigt, die, wie bei den männlichen Schmetterlingen, obcrhalb des Darmes in der Mittellinie des Rückens gelegen ist. Bei Schizoneura corni *) ist diese Masse ganz einfach, von einer fast kugelrunden Form, wio es nach Morren's Beschreibung (Annal. des sc. natur. 1836. T. VI. p. 87) auch bei Aphis persicae der Fall zu sein scheint, bei Aphis padi dagegen nicht bloss durch cine mittlere Finschnüung in eine rechte und linke II:ilfte getheilt, sondern anch jederscits vom Rande aus zweimal gekerbt, so dass der Hoden eine sechslappige Gestalt hat, wie es v. Siebold bei Aphis lonicerae beschreibt, nur dass dieser (besonders vergl. Annat. der Wirbellosen S. 654) dio Lappen als eben so vicle einzelne dicht an cinander gedrängte Hodensïcke ansicht. Der von der Hodenwand umschlossene Innenraum enthält Samenfïden, die bei Schizoneura zu anschnlichen Bündeln von kegel- oder birnförmiger Gestalt zusammengruppirt sind. Aus der unpaaren IIodenmasse kommen zwei ziemlich lange und geschlängelte Samenleiter, dic an der Seite des Darmkanales herablaufen und in der Medianlinie der IInterleibsspitze zu einem unpaaren, ziemlich muskulösen Ductus excretorius zusammentreten. An der Vereinigungsstelle inseriren sich zwei ziemlich lange kolbenförmig aufgetriebene

*) Die milnnlichon Individuen der von mir beobachteten Colonie gingen fast allo (auch im Freien) an einer Pilzkrankheit zu Grunde. Der Pilz ist eino neuo Art der Ger. Empusa (Entomophthora Fres.) und wird mit andern alhulichen Formen nllehstens von Herrn Dr. Fresenius beschricbon werden. 
Blindschläuche, die keine Samenblaischen sind, wie Morren wollte, sondern cin Paar Anhangsdrüsen darstcllen, deren Secret mit dem Sperma zugleich entlecrt wird, wic das bekanntlich sehr allgemein bei den Insekten der Fall ist. Das letzte Ende des Ductus excretorius functionirt als Penis, indem es sich durch die Geschlechtsöffnung nach aussen hervorstülpt, so dass die frühere Innenflïche zur :iusseren wird. Fs stellt in diesem Zustande cinen zicmlich ansehnlichen Anhang dar, der nach unten herabhängt und in der Mitte knieförmig nach vorn sich umbiegt, also Lagerungsverhältuisse zeigt, die mit der schon oben bei Lachnus quereus hervorgehobenen Stellung des Mïnnchens wïhrend der Begattung völlig übereinstimmen *).

Dic Bildung der weiblichen Organe habe ich besonders bei $\Lambda$ phis padi untersucht, wo sich dieselben leichter in continuo präjariren liessen, als bei Schizoneura, die sich uibrigens in allen wesentlichen Punkten an erstere anschliesst. Wie bei den übrigen Insekten, bestehen die weiblichen Organe unserer Aphiden (Fig. 2) aus zwei scitlich symmetrischen Eierstöeken, die den beiden Enden eines Y förmigen, deutlich muskulösen Leitungsapparates aufsitzen. Der untere, unpaare Schenkel dieses Leitungsapparates, der durch Lage und Ausmiundung nach aussen dem männlichen Ductus excretorius entspricht, steht an seinem unteren Ende, wic schon v. Siebold nachgewiesen hat, mit cincm rundlichen, gestielten Samenblïschen in Zusammenhang, das ich bei fast allen von mir untersuchten Weibehen voll mit Sperna gefült sah. Anhangsdrüsen fehlen, dagegen münden dicht linter dem Samengange noch zwei kurzgestielte, birnförmige Drüsensehläuche mit dicker Zellenwand und einem fettig aussehenden Inlialte, ein Apparat, der auch sonst schr allgemein bei den Insektenweibehen vorkommt und nach v. Siebold (unrichtiger Weise) dazu dienen soll, dic Eier beim Ablegen mit einem klebrigen Ueberzuge *; zu versehen.

*) Schon de Goer kannte diese Bildung des Penis bei den mänulichen Blattlitusen, a. a. O. Bd. III, Tab. 3 Fig. 19 u. Tab. 4 Fig. 6 u. 9.

*y) Dieser klebrige Ueberzug dur Insekteneier wird nach meinen Beobachtungen (Miillor's Archiv fiir Anatomic und P'hysiologie, 1856, S. 116) bereits im Hierstocke abgesondert. 
Der einzige Theil dieses Apparates, der uns hier naiher interessirt, ist der Eierstock. Derselbe besteht, wie gewölnnlich bei den Insekten, aus eine: Anzahl von Eiröhren, dio den Finden des zwcisehenklichen Leitungsapparates aufsitzen. v. Sicbold zailhlte bei seiner Art vier soleher Röluren in jeclem Ovarium; bei $\Lambda$ plis padi finden sich deren meist nur drei und bei Schizoneura corni sogar noch weniger, indem ich hier nie melı als zwei Röhren neben einander beobachten konnte. Die Darstellung, die v. Siebold (a. a. O.) von diesen Eirühren giebt, ist im Allgemeinen vollkommon richtig; sio ist aber in sofern unvollständig, als der Verfusser keine geniigende Linsicht in den Vorgang der Eibildung gewonnen hatte; ein Ucbelstand, der hier und da auch die Crenanigkeit der Besehreibung becintrichtigt*). So nennt v. Siebold u. a. die Eiröhren unserer Thiere zweikammerig, während sie in Wirklichkeit nur cinkammerig sind, d. $\jmath_{1}$. immer nur ein einziges Ei lervorbringen. Allerdings sicht man auf gewissen Entwieklungsstadien dio Eiröhren unserer Thiere dureh eine ringfürmige Einschnürung in zwei $\mathrm{Ab}$ schnitte getheilt, aber diese beiden Abschnitte reprïisentiren nicht zwei Eikammern, sondern die auch sonst so häufig bei den Insekten rorkommenden Keim- und Dotterfïcher einer cinzigen Eikammer. Nur das untere Fach enthält das Ei mit Keimblïschen und Dotter, wiihrend das obere Fach eine Anzahl grösserer Zellen (Dotterbildungszellen nach Stein) in sich einschliesst, die nur einen indirecten Antheil an der Entwickelung des Eies nehmen und keineswegs Eikeime darstellen, wie v. Siebold zu vermuthen geneigt war. Die 'Zilhl der Eier, die ein $\Lambda$ plidenweibchen im Innern eirschliesst**), ist niemals grösser, als die Zahl der Eiröhren - im Ganzen also nur unbedeutend und weit geringer, als wir das sonst bei den Insekten-

*) Gleiches gilt auch ron V. Carus, dessen Beschreibung (a. a. O. S. 23) übrigens auch sonst noch manche Mangel hat.

*a:) Ich sage hier mit Alssicht nicht ${ }_{n} \mathrm{legt}^{*}$, denn ich weiss nicht, ob sich nach Ausstossung des einen Eies nicht vielleicht ein zwoites in derselben Eirőhro bildet, 
weibchen zu finden gowolnt sinel. Freilich ist die Grösse dieser Wier dafür um so ansehnlicher; sic beträgt bei $\Lambda$ plis padi z. B, $0,56 \mathrm{Mm}$., mehr, als die Hälfte des ganzen Weibchens.

Mit dieser beträchtlichen Grösse der Eicr mag es denn auch wciter zusammenhängen, wenn wir sehen, dass die Eiröhren unserer Thicre mit ihrom Inhalte ganz constant auf sehr verschiedenen Entwickelungsstufen stchen. Es gelangt immer nur cin cinziges Ei auf einmal zur Reife; die betreffende Eirölure misst dann vielleicht das Doppelte und Dreifacho der übrigen.

Zur Untersuchung der frühesten Stadien empfohle ich dic noch im Innern ihrer Mutter enthaltenen weiblichen Embryonen*), bei denen die Genitalapparate bereits deutlich entwickelt sind. Die Eiröhren derselben messen etwa 0,1 Mm. und besitzen ( $\mathrm{Mig} .3$ ) cine einfache Keulenform. Sie bestehen histologisch aus einer structurlosen Membrana propria und aus zweicrlei zellenartigen Gebilden, die den inneren Raum derselben ausfüllen. Die einen dieser G'ebilde, die das weitere obere Fnde der Eirölıre cinnchmen, sind durch ihre Grösse ( $0,01 \mathrm{Mm}$.) und ihr bliischenförmiges helles Aussehen auserezeichnet. Sic umschliessen einen soliden, scharf contourirten Kern und liegen in einer zihen Zwischensubstanz, die sich im Umkreis der einzelnen Bläschen zu einer dünuen und unvollkommen abgegrenzten Belegsehicht verdichtet. Die übrigen, in dem zweiten, kegelförmig verjuingten Abschnitte der Eiröhren enthaltenen Zellen sind nicht bloss sehr viel kleiner $(0,003 \mathrm{Mm}$.), sondern auch mit einer dicht auf dem Kerne aufliegenden Zellenwand versehen, so dass man sie bei schwïcherer Vergrösscrung leicht für blosse Körner halten könnto. Von einem eigentlichen Eikeim ist in den meisten dieser Firöbren anch keine Spur aufzufinden. Nur hier und da gelang es in etwas grösseren Eiröhren auf der Grenze der zweierlei Zellengruppen ein kernloses helles Bläschen von 0,02 Mm. zu unterscheiden,

*) Die weiblichen Individuen werdon also - bei $\Lambda$ phis pađi - als solche erzeugt; was bedarf os dabci der II eyden'schen Annahmo, dass sio durch Umwandlung früheror Ammen entstlinden? 
das ich als Koimbliischen in Anspruch nehmen möchte. So viel ist jedenfalls gewiss, dass sich ein solches Kímblïschen in den 0,2 Mn. messenden kleinsten Eiröhren der frei lebenden Weibehen, die meist anch bald nach ilırer Geburt befruchtet werden, bei einiger Sorgfalt der Untersuchung fast beständig nachweisen lïsst.

Bei dem ersten Auftreten des Keimblïscliens ist dio Gestalt und Bildung der Eiröhre noch unverïndert dic frithere. Nur ist die Grösse der beiderlei Zellen etwas ansehulicher geworden, die der obern auf 0,014 Mm., der untern auf 0,0037 gewachsen. Nach kur'zer Zeit nimmt die Eiröhre jedoch eine abweichende Gestalt an.

Im Umkreis des Keimbläschens beginnt die Ablagerung ciner eiwcissartigen Massc. Aufungs (Fig. 4) Inur eine dünne Schicht, wiichst dieselbe sehr bald zu einem ansehnlichen Körper heran, der die kleinen Zellen, in deren Mitto er entstanden ist, an die Wandungen der Firölne drängt und durelı fortgesetztes Wachsen allmiilig die ganze untere Irïlfte dieses Gebildes zu einer selbstïndigen Anschwellung auftreibt. Der obere, früher dickere Abschnitt der Eiröhre veriindert sich keineswegs in gleich atuffallender Weise. Lr nimmt im Laufo der Entwickelung allerdings gleichfalls an Grösse zu, doch im Ganzen nur etwa um das Doppelte seines früheren Durchnessers (bis höelıstens $0,2 \mathrm{Mm}$.), wïhrend die untere $\Lambda \mathrm{n}$. schwellung der Eirölıre, die den Eikeim in sich cinschliesst, sich allmialig in ein Gebilde von mehr als 0,5 Mm. Iröhe und 0,23 $\mathrm{Mm}$. Dicke verwandelt. Durch das ungleiche Wachsthum dieser beiden Abschnitte entsteht nun zwischen beiden jene oben erwithnte ringförmige Furche, durch welche die Eiröhre in die zwei von v. Sicbold gesehenen Fiicher getheilt wird (Fig. 2).

I ür Jemand, der die Entwickelungsgeschichte der Insekteneier kennt oder auch nur die Monographic von Stein über dio weiblichen Geschlechtsorgane der Küfer (vergl. Anat. und Physiologic der Insekten 1847) zu Rathe zicht, kann die Bedeutung dieser beiden Eirölırenficher nicht dem geringsten Zweifel unterliegen

Das obere ist das sogenannte Dotterfach. Es enthält im Wosentlichen noch immer dieselben Gebilde, die wir früher in dem 
blinden kolbenförmigen Ende der primitiven Eirölre vorgefunden hatten. Insofern sind allerdings mit diesem Inhalte Verënderungen vor sich gegangen, als die hellen Blïschen allmilig bis auf 0,017 Mm. gewachsen sind und die Unhü̈llungsmasso derselben sich durch schärfere Begrenzung und Abscheidung einer zarten MIembran in eine Zelle verwandelt hat. Diese Zellen, die sogenannten Dotterbildungszellen, füllen trotz ihrer mässigen Anzahl (die ungefihr ein Dutzend beträgt) den ganzen Innenraum des Faches aus. Sie verbinden mit einer ganz ansehnlichen Grösse eine meist keilfürmige Gestalt und sind der Art zusammen gruppirt, dass ihre Spitzen im untern Ende des Dotterfaches genau auf einander stossen. Ihr Inhalt hat eine feinkörnige trübe Beschaffenheit.

Von ganz verschiedener Bildung ist dagegen das untere sogenannte Koim- oder Eifach. Dic Ablagerung im Umkreis des Keimbliischens, die den wesentlichsten Inlialt desselben ausmacht, liat unter beständiger Grössenzunahme ihre ursprünglich helle und eiweissartige Beschaffenheit verloren und sich allmiilig in eine undurchsichtige kürnige Masse verwandelt, die von zahllosen grösseren und kleineren Fetttropfen durchsetzt ist. Sie ist mit anderen Worten der Dotter des späteren Eies geworden. Je melr sich diese Dottermasse anhäuft, desto schwieriger wird der Nachweis des Keimbläschens im Inneren derselben, jedoch ist es mir mitunter noch an Eiern von 0,5 Mm., die dem Abschlusse ihrer Entwickelung sehr nahe waren, gelungen, mich von der Anwesenheit desselben mit Sicherheit zu überzeugen. Es war in diesen Falle, wie früher, eine helle, runde Blase, die einen Durchmesser von $0,37 \mathrm{Mm}$. besass und mehrere kleine Kerne, sogenannte Keimflecke, in sich einschloss. Die Zellenlage im Umkreise des Dotters, deren Elemente vor Entstehung des Keimbliischens den ganzen Inhalt des Keinfaches ausmachten, wird in demselben Verhialtnisse dünner, als das Ei sich entwickelt; sic besteht in der ganzen zweiten Ifältto der Eibildung aus ciner einfachen Schicht, die nach Art ciner Driisenzellenschicht die Immenfliche der Membrama propria auskleidet und neben den Zellen des Dotterfiches gewiss auch das Ihrige zu der Alscheidung der Dotter- 
masse beiträgt. Die Grösse dieser Zellen bleibt übrigens bestündig sehr weit hinter der Grösse der terminalen Dotterbildungszellen zurück; sie betrïgt nur 0,011 Mm. (Kern =:0,0032 $\mathrm{Mmm}$.)

Ilat der Dotter nun durch die secretorische Thätigkeit der umund aufliegenden Zellen seine vollstiindige Grösse erreicht, dann umgiebt er sich mit einer äusseren Hülle, einem Chorion, dessen Ausscheidung die Entwickelungsgeschichte des Eies zum Abschlusse bringt. Gleichzeitig geht dann auch an der Ëiröhre durch Verkümmerung des Dotterfaches eine Formverïnderung vor sich. Schon in der letzton Zeit der Dotterabscheidung hat dieses Gebilde an Grösse merklich abgenommen, während der $\Lambda$ usbildung des Chorions aber schrumpft dasselbe allmiilig so stark zusammen, dass es (Fig. 2) nach vollendeter Eientwickelung nur noch cinen kleinen und höckerartigen Aufsatz bildet, der überdies nach einiger Zeit vollkommen verloren geht. Schon V. Carus hat diesen Riickbildungsprocess beobachtet, ist aber der Ansicht, dass der Inhalt des Dotterfaches, dessen Natur ihm völlig riithsellaft blieb, in das Li aufgenommen werde. Ich habe mich mit aller Bestimmtheit von der Unrichtigkeit dieser Ansicht überzengt und die Rückbildung der Dotterbildungszellen mehrfach direct beobachtet. Die Zelle zerfällt, die bläschenförmigen Kerne derselben entwiekeln einige grössere Fetttropfen, diese werden durch $\Lambda$ uflösung der ungebenden Hülle frei das ungefähr ist die Reihe der einzelnen Erscheinungen, die sich hier beobachten lassen und in wesentlich derselben Weise auch an den verbrauchten Dotterbildungszellen der übrigen Insekten mit antloger Eientwickelung wiederkehren.

$\Lambda$ us den voransteheuden Bemerkungen gelit zur Genüge herror, dass die Gebilde, deren Entwickelungsgeschichte wir hier verfolgt haben, wirkliche und unverkennbare Eier sind, die sich von den gewöhnlichen Insekteneiern höchstens in so fern unterscheiden, als sie nicht in Mehrzahl hinter cinander in derselben Eiröhre ihren U'sprung nehmon, sondern immer nur cinzeln in ciner Lirühre entstehen.

Wis ist mir auch geglückt, die Micropyle dieser Eier aufufinden. Sie liegt an dem einen, oberen Endo des Lies und ist eine cinfache 
kleine Oeffnung; die den Boden einer grösseren schüsselförmigen Vertiefung einnimunt, so dass eine gewisse $\Lambda$ ehnlichkeit mit der Micropylbildung der Diptern entsteht. Das Chorion ist völlig structurlos und von brïmlicher Farbe. Eine Dotterhaut konnte nicht nachgewiesen werden.

Ueber die Befruchtung des Blattlauseies labe ich keine Erfahrung, doch ist wohl anzunehmen, dass dieselbe, wie bei den ïbrigen Insekten, erst hei dem Durchtritt durch die Seheide stattfindet. So viel ist gewiss, dass das neugeborne Ei noch keine Embryonalzellen im Innern erkennen lïsst, dass also die Embryonalbildung erst nach der Geburt des Eies anhebt. Bei Eiern, die in einem geheizten Zimmer aufbewahrt wurden, liess sich schon nach einer Woche eine unverkennbare Embryonalanlage, ein zelliger sogenannter Primitivstreif unterscheiden.

Gehen wir nun jetzt in unserer Betrachtung von den entschieden weiblichen Blattliusen zu den viviparen Individuen über.

Dass diese Thiere mit einem Keimapparate versehen sind, der nach seiner Anlage mit den weiblichen Geschlechtsorganen der Insekten uibereinstimmt, wenn er sich auch in einzelnen Zügen davon unterscheidet, ist eine fast von allen früheren Beobachtern ancrkannte Thatsache und so leicht zu constatiren, dass mau es kaum begreift, wie die Anwesenheit dieses Apparates den Untersuchungen von Burnett (1. c.) sich entzichen konnte. Mit aller Bestimmtheit unterscheidet man (Fig. 5) in den Seitentlıcilen des Abdomen eine Anzahl von vier Röhren, die nach Art der Eierstocksröhren einen Yfürmigen, dentlichen Leitungsapparate aufsitzen. Samentasche und Oeldrüse fehlen, dafür aber finde ich den unpaaren Kieimgang bei $\Lambda$ phis padi dicht vor der äussersten Mündung in eine ganz ansehnliche Tasche erweitert, die vielleicht zur Aufbewahrung der reifen Jungen dient. Dio histologische Struetur der Keinröhren ist insofern dieselbe, wie die der Firöhren, als beide aus einer structurlosen Membrana propria bestehen, die auf der Innenfliche von einer Driisenzellenschicht bedeckt wird. 
v. Siebold nennt die Keimröhren der viviparen Aphiden im Gegensatze zu den Eiröhren der ovipareu Weibchen vielkammerig und in der That verdienen sie bei fast allen Arten diese Bezeichnung. Es giebt indessen auch Species, bei denen diese Keimröhren nur einen cinzigen Embryo im Innern einschliessen, also einkammerig sind, ganz wie die Eiröhren, und zu diesen gehört u, a. (Fig. 4) auch die von mir untersuchte $\Lambda$ phis padi. Eine Trennung in zwei übercinander liegende Fïcher, wie wir sie oben an den einkammerigen Eiröhren kennen lernten, kounmt an den einkammerigen Keimröhren nicht vor. Allerdings bemerkt man hier und dort wohl oberhalb des Embryo's cine kleine Anschwellung der Keimröhre, aber diese ist nicht etwa dem Dotterfache zu vergleichen, sondern cnthält vielmehr den $\Lambda$ nfang eines neuen Keimes, der sich allmälig an der Stelle des alten, inzwischen geborenen Embryo's entwickelt.

Die Entwickelungsgeschichte dieses Keimes laabe ich übrigens weder an $\Lambda$ phis padi, noch an Schizoneura corni untersuchen können, denn die Jahreszeit war bereits zu weit vorgeriickt, als dass es möglich gewesen wäre, die einzelnen Stadien in vollständiger Reihenfolge zur Beobachtung zu bringen. Ich war genöthigt, mich fir diese Untersuchung an die Blattliuse unserer Stubengewüchse zu halten, die, wie die Ky ber'sehen Versuchsthiere, ganze Jahre hindurch ausschliesslich vivipar sind, und wiihlte zu diesem Zwecke dic allbekannte $A$ phis rosae, die ich schon früher einınal ganz in derselben Absicht untersucht hatte (vgl. Art. Zeugung in Wagner's Handwörterbuch der Physiologie IV.: S. 968).

Die Keimröhren dieses Thieres zeigen ganz dasselbe rosenkranzförmige $\Lambda$ nsehen, welches man an den vielkammerigen Eiröhren der Insektenweibchen anzutreffen gewohnt ist. Man zählt an ihnen etwa sechs bis sieben auf cinander folgende Anschwellungen, dic nach den Leitungsapparaten hin immer mehr an Grösse zunchmen und mit Ausschluss der allerersten, die mitunter etwas grösser und länglicher ist, als die zweite, je einen Keim in sich cinsehliessen. Die untersten Keime sind nicht bloss die grössesten, sie sind auch vollstindig entwickelt und erseheinen als junge, mit dem Kopfe nach 
rorn gerichtetc $A$ phiden, die selbst schon wieder ihre Keimstöcke mit einigen Keimen in Innern erkeunen lassen*) und auf dem Objectträger des Zootomen nicht selten trotz Kaiserschnitt und Accouchement forcé ganz munter herumlaufen. Eine eigene, den Eihäuten vergleichbare Umlüllung fehlt diesen Embryonen; die von Burnett beschriebene Kapsel, in der dieselben eingeschlossen sein sollten, ist offenbar nichts Anderes als ein Fragment der Keimröhre.

Um die Beschaffenheit und die Entwickelungsgeschichte des KEeimes näher kennen zu lernen, fassen wir zuerst die oberste Anschwellung ins Auge. Der Inhalt dieser Kammer (Fig. 6) besteht aus einer Anzahl von etwa zehn bis zwölf zellenartigen Körpern, die einige Aelonlichkeit mit den jüngeren Formen der oben aus dem Dotterfache der Weibchen beschriebenen Dotterbildungszellen besitzen, wenigstens wie diese einen hellen und bläschenförmigen, grossen Kern $(0,007 \mathrm{Mm}$.) mit scharf unschriebenem Kernkörperchen $(0,0033 \mathrm{Mm}$.) cinschliessen. Die Form dieser Körperchen ist sphärisch, ihr Durchmesser etwa 0,01 Mm. Leydig bchauptet in sciner zweiten Arbeit, dass dic feinkörnige Substanz, aus der diese Gebilde zumeist bestehen, olne ünssere Zellenmembran sei, wio das von uns oben auch für dio jüngern Dotterbildungszellen angegeben wurde. Ich muss gestehen, dass ich nach Wiederholung meiner Untersuehungen jetzt gleichfalls dieser Ansicht bin, obwohl ich mich früher (Art. Zeugung a a. O.) von dem Gegenthil überzeugt zu haben glaubte.

Durchmustert man cine grössere Anzahl von Keimröhren - und auch hier empfehle ich wieder die Untersuchung der noch in Innern ihrer Mutter enthaltenen Embryonen - so wird man wobl beständig in einzelnen Fällen an dem unteren Ende dieses oberen Keimfaches einen Körper wahrnehmen, der sich durch eine betrïchtlichere

*) Für die Aphiden gilt also dasselbo, was v. Siobold für Gyrodactylus elegans hervorhobt (Zeitschrift für wissenschaftliche Zoologie, I, S. 356); man kann bei denselben drei in einander eingeschachtelto Generationen nacliweisen. Freilich entwickeln sich dio Keime der Aphidenembryonen viemals so weit, dass sio selbst wieder als Embryonen sich orkenneu liessen.

Motescholt, Untersuchungen. IV. 
Grösse und ein etwas dunkleres Aussehen von den oben beschriebenen Zellen unterseheidet, sich denselben aber sonst dureh Bildung und Beschaffenheit des Kernes und Kerukörperchens anschliesst. Dieser Körper ist die erste Anlage des suatteren Embryos; er ist die primitive Keimzelle (Fig. 6).

Ueber die Entwickelung dieses Körpers bin ich im Ungewissen geblieben. Es ist möglich, selbst bis zu einem gewissen Grade wahrscheinlich, dass er durch Vergrösserung und Fortbildung aus einer der ganz allgemein in der obern Keimröhrenkanmer vorkommenden Zellen entstanden ist, aber andererseits könnte man für ihn nach der Analogie der Eibildung auch einen selbständigen Ursprung vermuthen. Doch dem sei nun, wie ihm wolle; die Keimzelle entstelst im untern Ende des obern Keimröhrenfaches und gewinnt sehr bald eine so beträchtliche Grösse, dass sie auf die Form desselben umändernd einwirkt. Anfangs eine ovale Anschwellung, nimmt dieses Fach zunüchst eine umgekehrt birnförmige Gestalt an, bis sich das untere ausgedehnto Ende mit seiner Keimzelle schliesslich durch eine immer tiefer greifende Einschnürung absetzt und dadurch dann in eine eigene Kammer sich verwandelt.

Die Keimzelle misst um diese Zeit etwa 0,023 Mm., der Kern im Innern 0,009. Die Körnerschicht in Umkreis des Kernes ist nicht bloss dicker, sie ist auch dunkler geworden und scheint jetzt an der äussern Fläche von einer eigenen zarten Membran umbüllt zu sein. Noch bevor sich nun iibrigens die neu entstandene Keimröhrenkammer vollstïndig gegen dic obere Anschwellung absetzt, gelit mit der Keimzelle sclbst eine ueue, sehr wichtige Veränderung vor sich. Die kürnige Substanz derselben verwandelt sich niimlich in gekernte Zellen, die Anfangs gegen 0,009 Mm. messen, sich aber bald bis zu 0,006 rerkleinern (Fig. 7).

Ueber den Ursprung dieser Zellen dürfte eiue mehrfach von mir gemachte Beobachtung vielleicht einigen Aufschluss geben. Ich salı nümlich Keimzellen (Fig. 8), in denen die körnige, dem Dotter verglcichbare Substanzlage von einer Anzahl heller Bliischen durchsetzt war, die sich von den Kernen der spätern 'Tochterzellen nur durch 
cine betrïchtlichere Grösse $(0,004 \mathrm{Mm}$.) unterschicden und zum Theil von einem dunkleren Hofe körniger Substanz umgeben waren. Der Kern der primitiven Keimzelle wurde dabei melhrfach noch unverändert aufgefunden, und einmal sogar mit einer knospenartigen Auftreibung, die, abgeselien von ihrem Zusammenhange mit dem Kern, ganz den eben erwähnten peripherischen Bläschen glich, so dass es fast den Anschein hatte, als wenn diese durch Prolification an dem Kerne ihren Ursprung nähṇmen.

Aus diesen Beobachtungen schliesse ich anf eine gewisse Analogie dieses Zellenbildungsprocesses mit der Entstehung der Embryonalzellen in dem befruchteten Insektenei (vergl. hierzu meine Beobachtungen über die Fortpflanzung und Entwickelung der Pupiparen, IIalle 1858, S. 64), mit cinem Vorgange, der sich selbst wieder nur als cine Modification des gewöhnlichen Furchungsprocesses ergicht. Auch die Schicksale des Zellenhaufens, der sich bei unseren Aphiden aus der primitiven Keimzelle hervorgebildet hat, sind genau dieselben, wie die Schicksale des durch Furchung in Embryonalzellen umgewandelten Dotters: ans beiden entstelit durch eine gesetzmässige Reihenfolge morphogenetischer Vorgïnge schliesslich der Embryo mit seinen äussern und inuern Organen. Dass diese Umwandlung bei den Aphiden von einer fortdauernden Massenzunahme des Keimes begleitet wirl, kann auf unser Urtheil über die Natur der betreffenden Vorgänge natïrlich nicht den geringsten Einfluss ausuiben, obwol:l diese Erscheinung nicht wenig zu den Eigenthümlichkeiten der Embryonenentwickelung bei den viviparen Aphiden beiträgt.

Dic Vergrösserumg und Entwickelung des Keimes nimmt natürlich eine längere Zeit in Anspruch, so dass sich die Bildung neuer Keimzellen und deren erste Metamorphose inzwischen mehrfach in derselben Keimrölıre wiederholen kann. Natürlich werden diese nachfolgenden Bruten den ältern Keim immer mehr und mehr von seiner ursprünglichen Bildungsstaitte nach abwïrts verdrängen und bei der verschiedenen Zeit ihrer Entstehung eine ziemlich vollständige Stufenfolge reprïisentiren. 
Die einzelnen Phasen der Embryonalbildung habe ich nicht so genau verfolgt, dass ich den Versuch machen könnte, davon ein erschöpfendes Bild zu geben; auch liegt solehes nicht in meiner Absicht. Uns genügt hier die Thatsache, dass der Embryo der viviparen Aphiden in wesentliclı gleicher Weise entsteht, wie jedes andere Insekt. Wührend die Zellen unseres Keimes Anfangs gauz gleichmüssig gebildet sind, entwickelt sich nach einiger Zeit und bisweilen schon sehr frühe ein Unterschied zwischen peripherischen und centralen Zellen; es entwickelt sich durch stärkere und frühere Ausbildung der Bauchfläche sogar ein Primitivstrcif - kurz es finden sich hier alle die cinzolnen Züge, die sich auch unter den gewöhnlichen Umständen an den Embryonen der Insekten beobachten lassen.

Die Frage, ob die Keimzellen der viviparen Aphiden als Eier, die letztern also als Weibchen zu betrachten seien, scheint mir nach den voranstehenden Beobachtungen eben nicht allzu schwer zu beantworten. Was die Keimzellen von den Eiern unterscheidet, ist nicht bloss der Umstand, dass sie keiner Befruchtung bedürfen; auch in der Entwickelungsgeschichte und der Gesammtbildung sprechen sich die auffallendsten Differeuzen aus. Beiderlei Gebilde sind allerdings als Zellen zu betracliten, die sich auf analoge Weise in einen Embryo entwickeln, aber in dem einen F'alle, bei den Keimzellen, beginnt diese Entwickelıng bereits ausserordentlich frühe, schon zu einer Zeit, in der das Material für den Aufbau des Embryo noch lange nicht vorhanden ist, wïhrend im andern Falle, bei den Eiern, die Entwickelung des Embryo in einer sehr viel spätern Zeit anlebt, erst dann, nachdem dieses Material vollständig herbeigeschafft und durch. Ausscheidung einer festen Hülle nach Aussen abgeschlossen ist. In dem einen Falle fillt gewissermassen die Entwickelunggeschichte des Keimes mit der des Embryos zusammen, während diese beiden Vorgänge im andern Falle der Zeit nach von einander getrennt sind. Dass es bei gewissen Thieren auch Eier giebt, die in dieser Bezichung mit den Keimzellen mehrerer Aphiden übereinstimmen (wie ich es fiur die Blasenbandwümer nachgerviesen habe; vergleiche meine Abhandlung über diese Thiere und deren Entwicke- 
lungsgeschichte, 1856, S. 84), kann hier nicht in Betracht kommen, da wir uns zur Vergleichung zunächst an dio Eier der Aphiden selbst zu halten haben.

Die hier hervorgehobenen Eigenthümlichkeiten der von den viviparen Aphiden producirten Keimzellen sind nun aber genau dieselben, die wir als charakteristisch für eine gewisse Form der ungeschlechtlichen Fortpflanzungsprodukte, die Sporen oder Keimkörner (vergleiche uneinen $\Lambda$ rtikel Zeugung a. a. O. S. 966), zu betrachten pflegen. Auf dieselbe Weise, wie die jungen Aphiden in den Keimröhren ihrer Mutter, entstehen auch die jungen Trematoden in der Lcibeshöhle der sogenannten Sporocysten oder Redien durch Entwickelung einer ursprünglich einfachen Zelle; mit demselben Recht, mit dem wir diesen letzten Vorgang als eine ungeschlechtliche Vermehrung betrachten und von der geschlechtlichen, durch Eier vermittelten Fortpflanzung unterscheiden, mit ganz demselben Rechte dürfen wir auch die Entwickelung der Embryonen in den Keimstöcken der viviparen Aphiden in solcher WVeise auffassen.

In den von mir und Andern näher untersuchten Arten verwandeln sich die viviparen Individuen niemals in ovipare WVeibehen; ungeschlechtliche und geschlechtliche Fortpflanzung sind bei ihnen also an verschiedene Individuen übertragen. In diesem Umstande liegt bekanntlich die wesentlichste Eigenthümlichkeit jener Fortpflanzungsweise, die wir seit Steenstrup mit dem Namen des Generationswechsels zu bezeichnen pflegen (Art. Zeugung S. 978); es crscheint demnach vollkommen gerechtfertigt, die Fortpflanzung der Blattliiuse, wie das Steenstrup zuerst gethan hat, nach wie vor dem Gesetze dieses Generationswechsels unterzuordnen, und die viviparen Individuen als Ammen zu bezeichnen.

2. Geschichtliches zur Lehrevon der Parthenogenosis.

Nachdom die auffallende Fortpflanzung der Blattläuse in solcher Weise durch Steonstrup ihre wissenschaftliche Erklärung gefunden hatte, Iag' es nahe, die übrigen Fälle einer s. g. spontanen 
Eicntwickelung oder Parthenogenesis*) von demselben Gesichtspunkte aus zu betrachten. Besonders waren es dic Angaben von älteren und neucren Beobachtern über die Fortpflanzung gewisser Sackträger, die zu einer Vergleichung mit den Vorgïngen bei den Blattläusen aufforderten. Wie bei diesen, so sah man ja z. B. auch bei Solenobia (Talaeporia) lichenella ganze Generationen von ausschlieslich wciblichen, ungeflügelten Individuen auf einander folgen; ja do Geer erhielt diese Sackträgerart ganz ebenso, wie Kyber später scine Blattliuse, mehrere Jahre lang ohne männliche Individuen am Leben (Abhandl. zur Gesehichte der Insekten II. 1. S. 279). Freilich suchte dieser umsichtige Forscher dic Resultate seiner Beobachtungen durch die Vermuthung zu erklären, dass bei der genannten Art - die beigegebene Abbildung lässt die von de Geer beobachteten Thicre ganz bestimmt als Sol. lichenella erkennen - auch die männlichen Individuen ungeflügelt seien, allein er musste doch selbst gestehen, dass or ausser einigen unbedeutenden Grössenverschicdenheiten lieinerlei Differenzen zwischen den Individuen sciner Colonie auffinden konnte. Auch spätere Beobachter sahen sich bei ähnlichen Erfahrungen vergebens nach männlichen Individuen um.

v. Siebold war der Erste, der diese scheinbaro Analogie in der Fortpflanzungsweise der Sackträger und Blattläuse einer nähern Prüfung unterwarf (über die Fortpflanzung von Psyche, Zeitschrift für wissenschaftliche Zoologie, I, S. 93). Er ging bei diesen Untersuchungen von der zuerst durch ihn festgestellten - wenn auch ihrer Tragweite nach Anfangs unterschätzten - Thatsache aus, dass dio Blattlausarten durch Abwesenheit der Samentasche und eine besondere Bildung ihrer Keimstöcke von den eierlegenden Weibchen ver-

*) Obwohl ich den - ursprünglich von $\mathrm{O}$ won in einem etwas abweichenden Sinne gebrauchten - Namen trotz seines Wohlklangs für unpassend halte, weil er etymologisch die Goburt einer Jungfrau und nicht das Geblhren dersolben bezeichnet, mag or doch hicr fermerhin gebraucht scin, da er von so vielen Seiten bereitwillig aufgenommen ist und in unserer Wissonscliaft bereits bein Bürgerrecht erlangt hat. 
schieden scien und hoffte nun ähnliche Unterschiede auch bei denjenigen Sackträgern nachweisen zu können, die in ähnlicher Weise, wic man behauptete, d. h. ohne Zuthun mämnlicher Individuen, eine Nachkommensehaft erzeugten.

Doch v. Sicbold sah sich in seinen Erwartungen getäuscht. Er musste sich davon überzeugen, dass die von ihm zu diesem Zweeke untersuchten zwei Arten (Fumea nitidella und Psyche graminella) Geschlechtsorgane von genau derselben Bildung besassen, wie man sic bei den gewöhnlichen Schmetterlingsweibchen anzutreffen pflegt und namentlich auch ganz in gewolnter Weise mit einer Samentasche' versehen waren. Statt nun aber aus diesen Beobachtungen den Schluss zu zichen, dass die untersuchten Snektrïger vielleicht nicht zu denjenigen Arten gehörten, bei denen eine Fortpflanzung „sine concubitu" vorkomme, oder dass diese, wenn sie sich wirklich bei denselben finden sollte, doch wenigstens keine ungeschlechtliche Fortpflanzung sei, wie bei den Aphiden mit Generationswechsel, glaubte v. Siebold seinen Fund in einer andern Weise, als gewichtigen Grund gegen die Zulässigkeit einer spontanen Entwickelung der Eier überhaupt geltend machen zu können. Fr hob hervor, dass die Annahme cines solchen Vorganges, die „einem der wesentlichsten Gesetze in der Geschichte der Zeugung geradezu in das Gesicht schlage ${ }^{\text {, }}$ nur dann zulässig sein dürfte, wenn die Thatsachen, auf die sie sich stütze, mit aller Sclıärfe und Genauigkeit erwiesen wären, dass cin solcher directer Beweis bis jetzt aber, trotz der grossen Zahl der dafür angeführten Fälle, noch nicht vorliege. Gleiclizcitig machte derselbe auf eine Reilhe von Erscheinungen aufincrksam, durch die sich das Begattungsgeschaift der Insekten und namentlich auch der Sacktriigerweibchen leicht der Beobachtung entzieht, durch die also auch leicht zu Täuschungen in der angedeuteten Richtung Veranlassung gegeben wird.

Leider hat es v. Siebold damals verabsiumt, die einzelnen Fälle, die für die Existenz einer spontanen Eientwickelung angeführt wurden, von seinem Standpunkt aus einer eingehenden Kritik $z u$ unterwerfen; er würde sich sonst vielleicht überzeugt haben, dass 
seine Zwreifel und Bedenken, so berechtigt sie auch im Allgemeinen sein mochten, doch keineswegs in allen jenen Fillen zu ciner unbedingten Negation genugten. So konnte es denn geschehen, dass v. Sicbold schon im folgenden Jahre (1850) sich genöthigt sah, seine frühere Ansicht schr bedeutend zu modificiren. Er musste zugeben, dass auch ausser den Aphiden Insckten vorkämen, die ohne vorhergegangene Befruchtung sich fortzupflanzen im Stande wären, und das sogar auf eine Weise, die mit der gewöhnlichen Fortpflanzung durch Eier die grösseste Analogie zeigte (28. Jahresbericht der schlesischen Gesellschaft für vaterländische Cultur, S. 84). Was v. Siebold zu dieser Concession veranlasste, waren Beobachtungen und Versuche von Reutti, die urspringlich in Gemeinschaft mit v. Siebold begonnen, nach dem Fortgange des Letztern von Freiburg aber von dem erstgenannten trefflichen Lepidopterologen allein zu Ende geführt wurden. Diese Versuche betrafen die von v. Siebold fruiher nicht specieller beriicksichtigte Solenobia lichenelia und führte zu dem unzweifelhaften Resultate, „dass aus den Raupen dieser Sackträger nichts als Weibchen und immer wieder nur Weibchen hervorkommen, welche sine concubitu Eier legen, aus denen später in der That Räupchen ausschlïpfen". v. Siobold spricht, wie die angeführten Worte beweisen, von "Weibchen " und "Fiern" bei unsern Sacktriigern, nichts desto weniger aber will er den rorliegenden Fall nicht als Beispiel einer spontanen Entwickelung zu Eiern gelten lassen. In der hypothetischen Voraussetzung, dass eine solche Annahme physiologisch nicht zu rechtfertigen sei, blieb nichts Anderes übrig, als die betreffende Thatsache, die jetzt nicht länger zu läugnen war, im Sinne des Generationswechsels zu deuten. Trotz der Achnlichkeit der Solenobia lichenella mit andern entschieden wciblichen Sackträgern, trotz der Aehnlichkeit auch der nach Aussen abgelegten Fortpflanzungsstoffe mit Eiern mussten die letzteren jetzt zu eiartigen Keimzellen, die scheinbaren Weibchon zu Ammen werden. Auf gleiche Weise wurde ohne irgend welche anatomische Gründe über die Natur einer zweiten Sacktrïgerart, Psyche helix, verfügt, da die Beobachtungen Routti's auch für diese eine 
Fortpflanzung ohne männliche Beiliulfo zur Evidenz erwiesen hatten.

Während v. Siebold den frühern Angaben einer jungfrïulichen Fortpflanzung gegenüber im höchsten Grade rigoros gewesen war und ïborall mit Recht auf dic schärfste Bewcisfïhrung gedrungen hatte, glaubt er dem Generationswechsel jetzt ein sehr ausgebreitetes Vorkommen bei den höhern Gliederthieren vindiciren zu können. Nicht bloss, dass fast gleichzeitig mit jenen Sackträgern auch ein Paar Milben mit unvollstiindig erkannter Fortpflanzung (a. a. O. S. 89) als $\Lambda$ mmen in Anspruch genommen wurden, „deren geschlechtliche Formen crst aufzusuchen seien", auch bei den Bienen wird ein Generationswechsel vermuthet, da die Belauptung der Bienenzüchter, dass unbefruchtete Königinnen und auch Arbeiter gelegentlich eine männliche Brut hervorzubringen vermöchten, keine andere Annahme zuliess (cbendaselbst, 29. Jahresbericht S. 48).

So standen dic Sachen, als ich mich im Jahre 18.52 an die Aufgabe machte, die wichtigsten Erscheinungen der Zeugung und Fortpflanzung bei den Thieren zusammenzustellen und wissenschaftlich zu bearbeiten*). Natürlich, dass mich dabei auch die im Vorstehenden beriilırten Verhältnisse in hohem Grade interessirten. Um üher dieselben ein eigenes Urtheil zu gewinnen und namentlich auch dic Zulïssigkeit der v. Siebold'schen Hypothese zu prüfen, schien es mir vor allen Dingen nothwendig und unerliisslich, die Beschaffenheit der Keimorgane und namentlich auch der Keimstoffe bei den in Frage kommenden Thieren zu untersuchen. Durch die Giite des Herrn Senator von IIoyden erhielt ich eine Anzahl ausgewachsener Raupen von Solenobia lichenclla, einer Art, an der v. Heyden selbst die Fortpflanzung oline Mïnnchen beabachtet hatte. Ich untersuchte

*) Ein Hinweis auf die Darstellung, die meine Thoilnahme an der Lösung der hier vorliogenden Frage in der schon mehrfach citirten Abhandlung v. Siebold's über dio "wahro Parthenogenesis" gefundun hat, mag es entschuldigen, wenn in der nachfolgonden Auseinandersetzung moino persönlichen Interessen vielleicht hier und da etwas mehr bervortreten. 
dieselben und fand die unverkennbarsten weiblichen Organe und namentlich auch Eier, auf einer Entwickelungsstufe, dic über die Natur der betreffenden Bildungen nicht den geringsten Zweifel liess. (Art. 'Zeugung in Wagner's Handwörterbuch der Physiologie, IV, S. 9.99.) Ebenso überzeugte ich mich durch histologische Untersuchung von der wirklichen Einatur der gewölınlichen sogenamuten Sommercier bei den Daphnien, mittelst deren sich diese Thicre nach den Beobachtungen Lieviu's (neueste Schriften der naturforschenden Gesellschaft zu Danzig, IV, Ileft 2, S. 28) dureh sechs Generationen lindurch olne Mämehen fortpflanzen sollten.

Nach den Resultaten dieser Untersuchungen glaubte ich mich vollkommen berechtigt, dic Richtigheit der v. Sicbold'sehen Erklärung zu bestreiten und der altern Annahme einer spontmen Eientwickclung mich anschliessen zu miissen. Tremn das mit ciniger Vorsicht und Reservation geschah, so war es das Bewusstsein, mit dieser Behauptung gegen die bestehende und besonders durch v. Siebold vertretene Anschaumgsweise zu verstossen, die mich dabei leitete. Ich selbst war so fest von der Richtigkeit der Annahme übcrzeugt, dass ich sogar den Versuch machte, die Erscheinung, um die es sich dabei handelte, mit anderen, viclleicht nicht minder auffallenden, aber einfachern Vorgängen zusammenzustellen und ilır dadurch dic firihere Ausnahmstellung zu nehmen.

Die merkwürdigen Fortpflanzungsverhältnisse der Bienen waren mir zu jener Zeit noch fast völlig unbekannt, wic sich dieselben denn iiberhaupt wohl bis auf die juingsten Tage der Kenntnissnahme von Seiten der Zoologen und Physiologen entzogen haben. Die oben angefülirten Bemerkumgen v. Sicbold's, dic ungef:̈ilır zu derselben Zeit ersehienen (1852), in der ich meine Abhandlung über 'Zeugung verfusste, waren unir noch nicht zu Augen gekommen, und eben so fehlte es mir damals auch an Gelegenheit zu ciner persönlichen Berathung mit gebildeten und aufgeklärten Bienenzüchtern, wie sie v. Siebold gehabt hatto.

Meine Bekanntschaft mit einer Anzahl der bedeutendsten Bienenzüchter (Kleine, Gundelach, v. Berlepsch, Dönhoff u. A.) 
datirt erst aus dem Jahre 1854, und erst seit dieser Zeit bin ich mit den Geheimnissen und Problemen des Bienenlebens vertraut geworden.

Da diese Vorgänge den Ausgangspunkt unserer heutigen Kenntnisse uber Parthenogenesis gebildet haben, dürfte es wohl erlaubt sein, hier ein Paar Augenblicke bei densclben zu verweilen.

Schon seit IIuber's Zeiten (vergl. II uber's neue Beobachtungen über Bienen, übersetzt von Kleine, $18 \overline{3} 6$, I, S. 62 ff.) ist es eine unter den Bienenzüchtern wohlbekannte Sache, dass es Königinnen giebt, dic nur. Drolmenbrut hervorbringen und niemals ein Ei legen, ans dem sich weibliche Individuen (Arbeiter oder Künigimen) entwickeln, so wie auch solche, welche die Fihigkeit der weiblichen Eierlage allmailig verlieren. Eben so kommen mitunter, besonders in weisellosen Stöcken, cierlegende $\Lambda$ rbeitsbienen ror, die aber gleichfalls blosse männliche Larven erzeugen (H uber a. a. O. S. $89 \mathrm{ff}$.).

Dic Thatsachen, die ich hicr hervorgeholoen habe, standen fest, obwohl die Wissenschaft von ihnen keine Notiz $11 \mathrm{ahm}$; sie waren durch zahllose, sorgfältige Beobachtungen bestätigt, aber sic waren den Bienenzüchtern uncrklärlich, „ cin $\Lambda$ bgrund, den Nicmand zu ergründen vermochte ${ }^{4}$. Da mit cinem MIale trat 1845 der jetzt so beriihmte Bienenziichter Pfarrer Dzierzon in Carlsmarkt (Schlesien), „dieses besonders hegnadigte Bienengenie", mit einer Hypothese hervor, die in der That - ihre Zulässigkeit vorausgesetzt - alle jene Erscheinungen in befriedigender Weise zu erklären sehien. Aber eben gegen die Zulässigkeit dieser Hypothese war von wissensehaftlicher Seite cinstweilen gar Vicles cinzuwenden, so dass wohl kamm irgend ein Physiologe bereit gewesen wire, diesclbe olme Wreiteres zu vertreten, ein Jeder sic vielmelı von vorn herein gewiss der Zalıl jener Hirngespinnste zugerechnet haben würde, von denen die Bienenliteratur der ältern und neuern 'Zeit - ich verweise hier nur auf MI agerstedt's praktischen Bienenvater, dritte Aufl. 1850 - leider noch so vicle Beispicle aufzuweisen hat.

Die Hypothese von Dzierzon lief nïmlich auf die Behauptung hinaus, dass die mïmnlichen Bieneneier zu ihrer Entwickelung keiner Befruclitung bedürften, und überhaupt niemals befruchtet würden, dass 
die Eier, wie sich Dzierzon ausdrückte, in Eierstocke sämmtlich als Drolmeneier entstünden und erst durch Befuchtung in weibliche Eier umgewandelt würden (Bienenzcitung 1845, S. 113; Theoric und Praxis 1849, S. 107; der Bienenfreund aus Schlesien 1856, S. 63 und a. a. O.). Die Grimde, die Dzicrzon für scine Hypothese anführte und an verschiedenen Orten, besonders in der Bienenzeitung, öffentlich besprach, waren natiirlich zumächst bloss aus der Erfahrung einer umfassenden Bienenpraxis entnommen und dürften der Hauptsache nach auf folgende Beobachtungen zurückzuführen sein.

Den ersten Anstoss zu dieser IIypothese scheint die Erfahrung gegeben zu haben, dass die drohnenbrïtigen Königinnen, die niemals etwas Anderes, als mïnnliche Eicr legten, sehr häufig flügellahm waren und damit naturlich dor Möglichkeit jenes Ausfluges entbehrten, von dem die Königinnen, wic bekannt, befruchtet ( Befruchtungszeichen versehen", d. h. mit den abgerissenen, in der Scheide steckenden männlichen Genitalien) zurïckkelıren. Andero von Anfang an drohnenbrütige Königinnen waren nach den Beobachtungen unseres Pfarrers solche, die sehr frühe oder spät im Jahre, also zu einer ' $/$ ceit, in der die Drohmen entweder selten waren oder vielleicht ganz fehlten, erbritet worden und dann, wie $\mathrm{Dzier} \%$ on annahm, vergebens ihren Hochzeitsausfug gelialten hatten. Wo nach einer normalen Eierlage Drolmenbrütigkeit eintrat, da handelte es sich nach Dzierzon's Erfahrungen meist um ältere Individuen, deren Samenvorrath im Juaufe der Zeit allıälig erschöpft scin könnte; wic es sich bei den eierlegenden Arbeitsbienen ferner un Thiere handelte, die erfahrungsmassig niemals befruchtet würden, auch vielleicht, nach der ganzen Bildung der Geschlechtsorgane, niemals befruchtet werden künnten. Alle diese Thatsachen schienen unserm grossen Bienenmeister zur Genüge zu beweisen, dass es zur Erzeugung von Drohnen einer Begattung nicht bedürfe. Dass aber auch bei gewöhnlicher Fortpflqnzung der Bienen die Drolınen sich aus unbefruchteten Eiern entwickeln, dafür fand $\mathrm{D}$ zierz on später, nach der Einführung der durch cine hellere Fïrbung besonders des Hinterleibes ausgezeichneten sogenannten italienischen Biene (Apis mellifica var. 
ligurica) einen hinreichenden Beweis in dem Umstande, dass die männlichen Nachkommen einer solchen italienischen Königin auch nach der Befruchtung mit einer deutschen Drohne die ächte italienische Race repräsentirten *), während die weiblichen Nachkommen entschiedene Bastarde waren.

So plausibel und verfïhrerisch diese Beweisführung auch zu sein schien, so verging doch fast ein Jahrzehend bis die Dzierzon'sche IIypothese eine allgemeinere Anerkennung fand. Und doch waren es zunz̈chst nur die Bienenzüchter, die über die Zuliissigkeit dieser Hypothese zu urtheilen hatten, also Mïuner, denen die Bedenken eines Plysiologen zumeist unbekannt gewesen sein dürften. Die Zukunft dieser Hypothose war erst da gesichert, als einer der scharfsinnigsten Bienenzüchter und Experimentatoren, Baron v. Berlepsch, nach einem langen und hartnäckigen Kampfe gegen dieselbe, offen zu ihr tuberging und sie nicht bloss mit neuen Beobachtungen, sondern auch auf experinentellem Wege als begründet und nothwendig nachzuweisen versuclte (Bienenzeitung 1855, S. 73. „Sind die Drohneneier befruchtet?") Unter den ron v. Berlepsch zur Entscheidung der vorliegenden Frage angestellten Experimenten, hebe ich hier nur, als besonders interessant, eines hervor. v. Berlepsch setzte drei früher ganz normal legende Königinnen eine Zeitlang (36 Stunden) der Temperatur eines Eiskellers aus. Die Königinnen erstarrten, aber eine derselben wurde nach der Fntfernung aus dem Eiskeller wieder lebendig und begann sogar wieder Eier zu legen, aber fortan blosse Drohnencier. v. Berlopsch, der in Mïller's Physiologie gelesen hatte, dass niodrige Temperaturen die Bewegung der Samenfeiden aufheben (und darauf auch sein Experiment basirte), sah in dem Resultate des Versuchs einen sprechenden Beweis für die Richtigkeit der Dzi orzon'schen Hypothese.

\#) Die wenigen, von Dzierzon boobachteten Ausnalumsfalle, die sich überdies imroer nur auf einzelno Drohnen eincs Stocks erstreckten (Bienenfreund aus Schlesion S. (64), lassen sich viclleicht durch dio Annahme erkluren, dass in den betreflenden Stöeken auch ciorlegendo Arbeitsbienen vorhanden gewesen sind, 
Als diese Abhandlung crschien, stand v. Berlepseh mit mir über den darin besprochenen Gegenstand im lebhaften Briefirechsel. Derselbe sah wohl ein, dass die Räthsel des Bienenlebens nur in Vorbindung mit einem Zoologen ihre definitive Lüsung finden würden und hatte sich deshalb auch schon früher ein Mal an v. Siebold gewendet, olne bei diesem jedoch eine sonderliche Theilnahme zu finden. Ieh gestehe, dass ich $\Lambda$ nfangs im hohen Grade gegen die Dzierzon'sche IIypothese eingenommen war. Nicht, dass ich die Möglichkeit einer spontanen Lintwickelung bei den Bienen - und nur eine solche, nicht aber ein Generationswechsel konnte hier bei einiger Kenntniss der Sachlage vermuthet werden - überhaupt in Abrede stellte; es war die Regelmaissigkeit, mit der dieser Vorgang wiederkehren sollte, dic ich bezweifelte, und besonders dic Angabe, dass die Drohnen sämmtlich aus unbefruchteten Eiern ihren Ursprung: nähmen. Doch je mehr ich die vorliegenden Grüncle prüfte und uiberlaupt mit der Geschichte des Bienenhaushaltes vertraut wurde, desto mehr mussten die Bedenken des schulgerechten Physiologen in den IIintergrund treten. $\Lambda$ ber immer noch schien es mir zur definitiven Erledigung der Frage unumgünglich nothwendig, die einzelnen Thatsachen, um die es sich handelte, auf directem Wege, durch mikroskopische Untersuchung, zu pruifen und resp. festzustellen.

Ich sollte dazu bald Gclegenheit finden.

Wenige Wochen nach der Publication der oben angefulhrten Abhandlung erhiclt ich von Baron v. Berlepsch eine Künigin, die gegen Ende September des vergangenen Jahres, zu einer Zoit, in der voraussichtlich keine Drohnen melr existirten, erbrütet und kurz darauf eingewintert war. Diese Königin erwies sich in folgenden Frühjalır als drohnenbrïtig; sic hatte bereits $\Lambda$ nfang Miirz anderthalbtausend Zellen mit männlicher sogenannter Buckelbrut besetzt und mehr als hundert Drohnen liefen schon im Stocke umher. Durch die vorgenommene Section und darauf folgende mikroskopische Untersuchung überzeugte ich mich davon, dass die betreffende Königin ein ganz normal gebildetes Weibchen mit Samentasche und Eiern war; aber die Samentasche enthielt statt der Samenfiden eine ganz 
helle, körner- und zellenlose Flüssigkeit, wio sie auch bei den Puppen der Königinnen vorkommt: die drohnenbrütige Königin war unbefruchtet geblicben. (Bienenzeitung 1855, S. 127.)

Durch diese meine Untersuchung war also ein Theil der Dzierzon'schen IIypothese zur Evidenz bewiesen. Es stand fortan fest, dass die Biencukönigin auch olne voransgegangene Befruchtung im Stande ist; entwieklungsfïhige Eier zu legen und dass diese Eier sich nur zu männlielıen *) Bienen entwickeln. Natürlich war damit denn auch der alte Streit iiber die Zulässigkeit ciner spontanen Eientwicklung uiberhaupt entschiceden und zwar in einer Weise entschieden, dic meine frühere Opposition gegen v. Siebold (Art. Zeugung a. a. O.) völlig rechtfertigto. So gering auch vielleicht mein Verdienst in dieser Untersuchung sein mochte, so is toch durch sic zum ersten Male der directe Beweis für die wirkliche Existenz einer sogenannten Parthenogenesis gefülrt worden ${ }^{*}$ ).

Doch es war, wie gesagt, nur ein Theil der Dzierzon'schen Hypothese, der auf solche Weise seine Erledigung gefunden hatte. Es musste weiter noch darauf ankommen, den Nachweis zu führen, dass auch bei ciner normal legenden, also befruchteten Königin die

*) Dass diese Minnehen vollkommen normal und befruchtungsfahig waren, davon komnto ich mich gleichzeitig durch Untersuchung einiger aus den Eiern der oben erwihnten drohnenbrïtigen Künigin hervorgegangenen Exemplare tiberzougen, A, a, 0 .

*:s:) Schon Dziexzon hat allerdings drohnenbrätige Kïniginnen untersucht und deren Samentasche, wic er sagt "leer" d. h. wasserhell, wie in den Nymphen gefunden, allein cine mikroskopische Untersuchung unterblieb. Wie trïgerisch aber das Resultat einer solchen blossen Ocularinspection ist, dafür werde ich spliter dic ïberzeugendsten Bewcise vorbringen. Auch noch in einer andern Beziolıung erscheinen die anatomischen Untersuchungen Dzierzon's, so anerkennenswerth sie auch sein mögen, verdilehtig, in so fern nilmlich, als derselbe keine gehörige Kenntniss von dem Bau der betreffenden Organe überhaupt hatto und z. 13. der Ansicht war, dass đle Küniginnen der Gifublaso der Arbeiterbiene entbehrten, indem diese sich bei ilnen in dic Samenblase verwandelt liabe. 
Drohnen aus unbefruchteten Eiern entwickelt werden. Es schien mir nach meinen Erfahrungen über die Micropyle der Insekteneier (vergl. Müller's Archiv 1855, S. 245 ff.) und die Befruchtung derselben eben nicht allzu schwer, über diese Frage in's Reine zu komnen. Mit Freuden und der besten Moffnung folgte ich daher der Einladung des Herrn Baron v. Berlepsch, die begomnenen Untersuchungen über die Fortpflanzung der Bienen und den Haushalt derselben überhaupt mit den reichen Lülfsmitteln seines grossartigen Bienenstandes fortzusetzen und wo inöglich zuin Absclılusse zu bringen.

Leider sollten die Erfolge meiner "Scebacher Studien” (Bienenzeitung 1855, S. 199 ff.), wenigstens so weit sie die Dzierzon'sche Hypotheso betrafen, hinter meinen Erwartungen zurückbleiben. Da ich mit Meissner (Zeitschrift für wissenschaftliche Zoologie Bd. VI, S. 295) die Annahme theilte, dass die durch die Micropyle in das Innere des Eies eingeschlüpften Samenfüden schr bald sich auflösten, ging mein Bestreben dahin, die Samenfiden auf dem Mieropylapparat selbst aufzufinden, wic das z. B. bei der Schmeissfliege und andern Insekten sehr leicht gelingt. Ich untersuchto deshalb die Bicneneier so frisch, als ich sie iberhaupt erbalten konnte, zum 'Theil schon eine Viertelstunde nach dem Ablegen, stiess aber dabei auf so grosse Schwierigkeiten, dass die gewomnenen Resultate für die Entscheidung der vorliegenden Frage nicht massgebend sein konnten, obwohl sie mehr für, als gegen Dzierzon sprachen. 'Trotz tagelangen angestrengten Untersuchungen fand ich überhaupt nur zwei Mal unzweifelhafte Samenfäden auf den (an sich schon schwer zu findenden und noch schwerer zu analysirenden) Micropylen, das eine Mal einen einzigen Faden, das andere Mal dann mehrere, vier oder fünf. Die betreffenden Eier waren beide Arbeitereier, wihrend dic Drohneneier beständig ohne Samenfäden zu sein schienen.

Während meine Secbacher Untersuchungen in dieser Bezichung ziemlich resultatlos blieben, fand ich doch in anderer Hinsicht Gelegenheit, meine Erfahrungen über die Fortpflanzung der Bienen zu erweitern. Herr v. Berlepsch besass schon seit längerer Zeit zwei in Branntwein aufluewahrte Axbeiter, die er beim Eierlegen 
beobachtet und gefangen hatte. Èr überliess mir dieselben zur ana. tomischen Untersuchung und durch diese wurde nun - besonders bei dem einen Individuun, da sich das zweite in einem Zustande befand, der keine vollstiindige Untersuchung zuliess - festgestellt, dass dio betreffenden Individuen trotz der Fähigkeit des Eierlegens ge. wöhnliche unbefruehtete $\Lambda$ rbeiter waren, die sich nur durch eine stärkere Entwickelung ihrer Eiröhren und besonders die $A$ nwesenheit von Eiern und Eikeimen in denselben auszeichneten. Line Samenblase wurde nicht gefunden; dieselbe möchte überhaupt wohl schwerlich bei einem jahrealten Spiritusexemplar nachzuweisen sein - vorausgesetzt, dass sie die bei den Arbeitern gewölnnliche Bildung besitzt -, während dic Samenblase der Königinnen auch bei schr schlecht gehaltenen Spirituspräparaten sich überall mit grössester Leichtigkeit nachweisen lässt*).

Iicrher nach Giessen zurückgekehrt, machte ich sodann weiter die interessante Beobachtung; dass bei den Wespen, Hornissen und Hummeln die Arbeiter trotz ihrer Jungfräulichkeit selrr häufig mit mehr oder minder entwickelten Eiern angetroffen werden, sehr constant also Verbaltnisse darbieten, die bei den Bienen zu den Seltenheiten gchören. (Nachtrïgliche Bemerkungen zu den Secbacher Studien, a. a. O. S. 211.)

Lis war den Untersuchungen des Professors v. Siebold vorbehalten, die Liicken auszufilllen, dic ich bei meinen Seebacher Studien in Betreff der normalen Drolmenerzeugung gelassen hattc. Derselbe

*) v. Borlepsch, der schon früher - wio II ubor - cino cierlegende Arbeiterin untersuchto, giebt gloichfalls an (Bienenzeitung 1855, S. 78), bei derselben neinen kleinen Eierstock mit etwa acht zicmlich entwickelten Eiern, aber kein Reeptaculum seminis und koinen Legekanal" gefunden zu haben. So sehr ich übrigens die Verdiensto meines hochverehrten Bienenfreundes anerkonne, kann ich auf diose Angabe doch nicht das Gewicht legen, wio v. Si cbold (wahre Parthenogenesis S. 77), zumal Hr, v. Berlopsch, als er mich zum orsten Malo eine Biene kunstgerecht seciren sah, mir bemerkto, dass er seine anatomischen Untersuchungen bisher mit einem Gartenmesser auf dem Nagel des Daumens vorgenommon habe. 
erschien einige Monate nach mir auf dem Gute des Hrn. v. B erleps ch, um die Dziexzon'sche IIypothese gleichfalls zu prüfen; und dieses Mal gelang es, was mir früher ummöglich gewesen war. v. Siobold sah schr häufig Samenfïden im Innern der Biencneier, aber es waren ausschliesslich weibliche Eier, in denen dieselben aufgefunden wurden, während sic in mäunlichen eben so sorgfïltig untersuchten Eiern durchweg fehlten. (Wahre Parthenogenesis u. s. w. S. $111 \mathrm{fr}$.)

Obwohl auch v. Siebold, wie ich das früher gethan hatte, ausdrücklich hervorhebt, „dass diese Untersuchungen des Bieneneies von allen ähnlichen Untersuchungen zı den allerschwierigsten gehörten", so blcibt doch das Resultat seiner Beobachtungen - in $5^{2}$ weiblichen Eiern gelang es 31 Mal Samenfaiden und 2 Mal sogar bewegliche Samenfüden aufzutindon - meinen eigenen gegenüber ein so auffallend günstiges, dass es natürlich seheint, wem v. Si c bold nach dem Grunde fragte, durch den dieser Unterschied bedingt werde. Fr findet denselben in der Vermuthung, dass ich mich damit begnïgt hätte, „die Bienencier im ganz unverletzten /Justande von Aussen einer Untersuchung zu unterwerfen". v. Siebold hätte wohl wissen können, dass ein Forscher, der in der Behandlung der Insekteneier cinige Geschicklichkeit hat, wic ich das von mir behaupten darf und anch durch meine Arbeit über die Micropyle bewiesen habe, seine Untersuchungen nicht in einer so laienhaften W Weise anstellt. Meine Methode war dieselbe, die v. Siebold anwendete: sie bestand in einem vorsichtigen Zerdrüteken des Eies unter dem Deckgläschen, meist nach Oeffumg des hintern Eipoles. Wenn trotzden meine Untersuchungen nicht die gleichen Erfolge hatten, so rülirt das ein Mal daher, dass ich aus den oben angeführten Grïnden meine Aufmerksamkeit weniger auf den Eiinhalt, als auf den Micropylapparat richtete, sodann aber auch und wohl vorzugsweise daher, dass ich zu meinen Untersuchungen möglichst frische Eier nahın, in der Hoffnung, die Samenfiden desto sicherer auf dem Micropylapparat anzutreffen. v. Sicbold hat fast ausschliesslich an iiltern (bis zu zwei Tage alten) Eiern untersucht; jüngere fand er (a. a. O. S. 116) weniger tauglich, da der Dotter derselben bei Anwendung eines 
Druckes nach allen Seiten aus einander fliesst, während derselbe in ältern, bereits mit der Keimlıaut versehenen Fiern zusammenhält und nur von der Dotterhaut zurückweicht, so dass zwischen beiden ein heller Raum entstelt, in dem dann dio Spermatozoen flottiren. Die Gründe, die mich bei meinen Untersuchungen leiteten und mich auf möglichst frische Eier hinwiesen, waren, glaube ich, vollkommen rationell; ich kann mir nur in so fern einen Vorwurf machen, als ich es unterlassen habe, auch iiltere Bieneneier einer Untersuchung zu unterwerfen. Hätte mir der Zufall solche Eier unter die Hände geführt oder wäre ich durch eine weniger günstige Jahreszcit gar vorzugsweise, wie v. Siebold, auf Untersuclung älterer Eier angewiesen gewesen, dann dürfte das Resultat meiner Beobachtungen wohl bestimmter gelautet haben. Die Sclıwierigkeiten, die solche ältere Eier der Untersuchung entgegenstellen, sind denjenigen nicht zu vergleichen, mit welchen ich bei frisch gelegten Eiern zu kämpfen hatte. Ich spreche hier aus eigener Erfahrung, denn es ist mir seither vielfach gelungen, die Richtigkeit der v. Siebold'schen Angabe über das Vorhandensein der Samenfiden im Innern der weiblichen Eier zu bestitigen.

Doch dem sei, wic ihm wolle, wir verdanken den Beobachtungen v. Sicbold's wenn auch nicht gerade die Lintdeckung vou der wirklichen Existenz der sogenannten Parthenogenesis, so doch jedenfalls .den exacten Beweis für die Richtigkcit der Behauptung, dass dic männlichen Bieneneier beständig auf parthenogenetischem Wege, d. h. ohne Befruchtung sich entwickeln. Und diese Thatsache, die wir fortan in der Geschichte unserer Wissenschaft als gesichert ansehen dürfen, ist gewiss eine der interessantesten, die wir in der Lelire vou der thierischen Fortyflanzung aufzuweisen haben. Wir haben ihr einstweilen noch keine zweite ähnliche Erfahrung an die Scite zu stellen, und können den Versuch, die hier gefundene Thatsache zu verallgeneinern, nur für einen selir unglücklichen halten.

Die hier hervorgehobenen Beobachtungen bilden den wesentlich. sten Inhalt der von v. Siebold über die "walre Parthenogenesis bei Schmetterlingen und Bienen" herausgegebenen Abhandlung (S. 48 bis 120). Was in dieser uns sonst noch über die Parthenogenesis 
der Sacktrïger (S. 31 ff.) und der Schmetterlinge (S. 120 ff.) mitgetheilt wird, enthält eben nichts Neues, und referirt nur über einige, meist von fremden Forschern angestellte Beobachtungen, die jedoch grossen Theils eben so wenig mit dem Mikroskope controllirt sind, wie die iltern Fälle, deren Beweiskraft früher von unserm Vorfasser in Abrede gestellt wurde. Dass dabei auch die frühero Vermuthung v. Siebold's, nach der diese Beobachtungen in der Existenz einer Ammenzeugung ihre Erledigung finden sollten, desavouirt wird, bedarf weiter keiner Bemerkung; v. Siebold erklärt seinen frühern derartigen Versuch geradezu für einen Irrweg (a. a. O. S. 11), ohne dabei jedoch zu bemerken, dass der Irrthum dieser $\Lambda$ uffassung bereits mehrere Jahre vorher von mir nachgewiesen sei*).

3. Parthenogenesis bei den Cocciden und Chermesarten.

Die Coceiden oder Schildläuse bilden bekanntlich eine Gruppe von Insekten, die trotz mancher Eigenthümlichkeiten in Bau und Lebensweise den Aphiden so nahe verwandt sind, dass es dem Systematiker schwer hält, eine scharfe Grenze zwischen beiden zu ziehen. Nichts desto weniger scheint die Fortpflanzungsgeschichte der Schildlïuso sehr abwcichend zu sein. Von cinem Generationswechsel, wie er den Aphiden zukommt, ist bei denselben bisher noch keine sichere Spur beobachtet; man kennt bei den Cocciden nur zweicrlei Individuen, die beflügelten aphisartigen Männchen und die weit grössern, mehr oder weniger bewegungslosen Weibchen, die meist wie schuppen- oder knollenförmige Auswiichse an den Blättern und Trieben der Pflanzen befestigt sind.

In dem Vorkommen dieser beiderlei Individuen herrscht jedoch ein grosser Unterschied. Während dic cicrlegenden Weibchen den ganzen Sommer über gefunden werden und in unsern Treibhäusern

*) Ueberhaupt wird der Darstellung, die ich in meinem Artikel Zeugung über den fraglichen Gegenstand gegeben habe, mit keinem Worte godacht, obwohl ihr doch eine Reiho eigener Beobachtungen zu Grunde liegen. v. Siebold weiss von jenem Artikel nichts weiter zu bemerken, als dass derselbo "trotz seincr Ausführlichkeit die merkwürdige Fortpfanzungsgeschichto dor Bienen kaum beribre". 
sogar überwintern, ist die Existenz der männlichen Individuen nur von äusserst kurzer Dauer und constant, wie es scheint, an cino bestimnte meist selır frühe Jahreszeit gebunden. Kein Wunder unter solchen Umständen, dass uns trotz den fleissigen Beobachtungen älterer und neucrer Forscher von Reaumur bis zu Bouch ef und v. Bärensprung einstweilen erst von wenigen Arten die männlichen Individuen bekannt sind.

Durch die Entdeckung der männliclen Cocciden, die wir dem grossen Entomologen Réaumur verdanken (Mém. pour servir a l'list. des Ins. T. IV, Mém. 1 et 2), schienen die frühern Räthsel in der Fortpflanzungsgeschichte der Cocciden ihre Erledigung gefunden zu haben. Man vindicirte denselben (so z. B. v. Bïrensprung, Zeitung fuir Zool. von Burmeister und d'Alton S. 166) nur cine einzige Generation, und diese erschien dann als Product einer vorausgegangenen Begattung. Es mag sich das Fortpflanzungsgeschäft unserer Thiere in manchen Fällen auch wirklich also gestalten, aber eino Uebertragung dieser Annahme auf alle Sclildläuse ist entschieden irrthümlich. Schon Leydig hat (Zeitschrift für wissenschaftliche Zoologie V, S. 10) darauf aufmerksam gemacht, dass man des Winters kaum ein einziges Fxcmplar von Lecamium hesperidum ohne Embryonen im Innern auffinden könne, und wïre es auch noch so klein, ja dass sich diese Embryonen sogar ganz allgemein in Individuen entwickelten, deren Samentasche der Spermatozoen entbehre. Leydig spricht deshalb denn auch von „viviparen Cocciden, die den viviparen $A$ phiden vergleichbar seien und, wie diese, als $\Lambda$ mmen betrachtet werden könnten", obwohl sie sich durch Organisation der Eierstocksröhren und crste Entwickelung des Embryo davon unterschieden.

Obgleich ich das Thatsächliche der Leydig'schen Angabe im Wesentlichen bestïtigen kann, muss ich die letztere Behauptung doch entschieden als unrichtig zuruickwcisen. Was Leydig für Ammen zu halten geneigt war, sind nach meinen Beobachtungen ganz unverkennbare Weibchen mit Eierstöcken und Eiern, nur in so fern ausgezeichnet, als sie sich durch Parthenogenesis, d. h. ohne Beihülfo männlicher Individuen fortptlanzen. 
Neine Untersuchungen erstrecken sich tiber die drei Hauptgenera der Schildliause: Coceus, Lecamium und $\Lambda$ spidiotus. Von ersterm untersuchte ich den bekannten Coccus adonidum, von dem zweiten ausser Lec. hesperidum noch zwei andere meines Wissens unbeschriebene Arten *) von der Myrthe und der Baumwolle (Gossypium religiosum), und eben so von $\Lambda$ spidiotus drei Arten, von dem Oleander ( $A$. Nerii), von Chamaerops humilis und $\Lambda$ ucuba japonica, ron denen die zwei letzten gleichfalls neu sind. Ausgebildete münnliche Individuen kamen (Januar, Februar) nicht zur Untersuchung ${ }^{* *}$ ); nur an einem Standorte fanden sich zahlreiche männliche Puppen von Aspidiotus Nerii und zwar meist massenweise an Blättern, die gewöhnlich nur von wenigen (ausgewachsenen und jungen) weiblichen Individuen bewohnt waren $* * *)$.

Alle diese Arten besitzen Geschlechtsorgane, die fast bis auf die Einzelnheiten genau mit cinander ubereinstimmen und im Wesentlichen die Organisationsverhältnisse der weiblichen Organe bei den Blattläusen (s. oben S. 335 u. folg.) zeigen. Besonders auffallend ist diese Achnlichkeit bei jungen Schildläusen, bei denen sich die Geschlechtsorgane auch vicl leichter priipariren lassen. Bei ihnen findet man (Fig. 9 von Lecamium hesperidum) denselben Yförmigen, ziemlich muskulösen Leitungsapparat, den wir oben für Aphis beschrieben haben, auch dieselben Anhangsgebilde: einkammerige Eiröhren, Samen-

*) Eine vierte Art, von Mesembryanthemum verticillatum konnte nur im unreifen Jugendzustande untersucht werden und wird hier nur deshalb erwilhnt, weil ich an ihr dieselbe Beobachtung machte, wie an den oben orwilhnten mänulichen Exemplaren von Schizoneura corni. Dio ganzo Colonie ging an einer Pilkrankheit zu Grunde. Dieses Mal aber war es keine Entomophthora, sondern der gewöhnliche Hyphomyectes herbarum, der auch auf den Blattern der Mutterpflanze in Unmasse vegetirte.

**: Von Lecamium hesperidum sind die Milnnchen - trotz der immensen Haufigkeit des Weibchens - bis jetzt übcrhaupt noch unbekannt geblieben.

***) Aehnlicho Bcobachtungen machten auch andero Forscher, wie v. IIeydon (in Jitter.) und $\vee, B$ ärensprung (a. a, 0, S, 166). 
tasche und Oeldriise. Nur in der Zahl der Eiröhren findet sich ein anffallender Unterschied, denn diese beträgt bei unsern Schildläusen vielleicht mehrere Hundert, withrend wir bei Aphis deren nur sehr wenige antrafen. Freilich leben auch die weiblichen $A$ phiden nur kurzc Zeit, höchstens ein Paar Wochen, während unsere Schildliuse Monate lang fruchtbar sind. Die grosse Zahl der Eiröhren bedingt auch eine beträchtlichere Länge der beiden Eileiter, denen dieselben in unregelmässiger Gruppirung (doch, wic es scheint, besonders auf der cinen Scitc) fast bis zum unpaaren Eiergange aufsitzen. Schon in einzelnen jüngern Individuen bemerkt man hier und $\mathrm{da}$ an den paarigen Eileitern eine klcine höckerförmige Auftreibung oder einen kurzen, gleichfalls mit Eiröhren besetzten Scitenzweig; bei älteren Schildlïusen wachsen diese Gebilde in mehr oder minder lange, zun Theil selbst wiederum verïstelte Röhren aus, die den ganzen Körper durchzichen und es auf solche Weise möglich machen, dass die Eier scheiubar allerorten in dem Leibe unserer Thiere ihren Ursprung nehmen.

Die voranstehendo Beschreibung weicht mehrfach ron der Darstellung ab, die Iseydig, der einzige Zootom, der die Generationsorgane der Coceiden bisher untersuchte, ron diesen Gebilden entworfen hat (a. a. O.). Ich glaube jedoch den Angaben Leydig's gegeniiber die Richtigkeit meiner Beschrcibung vertreten zu können. $\Lambda \mathrm{m}$ abweichendsten sind dic Resultate meiner Untersuchungen in Bctreff der Eiröhren und deren Inhalt. Le y dig bezeichnet diese Eiröhren als „Eierstocksbeeren" und lässt in denselhen nicht etwa ein Ei, sondern gleich von vorn herein einen Fmbryo scinen Ursprung wehmen und das überdies auf eine Weise, von der Verfasser selbst bemerkt, dass sie bis jetzt als eine ganz vereinzelte Erscheinung dastehe. Leydig würde wohl kaum zu dieser Ansicht gekommen sein, wenn er die Bildungsgeschichte der Eier bei den oviparen Aphiden gekannt oder auch seine Untersuchungen nur nicht gerade an einem Lecamium angestellt haitte, bei dem (cbenso freilich auch bei Aspidiotus) die eigentliche Einatur des im Innern der Eierstocksröhren sich entwickelnden Körpers wegen der Bliisse des Dotters und der Unscheinbarkeit des Keimbläschens in der That nicht ganz leicht zu erkennen ist. 
Um die Fntwiekelungsgeschichte der Eirölıren und Fier bei den Cocciden zu studiren, bedarf es nur eines einzigen, grlücklich präparirten Individums, da dic IIunderto von Eiröhren, die dieses Thier entlialt, in ihrer versehiedenen Ausbildung vielleicht alle nur denkbaren einzelnen Stadien der Entwickelung repräsentiren. Bei den von mir untersuchten Arten von Lccamium und $\Lambda$ spidiotus ïbersieht man sogar gleichzeitig die ganze Entwickelungsgeschichte des Embryo, denn die Eier dieser Thiere beginnen alsbald nach ihrer Reife den früherhin ganz in gewöhnlicher Weise gebildeten Dotter in den Körper eines neuen Geschöpfs $z u$ verwandeln. (Bei jungen Individuen ist iibrigens die Menge der reifen, mit Embryo oder Embryonalanlage versehenen Fier immer nur eine unbedentende.)

Die einzelnen Vorgänge der Entwickelung sind so genau dieselben, wie bei den $\Lambda$ phiden, dass ich es für tiberflüssig halte, hier nochmals cine ausfithrliche Schilderung derselben zu geben (vergl. Fig. 10-12). Die kleinsten Firöhren $(0,022 \mathrm{Mm}$.) enthalten ausser den Kernen der spätern Dotterbildungszellen, die übrigens nur selten mehr als in fiinffacher Anzahl vorhanden sind - die spätern Dotterbildungszellen finden sich meist nur zu dreien oder vieren in den Dotterfächern —, auch noch dieselben kleinen Zellen, die sich späterhin, nach Entwickelung des Keimbläschens und Dotters, in dic Drüsenzellen des Keimfaches umbilden. Das Kcimblïschen kann, wie schon bemerkt, leicht übersehen werden, ist aber, wie ich mich mit aller Bestimmtheit uiberzeugte, trotzdem vorhanden und besonders bei Coceus, wo sich der Dotter schon ziemlich frühe gelb fürbt, unschwer nachzuweisen. 13ei der ersten Bildung ist der Dotter hell und eiweissartig, später nimmt derselbe eine körnige Beschaffenheit an und schliesslich fiillt er sich mit grossen Fettropfen. Die ersten Fettropfen entstehen schon ziemlich früh, wenn die Fianlage etwa 0,01 Mm. misst und noch ziemlich schlank ist, meist in der untern Hälfte des Dotters, hinter dem Keimbläschen.

Das Ueberschen des Keimblëschens und der ersten Dotteranlage triigt wohl die Sehuld, dass Loydig die wahre Natur des in der untern Eiröhrenhälfte entstehenden Körpers nicht erkannt hat. Aber 
auch uber dic Bedeutung der Dotterbildungszellen ist unser Forscher im Irrthun, wemn er angiebt, dass sich dicsclben allmälig in cinen Haufen kleiner Zellen verwandelten, die mitsanmint dem fetthaltigen Dotter in die Eihaut eingeschlossen wiirden und dann die erste $\Lambda \mathrm{n}$ lago des künftigen Embryo darstellten. Es ist walr, man sieht häufig an dem obern Pole der reifen Eier eine helle Zellenmasse, von der die Entwickelung des Ëmbryo und zuniehst die Bildung des Primitivstreifens ausgelit, allcin diese Zellenmasse lat mit den Dotterbildungszellen nicht das Geringste gemein. Sie entsteht erst einige Zeit nach dem Schwunde des ehemaligen Dotterfachs mit seinem Inlalte, der auf dieselbe Weise, wie bei $\Lambda$ plis, und auch um dieselbe Zeit, gegen Ende der Eientwickelung, stattfindet. Ich habe ïbrigens nicht selten auch Eiröhren nit ganz reifen Eiern getroffen (die ziemlich übereinstimmend bei den meisten meiner Coceiden - mit Ausschluss von Coccus adonidum mit grössern Eiern - 0,028-0,03 Mm. messen und eine ovale Form besitzen), bei denen ich an :iussersten Ende noch ein kleineres Zïipfehen $(0,03-0,05 \mathrm{Mmm}$.) mit den letzten Resten der Dotterbildungszellen unterschied, obwohl der Dotter bereits von seinem Chorion umhiullt war (Fig. 12). Dieses Chorion ist einfach, olne darunter liegende Dotterhant, wie bei $\Lambda$ phis, aber heller gefürbt, meist nur gelblich oder wenig gebrïunt. Eine Micropyle wurde nirgends mit Bestimmtheit aufgefunden.

Bei Lecamium und Aspidiotus begimnt sehr bald nach der Reifung der Eicr, wie schon hervorgehoben wurde, die Bildung der Embryonalzellen und damit die Anlage des Embryo, der noch an der ursprünglichen Bildungsstïtte der Eier, im Innern der Eirülıre, zur rollkommenen Entwickelung gelangt. Niclits desto weniger sind die genannten Cocciden nicht vivipar, wie Ley dig vermuthete; sio legen viclmelır Eier, ganz wie die übrigen Schildläuse, nur dass die Embryonen bercits nach Isurzor Zeit, mitunter schon mach 24 Stunden auslaufen.

Die Embryonalentwiekelung habe ich nicht zum Gegenstande ciner besondern Untersuchung gemacht. Ich beschränke mich deshalb hier anf dio Bemerkung, dass die Embryonen in ihren Eiröhren 
mit dem Kopfo constant nach dem obern bliuden Ende hingerichtet sind (Fig. 8), also genau dieselbe Lage hahen, wie die Embryonen der viviparen $\Lambda$ phiden (Fig. 4), dic bekanntlich mit dem Finterleibe voran geboren werden.

Coceus adonidum verhëlt sich in dieser Beziehung etwas anders. Allerdings gesehicht auch bei ihm die erste Embryonalanlage noch wihrend des. Aufenthaltes der Eier in den Eiröhren, allein die Eier. lage geht weit frither vor sich, noch bevor die Embryonen ihre spätere Form und Bildung erkennen lassen. Daher kommt es denn auch, dass die Embryonen dieser Art erst eine lïngere Zeit nach der Geburt der Eier ausschlüpfen.

Was ich im Voranstehenden über die von mir untersuchten Cocciden mitgetheilt habe, wird, glaube ich, wohl genügen, dieselben als veritable Weibchen und ihre Geschlechtsproducte als gewöhnliche, entwickelungsfähige Eier zu kennzeichnen. Aber trotzdem erweisen sich diese Schildläuse zum grössten Theile als jungfräuliche Individuen. IBei keinem einzigen der mir zur Untersuchung vorliegenden $\Lambda$ rten des Gen. $\Lambda$ spidiotus und Lecanium gelang es einen Samenfaden nachzuweisen. Die Samentasche derselben war beständig -.. ich untersuchte woll] gegen hundert Indivividuen leer oder doch wenigstens ohne Samenfiden, wie es auch Leydig in seinen Exemplaren hervorhebt. Dabei zeigte sich die innere Chitinauskleidung des Receptaculum faltig und zusamnengefallen, so dass (Fig. 8) der Innenramm, der in einigen Fällen eine unbedeutende, wie Fett gliinzende, bröcklige Masse enthielt, viel kleiner erschien, als man nach der Grösse des Gesammtdurchmessers (0,08 Mm.) erwarten konnte.

Im Gegensatze zu diesem Bcfunde ergaben sich die mir vorliegenden ausgebildeten und fortpflanzungsfilhigen WVeibchen von Coccus adonidum sïmmtlich als befruchtet. Ihre Samentasche enthiclt rine meist freilich nicht eben sehr beträchtliche Menge von langen Fïlen, die eine eben so deutliche, wie zicrliche Schraubenform besassen und unzweifelhafte Samenfiden waren, obwohl ich nur leise und unbedeutend schwingende Bewegungen an ilmen auf- 
fand. Was mich aber fast noch mehr iilscrraschte, war der Umstand, dass dieselben Fäden auch in dem Leitungsapparate anzutreffen waren, also an Stellen, wo dieselben sonst bei den Insekten mit Samentasche zu fehlen pflegen. Freilich ist dabei in Anschlag zu bringen, dass die Cocciden auch vielleicht die einzigen Insekten sind, bei denen die Finbryonalentwicklung bereits im Eierstocke anhebt. Auch bei den Scorpionen (Sc. europaeus) lassen sich nach meinen Beobachtungen die Samenfiden nicht bloss im Receptaculum, sondern auch im ganzen Leitungsapparate bis zu den Fierfüchern nachweisen. (Dass uns diese Beobachtung übrigens in Fragen, wie die vorliegende, zu doppelter Aufmerksankeit veranlassen muss, liegt auf der Hand. Es bedarf auch wohl kaum der ausdrücklichen Bemerkung; dass bei den oben von mir als jungfräulich bezcichneten Schildläusen die Fiergänge eben so leer waren wie die Samentascho.)

$\mathrm{Ob}$ die für Coceus hervorgehobenen Unterschiede in dem Entwickelungsgrade der nach Aussen abgelegtèn Eier mit der hier aller Wahrsehoinlichkeit nach stattfindenden Befruchtung zusammenhängen, muss ich unentschieden lassen, doch diurte das leicht zu entscheiden scin, sobald man einmal Gelegenheit findet, die Entwicklungsverhältnisse der Fier bei befruchteten Individuen von Lecamium und Aspidiotus zu untersuchen *). Auch darf ich hier wohl weiter noch hervorheben, dass die Insertion der Samentasche bei Coceus einerseits und den übrigen von mir untersuchten Schildläusen andererscits einige Versehiedenheit darbictet. Bei den letzten findet sich nämlich diese Insertion (Fig. 8), wic auch Ley dig beschreibt, hoch oben, an der Bifurcationsstelle des Leitungsapparates, wihlend sich Coccus in Betreff seiner. Samentasche genau an die oben von mir bei $\Lambda$ phis geschilderten Verhältnisse anschliesst.

*) Ich habe jetzt, im Monat Mai, zahlreiche befruchtete Weibchen von $\Lambda$ spidiotus Nerii gefunden, und mich davon überzeugt, dass die Eicr derselben sich eben во weit in den Eierstücken entwickeln, wio bei den unbefruchteten Weibchen. Die befruchteten Exemplaro sind meist jüngero Individuen. Die Samenfiden, die in zwei beutelförnigen Hoden entstuben, sind fadenförmig und haben bei einer Laluge von 0,2-0,28 Mm. eine sehr ansohnliche Breito (von 0,003 Mm.). 
Wenn es nun auch nach den voranstehenden Beobachtungen jicht länger zweifelhaft scin kann, dass in der Gruppe der Schildläuse Faille von Parthenogenesis vorkommen und sogar, allem Anscheine nach, schr häufig vorkommen, so sind damit doch natürlich noch keineswegs alle Fragen nach der Fortpflanzungsgeschichte der betreffenden Thiere erledigt. Ob alle oder uur gewisse Arten die parthenogenetische Entwickelung besitzen, ob diese Entwickelung (wio es allerdings scheint) regelmässig bei dem unbefuchteten Weibchen stattfindet oder nur mitunter geschicht, ob vielleicht mehrere solcher jungfräulichen Generationen auf einander folgen - dies Alles sind Verhältnisse, die ich hicr cinstweilen noch umentschieden lassen muss.

So vicl iibrigens scheint ausgemacht, dass die Parthenogenese der Cocciden cine Erscheinung ist, die in einiger Beziehung dem Generationswechsel der Apliden verglichen werden kann, wenigstens für die Erhaltung der betreffenden Thiere cine ähnliche Bedeutung hat, wie der Generationswechsel. Fine Begründung dieser Ansicht finde ich nicht bloss in der nahen Verwandtsehaft der Coeciden mit den Aphiden, sondern namentlich in dem Uinstande, dass es auch unter den Letztern Formen giebt, die sich nach Art der Schildläuse durch Parthenogenese, statt durch Generationsweclisel fortpflanzen. Es sind die Arten des Gen. Chermes, dic ich dabei im Auge habe, dieselben Formen, auf deren eigentlümliches Verhalten schon oben gelegentlich (S. 328. Anm.) lingedeutet wurde.

Nach den Beobachtungen von de Geer (a. a. O. S.) und Kalten bach (a. a. O. S. 194) setzt sich dic Lebensgeschichte dieser Blattliuse aus zweien ron cinander verschiedenen, cierlegenden Generationen zusammen, einer Sommergeneration und ciner Friullings(oder Winter-) Generation, deren erstere wieder aus zweicrlei, wahrscheinlich männlichen und weiblichen Individuen besteht. Ich habo bis jetat noch keine Gelegenlıeit gehabt, die Sommergeneration dieser Jlattlïuse zu untersuchen*), was aber die zweite, flügellose Genera-

*) Ich hofle, im Laufo des Sommers moine Untersuchungen über Chermes (wio die über Coccinen und andere Pfianzenlkuse) noch weiter zu vervollständigen und meinen Fachgenossen spltter im Detail vorlegen zu künnen. 
tion betrifft, deren Individuen als Eier (Ch. larieis) oder als bereits entwickelto Thiere (Ch. abictis u. a.) überwintern, so unterliegt es nach meinen Beobaclitungen (an C. abietis und einer nahe verwandten neuen Art, Ch. pini) keinem Zweifel, dass dieselbe ausschliesslich jungfräulichen Weibehen gebildet wird. Ich habe viele Dutzende dieser Thiere untersucht, abor niemals einen Samenfaden in den Geschlechtsorganen angetroffen, obwohl die Eier schon bald nach der Geburt die deutlichsten Zeichen der Émbryonalentwicklung zu erkennen gaben. Die Entwickelung der Fier geschieht auf dieselbe Weise, wie bei den Cocciden und befruchteten Aphidenwcibchen, nur dass die Eirölı'en hier in Wirklichkeit zweificherig sind, d. h. ausser dem einen melr oder weniger vollstïndig entwickelten Eie noch eine zweite jüngere Eianlage mit Kein- und Dotterfach besitzen. Die Zahl der Eiröhren ist sehr verschieden; sie betriggt bei Ch. pini nur 3-5 jederseits, wie bei $A$ phis, bei Ch. abietis dagegen 20-24.

\section{Parthenogenesis bei don Sackträgern.}

Obgleich mir (wio schon oben S. 350 erwähnt) nach den Mittheilungen v. Siebold's uber die von ihm und Reutti angestellten Experimente nicht die geringsten Zweifel mehr geblieben waren, dass die spontane Entwickelung der Eier bei gewissen Sacktrigern und namentlich bei Solenobia lichenella cine sehr gewöhnliche Erscheinung sei, hiclt ich es doch - mit Rücksicht auf die von v. Sicbold selbst einst geforderte Strenge der Kritik - für wünsehenswertl, diese Vorginge einer mikroskopischen Prüfung zu unterwerfen. Musste ich doch den Werth des Mikroskopes in dem hier vorliegenden Falle um so höher sehätzen, als es mir durch Anwendung desselben bercits früher gelungen war, die v. Siebold'sche IIypothese ron dem Generationswechsel der Sacktrigger als irrthümlich zu erkennen, und später zuriickzuweisen (s. o.). Eine solche Controlle schien mir anch, nach dem Erscheinen der v. Siebold'sehen Abhandlung über die Parthenogenesis noch nicht überflussig. Allerdings giebt $\mathrm{v}$. Sicbold an, dass er jetzt cbensowrohl die Solenobia lichenella, wie auch die S. triquetrella, die sich beide olme Befruchtung fortpflanzten, als voll- 
ständig entwickelte Schmetterlingsweibchen erkannt habe, dass alle die von ilın untersuchten Exemplare ganz den bei den Schmetterlingsweibchen gewöhnlichen Bau der Geschlechtsorgane (doppelte Geschlechtsöffuung, Bursa copulatrix und Receptaculum seminis) besessen und überdies beständig einen leeren und linausgedehnten Samenbeutel, so wie eine cben solche Begattungstasche gezeigt hätten, allein ein Zweifler könnte doch noch immer hervorheben, dass v. Siebold keine einzige Beobachtung angeführt habe, dic speciell unter Controle des Mikroskopes angestellt und so gegen alle nur möglichen Anfechtungen gesichert sei.

Um diese Lücken in der Beweisführung auszufüllen, wandte ich mich im April v. J. an Ferrn Notar Reutti mit der Bitte, mir, wo möglich einige Exemplare sciner Solenobia lichenella für diese Zwecke zu ïbersenden. Ich hatte früher schon öfters von Iferrn Senator v. II eyden diesen Sacktrïger, wie auch die Sol. triquetrella im Raupenzustande zugeschickt bekommen, allein eimnal wollte mir dic Zucht derselben nicht gehörig gelingen und sodann schien es mir auch wichtig, genau dieselbe Art, wie v. Sicbold, zur Untersuchung zu erhalten. *) Herr Notar Reutti hatte die Freundlichkeit, meinen

*) Wie schwierig hier dio Artenkenntniss ist, geht vielleicht am Besten aus der nachfolgenden Stelle horvor, die ich einem Briefo des Hrn. Reutti entlehne. "In der Kenntuiss und Benennung dieser Arten (S. triquetrella und lichenella) herrscht noch grosse Confusion, zumal die Säcko derselben, auf die sich die Beschreibung zunächst stützt, nach der Farbe des Bodens, auf dem diese Thiere leben, sehr variirt. So finden $\operatorname{Sic}$ z, B. unter den boifolgenden Slicken von S. triquetrella zwoi Stïck, die ganz röthlich sind und von Thieren stammen, die hier (in Lahr) im bunten Sandstein leben, withrend dio tibrigen, melır grïnen, auf Gneis gefunden sind. Auf diese Weise sind die Sol. Mannii, Sol. pineti und unsere $\mathbf{S}$. triquetrella vermuthlich nur Varietiten einer Art. Unsere S. triquetrolla ist übrigons diejenige, von wclcher $/$ oller mir bemerkte, dass sie nur Weibchen gebe, whhrend wir sic in lreiburg ziemlich in gleicher Anzahl in beiden Geschlechtern erhielten. (Auch unter den Saclitrilgeru v. II eyden's war eine, dio mir nur Minnchen gab, so dass hier also thnliche Vorhultnisso obwalten, wic bei den Cocciden. Lt.) Hier in Lahr habe ich bis jetzt von denselben auch nur Weibchon bekommen, nio aber dabei spontane Entwickelung der Eier gesehen. (v. Siebold gicbt an, dass 
Wunsch zu erfillen und sandte mir unter dem 12. April eine ganze Anzahl lebendiger Puppen und Raupen seiner S. lichenella, mit der ausdrücklichen Bemerkung, dass dieselbon mit der von ihm und v. Siebold beobachteten S. lichenella identisch seien.

Bereits am 17. und 18. $\Lambda$ pril schlüpften die flügellosen*) Weibchen aus den $6 \div 8$ ïbersendeten Puppen. Sie legten fast unmittelbar darauf in der von v. Sicbold so naturgetreu (a. a. O. S. 35) geschilderten Weise ihre Eier und wurden nach Beendigung dieses Geschifftes der anatomischen Untersuchung unterworfen. Alle oline Ausnahmo erwiesen sich (Fig. 12) als Jungfrauen, da Samentasche, wie Bursa copulatrix, völlig lecr und zusammengefallen war. Eben so leer waren auch die Eirölren, in denen man sonst bei den weiblichen Schmetterlingen auch nach der Eierlage immer noch eine grosse Menge tuvollständig entwickelter Lier antrifft. Schon früher war mir bei Ustersuchung der von v. Ileyden überschickten Raupen die völlig gleichmaissige Lntwickelung allor Fikcime (deren meist 9-12 in jeder der acht Eiröhren gefunden werden) aufgefallen. Die jetzige Beobachtung stimmte mit dieser Thatsache völlig überein und diente zugleich anch zu deren Erklirung. Mit der Eierlage erlisclit übrigens auch in der Regel zugleich das Leben unserer Thierc. Sic sterben hïufig noch in derselben Lage, die sie beim Ablegen des letzten Lies auf ihrem chemaligen Sacke einhielten. Nahrung wird von dem ausgeschliipfton W Weibchen, wie es schcint, niemals genossen.

S. triquetrella - aus Freiburg? - parthenogenetisch sei. Lt.) Unsero S. lichenella scheint sehr wenig bekannt $z u$ sein; sie ist jedenfalls nicht $=\mathbb{S}$. lichenella Zell, und Bryand. Zellor kannte sio nicht und bestimmte sio als S. pincti (?). Seine $\mathbf{S}$. lichenella ist grösser, als unsere $\mathbf{S}$. triquetrella, mit lingerm, schmalem Sacke. $\Lambda \mathrm{m}$ Endo ist unsere S. lichenella $=\mathrm{S}$. petrella Geer, Réaum. (= Lichenum Schrk.), doch giebt es wahrscheinlich auch hier Varietilten, viclleicht auch gute, verschiedene Arten, wie S. lapicidella mir zu sein scheint. Wam aber alle diese Confusionen beseitigt sein worden und wer sie zu lösen im Stande whire?!"

*) Interessant ist ïbrigens, und meines Wissens bisher nocl niclit bemerkt, dass die Puppen dieser Weibehen mit ganz deutlichen Flügelscheiden verschen sind. 
Um das Ergebniss dieser Untersuchung zu controliren, wurde auch eine Anzahl Puppen der Section und mikroskopischen Analyse unterworfen. Auch hier keine Spur von Sperma in den Geschlechtsapparaten. Ebenso natiirlich bei den Raupen, die nir dabei übrigens von Neuem (Fig. 13) dieselben unverkennbaren Zügo der bei den Schmetterlingen gewöhnlichen Art der Fientıvicklung mit Keimfach und Dotterfach vorführten, die mich schon früher (Art. Zeugung a. a. O.) veranlasst latte, unsere Sacktriiger als genuine Weibchen in Anspruch zu nehmen. Nach dem Resultate aller dieser Untersuchungen konnte eben so wohl die Virginität, wie auf der andern Seite auch die Befruchtungsfähigkeit unserer Thiere als vollkommen ausgemacht betrachtet werden.

Es ist iibrigens nicht bloss dic Organisation der Geschlechtstheile, durch welche den $\Lambda$ nforderungen einer etwaigen Befruchtung Geniige geschicht; auch die Eier sind für eine solche Eventualität in passender Weise cingerichtet. Sie besitzen eine Nicropyle, die im Wesentlichen ganz mit der der übrigen Schnetterlinge übereinstimmt und sogar eine relativ sehr ansehmliche Ausbililung zeigt. Diesclbe besteht nämlich aus etwa $16-18$ radialen Kanälen, die von einer gemeinschaftlichen Centralgrube $(0,015 \mathrm{Mm}$.) ausgehen und dio Mitte eines ziemlich grossen, rundlichen oder ovalen Feldes $(0,04 \mathrm{M} \mathrm{m}$.) einnehmen, dessen Begrenzung in Form eines Ringwulstes nach Aussen aufspringt. Der Apparat ist, wie gewöhnlich bei den Schmetterlingen, an oberen Pol der ziemlich dickschaligen, sphärischen Lier angebracht. Die übrige Schale zeigt sich fein gekörnelt.

Die mit den Eiern unserer jungfrüulichen Solenobien gefüllten Sicke wurden nun einzeln in kleine Probirgliischen gebracht, mit zarter Leinwand verschlossen und an einer geschützten Localitït, im Freien, aufgehängt. In allen Säcken entwickeln sich die Eier und nach 6-7 Wochen wimmelten dic Behitilter von kleinen Rüupchen, die sogleich nach dem Ausschlïpfen den mütterlichen Sack benagten und die Bruchstücke desselben zum Aufbau neuer Saicke verwendeten. 
Der Versuch, diese jungen Solenobien an einer flechtenreichen, mit Stcinen durchsetzten Brettcrwand einheimisch zu machen, ist mir missglückt, wic ich dic S. lichenella denn überhaupt bis jetzt noch nirgends bei Giessen habe auffinden können.

Zur Beobachtung der Psycho helix hat es mir bisher an Gc. legenheit gefehlt; ein Paar zugesponnene Säcke, die ich der Freundlichkeit des Ilerrn Prof. $\mathrm{F}$ ischer in Freiburg verdanke, waren mit einer Sehmarotzerlarve besetzt. Aus den Mittheilungen von v. Sicbold und Reutti geht übrigens hervor, dass dic Parthenogenese hier eben so constant ist, wie bei Solen. lichenella. Ilat es doch bis jetzt noch nicht einmal gelingen wollen, mit Sicherheit die Miinnchen dieser beiden Sacktrüger kennen zu lernen, und doch sind vielleicht schon viele Hunderte derselben der Zucht unterworfen gewesen. Aelnnliches gilt übrigens auch, wie wir oben bemerkten, von manchen Schildlïusen (z. B. Lecamium hesperidum), wie denn überhaupt die Parthenogenesis in der Fortpflanzungsgeschichte beider Thicrgruppen eine gleich bedeutungsvolle Rolle zu spielen scheint; eine Analogie, die um so interessanter ist, als beide Gruppen auch in den auffallenden Formversehiedenheiten der Geschlechter und der stationären Lebensweise der weiblichen Individuen mancherlei Anknüpfungspunkte besitzen.

Wie nun übrigens allem Anscheine nach die Parthenogenesis nicht boi allen Coccinon in gleicher Constanz und Regelmüssigkeit auftritt, so scheinen auch unter den Sacktrïgern in dieser Hinsicht bei den verschiedenen Arten mancherlei Differenzen vorzukommen. Schon bei Solenobia triquetrella dürfte die Parthenogenesis viel wcniger constant sein, als bei Sol. lichenclla, wie das anch $R$ eutti hervorhebt, wenn er angiebt, (s. S. 372, Anm.), dass er in Lalır noch niemals cine spontane Entwicklung bei derselben beobachtet habe. In noch anderen Arten mag eine solche spontane Entwickeluug nur in seltenen Ausnahmsfüllen vorkommen, wie das auch sonst bei den Schmetterlingen, besonders Nacht- und $\Lambda$ bendsclimetterlingren und namentlich bei den Seidenspinnern, gelegentlich beobachtet ist.

Unter diesen letzten Fällen verweise ich hier besouders auf die von dem verdienten Redacteur der Bienenzeitung Schmid ange- 
stellten Experimente, über die v. Siebold in seiner „wahren Parthenogenesis" S. 130 ff. berichtet hat. Dicselben sind uns namentlich auch deshalb interessant, weil sie durch vollständig gelungene Zucht der parthenogenetisch erzeugten Raupen zu der Erkenntniss fiihrten, dass die sich spontan entwickelnden Eicr kcineswegs in allen Fällen bloss zur Erzeugung einer ausschliesslich münnlichen (Biene) oder weiblichen (Coccinen, Sacktrïger) Nachkommenschaft bestimmt sind. Schmid und v. Siebold zogen aus jenen Riupchen Seidenspinner beiderlei Geschlechtes.

Meine eigenen Erfahrungen über die Parthenogenese der Seidenspinner beschrïnken sich auf eine unvollständige Beobachtung aus dem Jahre 1854. Im October dieses Jalıres erhielt ich von dem bekannten, jetzt verstorbenen Apisten Gundelach eine Anzahl Scidenspinnereier, dic mit vielen andern nach 24stündigem Zügern von einem unbefruchteten Seidenschmetterling abgelegt waren. Gundelach, der den Rest behiclt, gab spïter an (Bienenzeitung 1855, S. 26), dass seine Eicr unverindert geblieben seien, allein mit den mir übergebenen Eiern verhielt es sich anders. Vielleicht der vierte Theil derselben durehlief in den folgenden Wochen (wie ich damals auch an Herrn v. Berlepsch mitgetheilt habe, Bienenzeitung 1855. S. 26. Note 2.) jenen eigenthümlichen Farbenwechsel, der schon seit lange als charakteristisches Zeichen der beginnenden Ëmbryonalentwicklung bekannt ist. $\mathrm{Zu}$ ciner rollstindigen Entwickelung des Embryo brachten es übrigens nur einige wenige Eier und auch bei diesen kam es nicht bis zum Ausschlüpfen der Riiupchen. Trotz des Farbenwechsels verschrumpften die Eier gegen Ende des Winters ebenso, wie es die übrigen gelb gebliebenen Eier schon früher gethan hatten. Die zwei oder drei am weitesten entwickelten Eier enthielten ein zusammengetrocknetes, doch bereits deutlich erkennbares Räupchen.

Diese Beohachtung war mir um so interessanter, als ich aus einer älteren Mittheilung von Herold (Disquisit, de animal. vertebr. car. in ovo format. Pars II. 1838. Tab. VII.) entnehmen durfte, *) dass

*) $\nabla$. Siobold bemerkt in Betreff dieser Angabe von IIorold (wahre Parthenogenesis S. 122), dass dieselbo nauffallonder Weiso bishor der $\Lambda$ uf- 
solche Fälle eines frühzeitigen Absterbens bei unbefruchteten Seidenspinnereiern eben nicht selten sind und jedenfalls viel läufiger vorkommen, als bei befruchteten.

\section{Parthenogenesis bei den Bienen und den übrigen gesellig lebenden Hymenopteren.}

Wenn ich nach den ausführlichen Erörterungen, die v. Sicbold der Parthenogenesis der Bienen gewidmet hat (a. a. O.), auch nach den eigenen früheren Bemerkungen (S. 353 fí.) hier nochmals auf diese Erscheinung zurückkomme, so geschicht das theils aus Rücksicht auf das besondere Interesse, welches an dic Parthenogenesis dieser Thicre anknüpft, theils auch deshalb, weil ich durch meine Verbindung mit mehreren der bedeutendsten Bienenzüchter viellecicht häufiger, als andere meiner Fachgenossen, zu Untersuchungen über die Fortpflanzungsverlhïltnisse der Bienen veranlasst worden und zu mancher sonst seltenen und interessanten Beobachtung Gelegenheit fand So werthvoll auch die Beobachtungen und Zusammenstellungen v. Siebold's sind, so haben sie unsere Kenntnisse von den Fortpflanzungsverbältnissen der Bienen doch noch keineswegs zu einem vollständigen Abschlusse gebracht.

Was ich im Nachfolgenden näher zu behandeln gedenke, sind weniger die Verhältuisse der normalen Drohnenbrütung (für die ich auf v. Sicbold verweise), als vielmehr die Erscheinungen der Drohnenbrütigkeit und das Eierlegen der Arbeiter, zwei Vorgänge, die bei v. Siebold cine nur beiläufige Erwilhnung gefunden haben und doch in mehr als ciner Bezichung eine speciellere Berücksichtigung verdienen. Dass ausser den Bienen auch noch die übrigen gesellig lebenden Hymenopteren hier ein reiches Material bieten, ist bereits in der Ueberschrift angedeutet; wir werden daranf in Laufe unserer Darstellung viclfach zuriekkkommen und auch zugleich Gc-

merksamkeit der Plysiologen ontgangen sei๘. Er haltte sich durch meinen Artikel Zeugung (a. a. O.) leicht davon überzcugon künncn, dass dem nicht so ist. 
legenheit finden, eine Reihe von physiologischen Fragen zu erörtern, die an die Fortpflanzungsgeschichte unserer Thiere anknüpfen.

\section{Ueber Drohnenbritigkeit.}

Unter den gewöhnlichen, normalen Verhältnissen entwickeln sich bekanntlich dic dreierlei Individuen eines Bienenstockes in eben so vielen durch Form und Grösse von einander verschiedenen Zellen und zwar so constant, dass man in früherer Zeit sclbst cinen causalen Zusammenhang zwischen diesen Erscheinungen vermuthen konnte. Es giebt indessen auch Fälle, in denen sich diese Verhältnisse insofern anders gestalten, als die Entwickelung der männlichen Brut, statt auf das s. g. Drohnenwachs beschränkt zu bleiben, auch in den kleineren Arbeiterzellen und selbst in den Weiselwiegen vor sich geht. Dic geringeren Grade dieser Abnormität mögen vielleicht häufiger scin, als man gewöhnlich vermuthet*); der Bicnenzüchter und besonders derjenige, der seine Zucht obne Dzierzonstöcke treibt, die bei der Beweglichkeit ihrer Waben eine bessere und vollständigere Ueberwachung zulassen, wird meistens erst dann auf diese Erscheinung aufmerksam, wenn das männliche Brutlager cine schon bedeutende Ausbreitung gewonnen hat und vielleicht die Melirzahl, wenn nicht gar die gesammte Menge der auslaufenden Bienen aus Drohnen bestcht. Solche Fïlle sind es, die den Bienenzüchter veranlassen, von einer "Drohnenbrütigkeit " zu sprechen.

Diese Erscheinung der Drohnenbrïtigkeit ( $\Lambda$ rrenotokic) beobachtet man bald in einem Stocke, der, ohne Wechsel der Königin, früher in ganz normaler Weise sich fortgepflanzt hatte, bald aber auch unmittelbar nach dem Absterben oder dem Abzuge der alten Königin. Im ersten Falle entsteht die Drohncnbrütigkeit meist allıälig, indem die Zahl der Drohnen immer mehr und mehr zunimmt und schliesslich nur noch wenigo oder gar keine Arbeiter mehr erbrïtet werden - wir wer-

*) nAuch bei höchst fruchtbaren Königianen kommt es nicht selten vor, dass cinzelno Drohnen aus Bienenzellen mitten zwischen Arbeitern auslaufenu. 7. Borlepsch, Bienenzeitung 1855, S. 78. 
den diese Form fortan als secundüre Drohnenbrütigkeit bezeichnen -, während die Drohnenbrütigkeit im zweiten Falle beständig plötzlich eintritt und stets von $\Lambda$ nfang an eine vollständige ist (primäre Drohnenbrütigkeit).

Dass der Grund dieser auffallenden Erscheinungen in einer abnormen Beschaffenheit der eierlegenden Königin zu suchen sei, daruber waren die Bienenzïchter nic im Zweifel, wenn auch die $\mathrm{Na}$ tur dieser Abnormität ihnen unbekannt blieb. Schirach, der, soweit bekannt, den ersten Fall von Jrohnenbruitigkeit beobachteto (Naturgesch. der Bienenkönigin 1771), vermuthetete irgend einen Fehler am Eierstocke der Bienenkönigin, wälrend dagegen $\mathrm{Huber}$, mit specieller Berucksichtigung der ihm besonders hïufig vorkommenden Fälle von primärer Drohnenbrutigkeit, den Nachweis zu fülıren suchte (Neue Beobachtungen u. s. w. Dritter Brief), dass dieselbe durch eine Verzögerung der Begattung (bis über den 16. Tag hinaus) bedingt sei. „MIan hat bisher, so sagt derselbe (a. a. O. S. 67), von der Verzögerung der Befruchtung keine andere Wirkung anf die Weibehen der Thiere wahrgenommen, als dass sie dadurch ganz unfruchtbar werden. Die Bienenköniginnen liefern das erste Beispiel cines Weibchens, dem diese Verzögerung noch die Fähigkeit belïsst, Männchen zu crzeugen." (Aehnliche Erscheinungen vermuthet Huber auch bei anderen Insekten, besonders bei Wespen, Humineln und verwandten Formen.)

Die glückliche Lösung dieses Problemes war, wie schon oben erwähnt ist, dem Beobachtungstalent und der Combinationsgabe $\mathrm{D}$ ziorzon's vorbehalten. Die Drohnenbrütigkeit, so lehrte derselbc, entstelit nicht durch eine Verzögerung der Begattung*), sondern durch

*) v. Borlepsch sah Königinnen noch nach dem 21. Tage normal fruchtbar werden (Bienenzcitung 1856, S. 220, Note). Uebrigens ist auffallend, dass II ubor in seinen Fullen zum Theil ausdrücklich hervorhebt, dass dio betreffenden Küniginnen mit den Begattungszeichen (d. h. dem abgerissenen Penis) in der Vagina von dem Hochzeitsausflugo zurückgekchrt scien. Dönhoff, dor dio Huber'schen Experimento wiederholto und wirklich dureh Verzöge. 
ein Unterbleiben *) derselben (primïre Drohnenbrïtigkeit) oder durch allmälige Erschöpfung des im Receptaculum seminis vorhandenen Samens (sccundäre Drohnenbrütigkeit), der sonst unter gewöhnlichen Verhältnissen für die ganze Lebensdauer der Königin (3-4 Jahre) ausreicht $\left.{ }^{* *}\right)$.

Dzicrzon und später auch v. Berlepsch haben schon zu einer Zeit, in der die Physiologen von den Bestrebungen der Bienenzüchter noch wenig oder gar keine Notiz nahmen, den Versuch gemacht, die Richtigkeit dieser Behauptung; die sich ursprünglich bloss auf die Empirie stützte, der wissenschaftlichen Controlle zu

rung des IJochzeitsausfluges zwei Königinnen drolnnenbrütiğ machte, fand beide Male cine jungfralulicho Samentasche (IBienenzcitung 1856, S. 220). Dor IJochzeitsausflug selbst wurde lcider nicht beobachtet, doch ist Dönhoff geneigt, in Wirlilichkeit eino - freilich erfolgloso - Begattung anzunehmen.

*) Schon Hattorf, ein Zeitgenosse Schirach's, behauptete dio Fortpflanzungsfahigkeit jungfrłulicher Königinnen und suchte dieselbe auch auf experimentellem Wego zu beweisen. (Physikalischo Untersuchungen über dio Frago: ist die Bienenkönigin von den Drohnen befruchtet worden? Schirach's Gesch. der Bienen.) II ubor glaubte sich jedoch durch thanliche Experimento berechtigt, die Bewciskraft der IIattorf'schen Versuche in Zweifel zu ziehen (a. a. O. S. 12) und suchte seinerseits den Nachweis zu licfern, dass die Königinnen erst durch die Paarung fruchtbar würden.

**) Die ersten $\Lambda$ gaben über dieso Thatsache finden wir bei Huber, der freilich nicht wusste, dass der Samen in Substanz so lange sich erhielt. „Ich habo mich überzeugt, dass eino einzigo Anhilngung ausreicht, allo Eier, welcho eino Königin mindestens wihrend zwei Jahren legt, zu befruchten; ich habe sogar Grund, anzunchmon, dass dieser einzigo Act zur Befruchtung aller Eier, die sie ihr Leben lang legt, ausreicht; indess liabo ich nur für den Zeitraum von zwei Jahren sichern Beweis." $\Lambda$. a. O. S. 61. (Huber war der Ansicht, ndass der männliche Samen von vorn herein auf die Gesammtmasso der Eier einwirko", dass, wio spiltcro Bienenzüchter sagten, nicht das Ei, sondern der Eierstuck befruchtet werde.) Dio wissenschaftliche Erkllirung dieser Thatsache verdanken wir A udouin (Ann, des sc. nat. 1824, II, p. 284), dessen nLettro sur la génération des Insectes" für dic Entwickelung dex neueren Kenntnisse von der Natur der Anhangsorgane bei den weiblichen Insekten überhaupt von grossem Einflusse gewesen ist, 
unterwerfen und drohnenbrätige Königinnen secirt. Obwohl nun diese Untersuchungen in ziemlich roher Weise, ohne genügendo Sachkenntniss und mit unzulänglichen Hülfsmitteln angestellt wurden, so schien doch das Resultat derselben der Dzierzon'schen Hypothese durchaus günstig zu sein. In allen Fällen, die zur Beobachtung kamen, war der Samenbeutel hell und durchscheinend, wie bei einer jungfrïulichen Königin, während derselbe bei einer normalen Legekönigin constant mit einer "weissen und schleimigen Materie", dem. Sperma, gefüllt erschien. Beide Forscher schlossen aus diesem Ausseben auf die Abwesenheit von Sperma in dem Receptaculum - ob freilich in allen Fällen mit Recht, muss dahin gestellt bleiben. So viel ist jedenfalls gewiss, dass der wissenschaftliche Beweis eines Samenmangels mit einer blossen Ocularinspection noch nicht gefuhrt ist. Dazu bedarf es einer genaueren Untersuchung und vor allen Dingen der Constatirung durch Hülfe des Mikroskopes.

Ich habe schon oben bemerkt, dass es mir gelungen ist, diesen Beweis mit aller Bestimmtheit zu führen und der Dzicrzon'schen Lehre von der Causalität der Drohnenbrütigkeit damit ihre volle Gultigkeit zu sichern. -

Meine Beobachtungen über drohnenbrütige Königinnen umfassen fast ein Dutzend einzelner Fälle, unter denen drei Fälle von primärer Drohnenbrütigkeit, die ich hier zuerst in Betracht ziehe.

\section{Erster Fall.}

Der erste dieser Fälle ist der schon oben (S.356) erwähnte, der im April 1855 zur Untersuchung kam. Am 3. MIärz d. J. erhielt ich einen Brief des Herrn v. Berlepsch, der mir die demnäclistige Ankunft dieser Königin, der ersten Drohnenkönigin, die ich überhaupt untersuchte, ankündigte. "Ich habe", so schrieb derselbe, „gegen Ende September v. J., nachdem hier längst keine Drohnen mehr existirten, in drei sehr starken deutschen Stöeken italienische Königinnen erbrüten lassen. Sie flogen bis tief in den October aus, natürlich ohne befruchtet werden zu können. Zwei dieser Königinnen gingen mir leider durch die rauhe Witterung verloren und nur eine 
kam zur Einwinterung. Gestern wurde nun der Stock mit dieser Tïnigin untersucht und siche! bercits waren etwa 100 italienische Männchen ausgelaufen und etwa 1500 Zellen waren mit Buckelbrut *) besetzt. Dic Königin hatte Zelle für Zello mit Eiern besetzt, um Arbeiterbienen zu crzeugen, aber nur Mïnnchen gingen und gehen hervor!" Vier Wochen später lag die Königin, die, wie fast alle übrigen hier zu erwähnenden Exemplare, lebendig bei mir ankam, auf meinem Secirteller. Ich will gestehen, dass ich mich mit ciner gewissen Unruhe an die Untersuchung machte, denn ich ahnte wohl, dass der Satz der Physiologen: "keine Entwickelung der Eier ohne Befruchtung* hier seine schlagende Widerlegung finden werde. Die Geschlechtsorgane waren von derselben starken Entwickelung, wic bei allen eierlegenden Königinnen, mit reifen und unreifen Eiern der verschicdensten Ausbildung. Dass es ein wirkliches Weibchen war, das hier vor mix lag und nicht etwa eine Amme, konnte keinen Augenblick bezweifelt werden; die Bildung der Eier (Micropyle) und deren Entwickelung in den Eiröhren (mit Keim- und Dotterfächern) bewies das nicht minder, als dic Anwesenheit einer Samentasche an der Scheide (Fig. 14 u. 15). Diese Ietztere hatte mit ilırer Anhangsdrüse ganz die gewöhnliche Grösse und Bildung, aber sic war in der That die Samentasche einer jungfrïulichen Königin. Nach Entfernung des ätssern (schon von $\mathrm{S}$ wammerdam abgebildeten, Bibel der Natur Taf. XIX, $t$ ) starken Tracheennetzes erkannte ieh augenblicklich die Richtigkeit der Dzierzon'schen Angabe; ich sah ein klares und durchsichtiges Bläschen, wic eine wasserhclle Perle und ïberzcugte mich durch Hülfe des Mikroskopes von der völligen $A b w e s c n h e i t$ etwaiger Samonfäden. Auch in den ïbrigen Geschlechtsorganen war keine Spur von Sperma nachzuweisen, wie ich denn hier überhaupt niemals bei den Bienen und andern Insekten ausser den Coceinen Samenfäden gefunden habe. Dor Inhalt

*) Dio Zellen mit Drolınenlarven werden bei Annlherung des Puppenschlafes mit cinem stark gesvölbten, dic mit Arbeiterlarven dagegen mit einem flachen Deckel verschlosson. Buckelbrut also $=$ Drohnonbrut. 
der Samentasclıe bestand aus ciner lıellen, völlig körnerlosen Flüssigkeit von ziemlicher Consistenz, dic übrigens wohl kaum ausschliesslich von der $\Lambda$ nhangsdruse, sondern zum Theil auch von den auf der der innern Chitinhaut aufliegenden Drisenzellen abgesondert sein durfte*).

\section{Zweiter Fall.}

An diesen ersten Fall schliesst sich ein zweiter, den ich durch die Freundlichkeit des in der apistischen Litteratur sehr wohl bekannten Herrn Vogel, Lehrer in Lehmannshöfel bei Cüstrin zur Untersuchung bekam**). In dem begleitenden Briefe (d. d. 9. Juli 1857) bemerkte der Uebersender Folgendes: „Ende October v. J. entweiselte ich einen Bienenstock und am 8. November verlicss die beifolgende Königin ihre Zelle. Die Bienen flogen nach diesem Tage nicht mehr aus, und ich bin im Stande zu versichern, dass diese Königin keinen Begattungsflug gehalten hat. Trotzdem legte dieselbe bereits Mitte Miärz Eier, aber aus allen entwickelten sich bloss Drohnen." Das Resultat der Untersuchung war, wie unter den vorliegenden Verhältnissen vorauszusehen, genau dassclbe, wie in dem vorigen Fall: die drohnenbritige Kö̈ngin war cine jungfrüuliche Königin. Ich sage, dass ein solches Resultat mit Sicherheit zu erwarten gewesen wäre; das Gegentleil würde cin Mal eine Begattung im Stocke, und sodann auch die Existenz ïberwinternder Drohnen roraussetzen, zwei Vorgänge, von denen der eine noch niemals beobachtet ist, und der andere zu den grössten Seltenheiten gehört.

*) Einen Boweis für die Richtigkeit dieser Vermuthung finde ich nicht bloss in der ganz allgemeinen Verbreitung dicser Drüsenzellen (dio auch bei den Coc. cinen ohne Anhangsdriise vorkommen), sondern auch weiter in dem Umstande, dass dio darunter liegendo Chitinschicht da, wo sio sich etärker verdickt, z. B. bei Gomphocerus u. a., mit sehr deutlichen Porencantilen - zum Durchlassen des Secrets - versehen ist.

**) Unter den verschiedenen der Bienonzeitung einverleibten Aufsützen des IIerrn Vogel erwahno ich hier besonders neinigo Sitze über Geschlechtstrieb, Begattung und Befruchtung der Bienen", I-III (1857 und 1858), dio in eben so cinfacher, wio rationeller Woiso dieso sohwierigon Gegenstïndo bchandeln. 


\section{Dritter Fall.}

Der dritte Fall, der Zeit nach eigentlich der zweite, wurde von mir selbst beobachtet. Derselbe betrifft cine Königin, dic noch in demselben Sommer, in dem sio erbrïtet wurde, Eier legte. Es war im September 1856, als ich während eines Besuches bei einem mir verwandten Pfarrer G. im Braunschweigischen Gelegenheit fand, den ziemlich reichen Bicnenstand eines dortigen Bauern in Augenschein zu nchmen. Unter den hier aufgestellten Stöcken, lauter Strohkörben, war einer, der, nach der Aussage des Besitzers, trotz der vorgerückten Jahreszeit und der sonst schon überall beendigten Drohnenschlacht noch zahlreiche Drohnen enthiclt. Natürlich, dass dieser Umstand meine volle $\Lambda$ ufmerksamkeit erregte. Ich erfuhr auf näheres Befragen, dass dieser Stock im Laufe des Sommcrs zwei Schwärme abgegeben habe und, früher volkreich, allmälig immer mehr heruntergekommen sei, so dass er wohl schwerlich olne bedeutenden $\mathrm{Zu}$ schuss durchivintert werden könne. Es ward mir unter solchen Verhältnissen ziemlich leicht, den Bauer, einen gauz intelligenten Kopf, zu einer näheren Untersuchung zu veranlassen. Die Bienen wurden betäubt. Wohl ein Drittheil des gesammten, im Ganzen nicht sehr zahlreichen Volkes bestand aus Drohnen; auch wurde noch viel Drohnenbrut auf verschiedenen Stadien der Entwickelung in dem Stocke angetroffen, wogegen die Menge der Vorraithe trotz des honigreichen Jahres eben nicht allzu gross war. Der erste, flüchtigo Blick auf die bald aufgefundene Königin bestätigte die Vermuthung, dass es ein Fall von Drohnenbrütigkeit sei, der hier vorlag. Die Königin besass nämlich nur cinen einzigen normal gebauten Flïgel, sie war flügellahm, wic der Bienenzüchter sagt, und das von Geburt an gewesen, so dass sic natürlich auch keinen Hochzeitsausflug hatte halten können. Dio Section und mikroskopische Untersuchung liess mich die Königin auch wirklich als ein jungfräuliches Thier crkennen. In dem Leitungsapparato fand sich ein Ei, das unter anderen Verhältnissen vielleicht wenigò Minuten später würde gelegt sein.

Solche Fälle von flügellahmen Drohnenköniginnen sind cben nicht selten; es scheint selbst, dass die primäre Drohnenbrütigkeit, 
wenigstens dann, wenn sic olıne Beiliilfe des Fxpcrimentators entsteht, in der bei weitem grössten Mehrzahl der Fall durch eine Missbildung der Fliigel und dic damit im Zusammenlange stehende Unfühigkeit des Fluges bedingt wird. So giebt namentlich auch v. Berlepsch an, dass unter den eilf von Dzicrzon und ihm beobachteten primär drohnenbrütigen Königinnen $\mathrm{z} c h \mathrm{n}$ *) von Geburt an flügellahm gewesen seicn (Bienenzeitung 1835. S. 75). Natürlich bietet dieser Unstand auch dic Möglichkeit, mittelst eines schr einfachen Experimentes, durch frühzeitiges Abschneiden der Flügel, nach Belieben drohnenbrütige Königinnen zu erzeugen, wie das denn u. A. auch durch v. Berlepsch (a. a. O. S. 78) und Vogel (Bienenzeitung 1858. S. 16) mehrfach geschehen ist.

Nach den voranstchenden Beobachtungen ist es umuöglich, die Existenz der Parthenogenesis bei den Bienen noch länger zu bezweifeln. Es steht hicrnach fest, dass die Bienenkönigin a uch im unbefruchteten Zustande entwickelungsfähige Eier produeirt, ganz eben so, wic die in den rorliergehenden Kapiteln von uns betrachteten Insckten. Es scheint auch, dass solehes mit derselben Regelmïssigkeit geschieht, die wir bei Solenobia lichenella, Lecamium hesperidum u. a. hervorzuheben hatten. Dzicrzon und v. Berlepsch waren fruiher allerdings der Ansicht, dass es nur eine Ausnahme sei, wenn eine Bienenkönigin ohne vorhergegangene Begattung Eier loge (Bienenzeitung 1855. S. 76), allein nach spätcren Erfahrungen von Rothe (ebendas. 1856. S. 179) und Vogel (ebendas. 185̄8. S. 17) dürfte diese Behauptung lkam noch lïnger zu vertheidigen scin. Auch hat v. Berlepsch selbst bereits (in einer Nachschrift zu dem Aufsatze von $R \circ t_{h}$ ) seine frühere Angabe zurïckgenommen. Jedoch hat es den Anschein, als wenn die Eierlage bei unbegatteten Königinnen in der Regel etwas später eintrete und sich oftmals bis zum folgenden Frühjahro linausziehe. Freilich giebt

*) In den von Vogel beobachteten Fullen (Bienenzeitung 1858, S. 18) scheint dio Zahl der Aügellahmen Küniginnen freilich nicht in gleicher Weiso zu pritialiren. 
es auch unter den gewöhnlichen Verhiiltnissen solche Fulle von verspäteter Eierlage, indessen dürften dieselben hier sehr viel seltener sein. Als Regel darf man annehmen, dass die Königin am zweiten oder dritten Tage nach der Begattung, also meist schon in den ersten Tagen ihres Lobens die Eierlage beginnt, während unbefruchtete Königinnen nicht etwa bloss ihre Ausfüge eine lange Zeit hindureh wiederholen, sondern oftmals auch nach dem Einstellen derselben noch wochenlang obne Brut bleiben*).

Die Frage nach der Causalität dieser Erscheinungen gehört nicht liieher. Sie füllt zum Theil mit der Frage nach den physiologischen Bedingungen der Fruchtbarkcit überhaupt zusanmen und wird an einem anderen Orte, in einer besonderen Abhandlung über die Fortpflanzungsverhältnisse der gesellig lebenden Hymenopteren, von mir besprochen werden. Ich will hicr nur bemerken, dass ähnliche Erscheinungen auch sonst nicht eben sclten sind. Es genügt, an unsere IIaushühner zu crinnern, die bei Anwesenheit eines Halns gleichfalls zcitiger zu legen hegimmen und auch fleissiger legen, als sonst; an einen Fall, der vielleicht $u$ m so mclir passt, als v. Berlepsch auch von den drohnenbriitigen Königinnen (a.a.O.) herrorhebt, dass sic in der Regel weniger Eier, als normale Königinnen unter sonst gleichen Verhältnissen absetzten.

Obgleich es num, wie bemerkt, immerhin als Regel angenommen werden darf, dass die Bienenköniginnen, auch wenn sie unbefruchtet bleiben, über kurz oder lang, nach Art der befruchteten Weibchen, ihre Eierlage beginnen, so scheinen doch dio Fialle der Sterilität bei ihnen häufiger zu sein, als unter anderen Verhuiltnissen. So giebt z. B. v. Berlepsch an (Bienenzeitung 1855. S. 76), dass von etwa zwanzig theils von Geburt aus flïgellahmen, theils gleich nach der Geburt von ihm fliigellahm gemachten Königinnon nur drei

*) Nach Beginn der Eierlage fliegt dio Königin niomals mohr aus, mag sio befruchtet oder unbefruchtet sein; eine Thatsacho, aus der dann weiter folgt, dass eino ein Mal drohnenbrïtigo Königin auch ihr Leben lang drohnenbrütig bleibt. 
eierlegend resp. drohnenbrütig geworden seien. Wenn man nun auch zugeben kann, dass sich dio Eierlage vielleicht später noch bei mchreren dieser Königinnen eingestellt haben würde, so scheint es doch kaum glaublich, dass solches bei allen oline Ausnalıme stattgefunden haben möchte. Auch Vogel, der die Constanz der Fierlage bei unbefruchteten Königinnen vertheidigt, bemerkt (a. a. O.), dass unter fünf von ihm noch am Tage der Geburt fluggellahm gemachten Königinnen nur drei Eier gelegt hätten. Freilich sucht er diese Thatsache durch die Vermuthung zu erkliaren, dass die betreffenden Königinnen beim Absclmeiden der Flügel vielleicht zu stark gedrückt seien und möglicher Weise an ilren inneren Organen irgend einen Schaden genommen hätten, allein nach den Beobachtungen von v. Berlepsch kehrt ein ähnliches ungünstiges Verhältniss anch bei den flügellahm geborenen Königinnen wieder. Ueberdies giebt $\mathrm{V}$ ogel auch weiter an, dass unter sechs auf fremden Stöcken von ihm beobachteten unbegatteten Königinnen nur fünf Drohnenküniginnen und cine unfruchtbare gewesen seien, also ein Verhïltniss von $5: 1$, das auch dann, wenn man dic von $\mathrm{Vogel}$ auf scinem eigenen Stocke beobachteten zwei selbständig (olne Experimentiren) entstandenen Drohnenkönigimnen hinzurechnet, immer noch viel ungünstiger ist, als bei normalen Königinnen. Dazu kommt schliesslich noch, dass die Sterilitït der letzteren meist erst nach einer längeren oder kürzeren Eierlage eintritt*), und nur sehr selten von $\Delta$ nfang an vorhanden $z u$ sein scheint.

*) Ich habe mehrere solcher sterilen Bicncnküniginnen untersucht, eine von Hrn. v. Berlepsch (August 1857), die früher zwei Jahre lang schr fruchtbar gewosen war, dio aber plötzlich 17-18 Tage vor der Soction unfruchtbar wurde, und eino zweito (Juni 1856) von Hin. Pfarrer Doichort in Grüningen bei Giessen, bei der sich die Sterilitüt mohr allmullig ausgebildet hatto. Beide Male wurden keinerlei besondero Abnormitaten nufgefunden. Namentlich waren in beiden Fullen dio Eirühren, ganz wie gowöhnlich willurend des Sommers, mit zahlreichen reifen und halbreifen Eicrn besetzt. In dem zweiten Falle müchto violleicht der stark ausgedehnto Mastdarm, der fast bis in dio Basis des 
Sobald eine Bienenkönigin nun aber cinmal Eier legt, geht unter den gewöhnlichen Verhültnissen, d. h. im Bienenkorbe, auch sogleich die Entwickelung derselben vor sich, mag eine Befiuchtung stattgefunden haben oder nicht. Diese Thatsache ist so constant, dass sich v. Berlepsch dazu erbieten kounte, zwanzig der schönsten Dzierzonbeuten mit italienischen Völkern gegen eine Königin zu geben, deren Eier, wenn sic bebruitet, d. h. dem warmen Stocke und der Obhut der Bienen belassen wurden, taub und unentwickelt blieben (a. a. O. S. 77). Doch Hr. v. Berlepsch hitte fast Gelegenheit zu solehem Tausche finden können. Im September v. J. erhielt ich von einem schr eifrigen und erfahrenen Bienenziuchter, Hern Hucke, Lehrer in Kleinrettbach bei Neudictendorf, cine Zusendung: mit folgendem Briefe: „Im Laufe dieses Sommers kam auf meinem Bienenstocke cine Königin vor, welche fleissig Eier legte, olıne dass je eines derselben ausgelaufen wäre, auch dann nicht, woun ich dieselben entweiselten Stöcken einhing. Da ich nun in der mir bekannten Bienenliteratur nie den Fall erwilint gefunden habe und IIerr Baron v. Berlepseh die Existenz von tauben Bienenciern sogar geradezu in Abrede stellt, hatte ich die Absiclıt, Ilınen diese Königin zur Untersuchung zu übersenden. Heute will ich dieselbe ausfangen, finde jedoch zu mcinem Schrecken, dass sie nicht melur vorhanden ist, obwohl noch zwei Tafeln mit Eiern besetzt sind. Da nun aber, die Königin mag befruchtet oder unbefruchtet gewesen sein, der Fehler doch wohl an den Eicrn liegt und an dicsen auch viclleicht ersichtlich ist, so süume ich nicht, Ihnen zwei Stitckehen Waben mit solelen Liern zu ïbersenden." Leider kam diese Sendung hier in Giessen an, während ich auf einer Reise begriffen war, so dass ich die Untersuchung der Eier, die bei meiner Rückkehr gänzlich eingetrocknet waren, nicht vornehmen konnte. Doch muss ich offen gestehen, dass ich die Hoffnung von Hucke, es möchte sich der Grund der Taubheit an den Eiern nachweisen lassen, kaum zu theilen wage.

Hinterleibes emporreiohte, ein mechanisches Ifinderniss für das Ablogen der Eier abgegeben haben. 
Die Bedingungen, unter denen eine spontane Entwickelung der Eier vor sich geht, sind uns einstweilen noch völlig unbekannt; wir können nur aus dem Erfolge erschliessen, dass diese Bedingungen bei den einen Thieren leichter, bei den anderen sehwieriger oder gar niemals sich zusammenfinden. Unsere Biencu gehören offenbar zu denjenigen Insekten, bei denen eine solche spontane Entwickelung fast jedes Mal geschicht, so bald dio Eier nur abgelegt sind *). Wie es aber auch unter den sonst parthenogenetisch sich fortpflanzenden Sackträgern (z. B. Solenobia triquetrella, vergl, oben S. 35̃7, die Beobachtung von $\mathrm{R}$ eutti) Individuen giebt, deren Eier sich nicht entwickeln, so mögen diese Verhältnisse auch immerhin lier und da bei einer Bienenkönigin wiederkehren.

Was ich bisher über die Drohnenbrütigkeit mitgetheilt habe, betrifft solche Königinnen, bei denen eine Begattung überhaupt nicht stattgefunden hatte, also Fülle einer Parthenogenesis, die sich unmittelbar an die bei den Schildläusen und Sackträgern nachgewiesenen Verhältnisse anschliessen. Dass die Eier der unbefruchteten Bienenkönigin sich ohne Ausnahıne zu Drolnen entwiekeln, dass die Parthenogenesis der Bienen also unter der Form der s. g. Drohnenbrütigkeit auftritt, ist allerdings in höchsten Grade interessant und auffallend, doch im Grunde nicht eigenthümlicher und wunderbarer, als wenn wir umgekehrt bei den unbefruchteten Sackträgern eine bloss weibliche Brut sich entwickeln selen. Die Causalitït des Geschlechts ist immer noch so unbekannt und dunkel, dass wir uns hier einstweilen wiederum bloss mit der constatirten Thatsache begnügen müssen.

Doch ausser den Füllen solcher primären Drohnenbrütigkeit giebt es, wio wir wissen, auch $F$ älle einer secundären Drohnenbrütigkoit und auch diese haben wir hier in's Auge zu fassen.

*) Selbst wahrscheinlich, dass auch dio aus den Geschlechtsorganen genommenen reifen Bieneneier sich entwickeln würden, sobald es nur golilngo, sie zur Bcbrïtung zu bringen. (Vielleicht würdo dieses Experiment mit Hülfe der Brutmaschine sich ohne sonderlicho Schwierigkeiten anstellen lassen.) 
Vierter Fall.

Herr Organist Kehrhahn in Dreveskirchen bei Wismar übersendete mir d. d. 30. Juni 1857 eine Königin mit nachfolgendem Bricfe: „Die italienische Königin, dic Sie anbei erhalten, wurde gegen Ende Juli 1854 fruchtbar. Sie war cine ganz ausgezeichncte Bienenmutter, nicht bloss durch ihre Färbung, sondern namentlich auch durch eine ganz uncrhörte Frnehtbarkeit, und auch ihre Nachkommenschaft zeichnete sich durch Fleiss und Ilonigreichthum vor allen andern Stöcken aus. (Nach Entfernung der MLtter im Jahr 1855 setzte dieselbe nicht weniger als 29 Weiselwiegen an!). Leider zeigte sich die Mutter im vergangenen Frühlinge drolnnenbritig und seit dieser Zeit hat sic kein einziges weibliches Ei gelegt." Die Untersuchung dieser Königin zeigte genau dieselben Verhältnisse, wie bei den primär drohnenbrütigen Königinnen, d. h. es fand sich trotz allen Suchens und Spïhens auch nicht ein einziger Samenfaden, weder im Receptaculum, noch sonst wo. Der ganze Inhalt der Samentasche war also in cinem Zeitraum von nicht drei Jahren verbraucht; ein Umstand, der gewiss nicht gering dazu beitrïgt, die Fruchtbarkeit der vorliegenden Königin als cine wirklich aussergewöhnliche erscheinen zu lassen. *) Die Grösse der Samentasche

*) Berechnet man den Raurninhalt der Samentasche, so wio den eines Samenfadens, so findet man, dass orstero miudestens 25-30 Millionen Samenfulen zu fassen im Stando ist. Nimmt man auch nur die Halfte dieser Menge oder noch weniger, und berücksichtigt dann wciter, dass bei der Befruchtung der cinzelnen Eier immer nur einigo wonige Fuden (vielleicht selten mehr als 6-8) verbraucht werden, so wird man leicht im Stando scin, zu begreifen, dass der Inhalt der Samentasche unter gowöhnlichen Verhältnissen, wo juhrlich vielleicht 150-200,000 Eicr abgesetzt werden, für dio Dauer eines 3-4jkhrigen Lebens völlig ausreicht, es müssto denn vielleicht, wie auch mitunter vorkommt - vergl. den sechsten Fall, S. 394 - cine nur unvollstindigo Fullung der Samontasche bei der Begattung stattgefunden haben. (Ich habe für die durchschnittlicho Lebensdauer der Bienenkünigin nur 3-4 Jabre angegeben; es gicbt jedoch sicher constatirte Fulle von Bienenköniginnen, die 7 Jabro lang lebten und in normaler Weiso fruchtbar blieben.) 
war ganz die gewöhnliche, dieselbe war nicht zusammengefallen und lecr, sondern mit der bekannten hellen und körnerlosen Flüssiglecit gefüllt. Der Eierstock zeigte eine starke Turgesecnz und zahlreiche reife Eier, von denen einige auch in den Leitungsgïngen gefunden wurden.

Man würde jedoch irren, wonn man das Resultat dieser Untersuchung auf alle Fälle einer secundären Drohnenbrütigkeit übertragen wollte.

\section{Fünfter Fall.}

$\Lambda \mathrm{m}$ 17. Mai 1856 untersuchte ich eino Köönigin, die mir Herr v. Berlepsch mit folgenden Bemerkungen übersendet latte. „Dieselbe ist mindestens drei Jahre alt und war im vorigen Jahre noch sehr fruchtbar, hat auch in diescm Frühjahr (Anfangs $\Lambda$ pril) noch einige Waben mit $\Lambda$ rbeiterbrut besetzt. Gegenwairtig nun steht sie im Begriffe, die Filhigkeit, weibliche Eier zu legen, zu verlieren, oder vichnehr hat sie diese Fühigkeit bereits verloren, deun unter hundert bedeckelten Brutzellen, die alle Arbeiterzellen sind, finden sich kaum 2-3 weibliche Nymphen, alles übrige ist Buckelbrut. Was aus den noch vorhandenen, im Ganzen aber nur wenig zahlreichen Eiern wird - das Volk ist sehr zusammengeschmolzen und auch eine normale Königin würde unter solehen Verhältnissen nur wenige Eier legen - lässt sich noch nicht sagen, walhrscheinlich alles Drohnenbrut", wie das denn auch nach späteren Nachrichten wirklich der Fall war. Die Samentasche dieser Königin crschien nach Entfernung des T'racheenüberzuges auf den ersten Blick genau von der uns bekannten jungfräulichen Beschaffenheit, aber bei näherer Betrachtung bemerkte ich im Mittelpunkte derselben eine leichte Trübung, wie ein Wölkcheu, das durch den sonst ganz wasserhellen Inlalt hindurehschimmerte. Dic mikroskopischo Untcrsuchungliess in diesem Wölkchen ein Convolut von ganz normalon, in gewöhnlicher Weise beweglichon Samenfäden erkennen. IIorr v. Berlepsch hatte dieses Resultat nicht erwartet; er vermuthete in seinem Briefe vollkommenen Samenmangel oder Anwesenheit von „Sperma 
ohne bewegliche Fäden" und schrieb mir später, dass er eher geglaubt Lätte, „die Königin habe cinen Elophanten im Receptaculo, denn bewegliche Samenfüden". Ich, für meine Person, muss gestehen, dass mich der hervorgehobene Befund viel weniger überraschte*), zumal auch aus dem Begleitbriefo hervorging, dass betreffende Künigin noch vor Kurzem einzelne weibliche d. h. befruchtete Eier gelegt hatte. Allerdings stand die äusserst geringe Anzahl dieser Eier scheinbar in gar keinem Verhältnisse mit der immer noch sehr beträchtlichen Menge von Samenfüden (dic gewiss auf vicle Ifunderttausende abgeschätzt werden durfte), allein andererscits war dabei zu berücksichtigen, dass dieser Samenfadenknïucl so ziemlich im Centrum des Receptaculum gelegen war und an allen Seiten von der bekannten hellen Flïssigkeit umgeben wurde. Denken wir uns nun bei unserer Königin eine Contraction der Samentasche, wie sie (vgl. weiter unten) zur Befruchtung eines Eies oder vielmehr zum Austreiben einer gewissen kleinen Menge des im Innern enthaltenen Fluidums nothwendig ist, so wird unter den hicr vorliegenden Verhältnissen aller Wahrscheinlichkeit nach eher ein Tröpfehen jener peripherischen Flüssigkeit ausfliessen, als cine Anzahl Samenfiden. Die bei weitem grössere Wahrscheinlichkeit ist unter solchen Umständen also dafür, dass dic vor dem Samengange vorbeistreichenden Eier nicht befruchtet werden, und sich dann natürlich zu Drohnen entwickeln. Immerhin aber ist die Drohnenbrütigkeit unserer Königin nur als eine rel a tive anzusehen, die mögliehen F'alls durch eine Lagenverïnderung des Samenknäucls, wenn diese violleicht eine Annäherung

*) Dr. Alefeld hat schon früher einmal bei der Scetion einer drohnenbrütigen Königin Samenfuden im Receptaculum gefunden. (Bicnenzeitung 1854, S. 170.) Da aber Dr. Alofeld der irrthümlichen Ansicht war, dass dio Samenfiden der Bienen, wio dio der Mensebon und Süugetbiere, mit cinem nolliptischen Krrper" versehen sein müssten, so crkllirto er dio aufgefundenen Fuden für blosse Bruchstücko und stellto deshalb dio Anwesenheit nvollstilndiger Samenthierchen" in $\Lambda$ brede. Die Bewegungen konnten, da Alofeld ein Spiritusexcmplar untersuchto, antürlich nicht beobachtet worden. 
an den Samengang zur Folge gehabt hïtte, für einige Zeit wieder einer normalen Eierlage Platz gemacht haben würde.*)

Bei der voranstehenden Deduction ist natürlich vorausgesetzt, dass die Bienenkonigin ein nur beschränktes Contractionsvermögeu ihrer Samentasche besitze. Dass dem in Wirklichkeit so ist, dafür spricht nicht bloss der Umstand, dass man die Samentasche bei der Bicnenkönigin niemals, wie bei zahlreichen andern zum Theil nahe verwandten Insekten, in einem merklich zusammengezogenen Zustande antrifft, sondern namentlich auch dic Anwesenheit des schon oben erwähnten Tracheenüberzuges, der bei der Weite der anastomosirenden Stämme und der Stärke des Spiralfadens einen sehr wirksamen elastischen Apparat bildet, dessen Federkraft eine stärkere Contraction und damit cin vollstïndigeres Auspressen des Inhaltes kaum zulassen möchte. Dass es, wie wir bei der vorhergehenden Königin gesehen haben, auch Fälle giebt, in denen die gesanmte Menge der im Receptaculum enthaltenen Samenfüen nach Aussen ausgetrieben wird, kann wohl schwerlich gegen solche Annahme geltend gemacht werden. Wir brauchen nur darauf hinzuweisen, dass bei der Entlecrung des Sperma wahrscheinlicher WVeise noch andere Momente in Betracht kommen. Neben dem Sperma findet sich, wie wir wissen, auch eine Fliıssigkeit im Samenbehälter; die Verschiedenbeit in den Quantitätsverhältnissen dieser Flüssigkeit werden auf die Vorgänge der Samenentleerung voraussichtlich von Einfluss soin. Wenn sich z. B. diese Flüssigkeit dureh stïrkere Abscheidung oder verminderten $\Lambda$ bfluss in grösserer Menge ansammelt, dann wird dic Samentasche bis zu einem bestimmten Grade sich ausdehnen müssen. Der elastisehe Trachcenüberzug wird dabei mehr oder minder gespannt, und diese Spannung wird den Muskeldruck im Augenblicke der Contraction natürlich verstärken. Denken

*) Ich muss übrigons gestehon, dass mir solcho Fulle von intercurrirender Drohnenbrïtigkoit bis jetzt noch nicht anders bekannt geworden sind, als durch dio Beobachtungen von Bartels (Bienenzeitung 1856, S. 203), dic dieser freilich in ganz anderer Weise zu deuten sucht. 
wir uns gleichzeitig den Verschluss des Samenganges aufgehoben, so wird eine verhältnissmüssig ganz krïftigo Strömung entstehen, dic möglicher Weiso auch solche Samenfïden mit sich fortreisst, welcho sonst violleicht noch lïngere Zeit im Receptaculum verweilt haben wïrden.

Dass die anatomische Bildung der Samentasche und des Samenganges allen diesen Voraussetzungen entspricht, wird bei ciner spaiteren Gelegenheit nachgewiesen werden; cinstwcilon will ich hicr nur noch bemerken, dass ich in dem zuletzt beschriebenen Fallo von Drohncubritigkeit ohne vollständigen Samenmangel an der Anhangsdrüse cine Beobachtung machte, die es möglich erscheinen liisst, dass jene Abnormitat hier in der That durch eine ungenilgende Thïtigkeit dieser Gebilde bedingt wurde. Die Drïsenzellen derselben waren nümlich sehr wenig stark cntwickelt und fast verschrumpft zu nennen, so dass das eigenthümliche Chitinskelet, die Tunica intima mit den davon ausgehenden zarten Röhren, die das Secret der Zellen aufnehmen *), auf das deutlichste durch die Drüsenschläuche hindurchschimmerte, während diese Bildungen sonst erst durch Druck und Zerstörung des eigentlichen Drüsenparenchymes zum Vorschein kommen. Für mich hat diese Beobachtung einen un so grösseren Werth, als sio ganz in derselben Weise auch in dem folgenden, dem anatomischen Befunde mach sehr ihnlichen, Fallo gemacht wurde. Jedoch muss ich bemerken, dass ich mitunter auch in ganz normalen Königinnen dassello geschen habo, freilich unter Verhältnissen, wo die Samentasche mit Sperma vollstïndig gefüllt war, wo also auch vielleicht die Nachtheilo einer ungenügenden secretorischen Thaitigkeit der Anhangsdrüsen weniger hervortreten konnten.

\section{Sechster Fall.}

Der eben erwähnte dritte Fall von secundärer Drolnnenbritigkeit kam fast gleichzcitig mit dem vorhergehenden und ebenfalls durch dio unermüdliche Theilnahmo meines hochverchrten Bienenfreundes

*) Der feine Bau der Anlrangsdriisen ist bei der Bienenlsünigin derselbe, wie or von H. Mockol zucrst boi andern Drüsen der Insekten nachgewiesen wurde. Vergl, Muller's Archiv, 1846, S. 25. 
v. Berlepsch zur Untersuchung. Die Geschichte dieser Königin ist höchst interessant und eigenthümlich; sio wird durch $\nabla . B \mathrm{crlepsch}$ folgender Massen dargestellt. „Im September 1855 liess ich mchrere Königinnen erbrüten, um dieselben unbefruchtet einzuwintern. Es zeigten sich jedoch die meisten gegen Ende September als eicrlegend, was sich durch Anwesenheit einzelner auf meinem Stocke noch übrig gebliebenen Drohnen und die für die Befruchtung der Drohnen nusserordentlich günstige Witterung zur Genüge erklärte. Nur drei legten nicht. Aber auch diese drei hatten im nächsten Mürz die Waben mit Brut besetzt, und zwar zwei mit ausschlicsslich weiblicher, die dritte aber mit weiblicher und männlicher, die beide untermischt standen. Die männliche Brut war dic iiltere, so dass vielleicht die ersten 40-50 Eier, die unsere Künigin legte, ausschliesslich Drohneneier waren. Später prïvalirte die weibliche Brut, und während der ganzen ersten IÏilfte des April wurden Eier gelegt, von denen auf jo zehn etwa ein mïnnliches kam. Diese Erscheinung war mir nen, denn bisher war mir noch keine Königin vorgekommen, die Anfungs nur Mïnnchen, dann aber in immer steigendem Verhältniss Weibchen erzeugte. Wo mir früher eine Königin männliche Eier zwisehen weibliche in Arbeiterzellen legte, da mehrte sich stets die männliche Brut, bis endlich gar keine wcibliche mehr erschien. Mier war gerade der umgekchrte Fall. Plötzlich aber begann die Königin wieder die münnlicho Kierlage und heute (den 14. Mai) fand ich auf zwei Tafeln etwa 800 Zeilen bedeckelte und 1200 Zellen unbedeckelte Buckelbrut, aber nux noch wenige Eier, vielleicht kaum 70-80. Die Künigin ist jetzt also vollstïndig drohncubrütig, d. h. sic erzeugt nur Mïnnchen. Wie mag dio Samentaselıe beschaffen sein? Fehlt sie jetzt ganz?*) Ist

*) Gerichtsarzt Dr. Barth, der Mitherausgeber der Eichstadter Bienenzeitung, vermisste in zwei, von ihm untersuchten Drohnenköniginnen dic Samenbllschen (Bienenzeitung 1852, S. 204 und 1853, S. 97), obwobl dio eino derselben bestimmt, dio andero gleichfalls wahrscheinlich früher weibliche Eier gelegt hatto. Nach unsern heutigen Kenntnissen erscheint dieser Befund sehr zweifellaft. Es ist überdies im höclısten Grado unwahrseheinlich, dass ein Gebilde, wie die Samentasche, spurlos verloren gehen sollte. 
sie spermaleer? Sind die Spermatozoen todt? Alle drei Fälle würden für die Dzierzon'sche 'Theorie sprechen. Wic aber wenn die Samenfäden beweglich wären? Dann - doch dieser Fall wird nicht obwalten." Und dennoch waltete or ob, olne dass dadurch die Dzicrzon'sche Theorie gestürzt würde. Aussehen und Füllung der Samentasche war genau wie im vorhergehenden Fall: es fand sich in derselben ein Ilaufen beweglicher Samenfiden, rings umgeben von der uns bekannten indifferenten Flüssigkeit.

Es würde eine unnöthigo Wiederholung sein, wenn ich den hier vorliegenden Fall von Drohnenbrütigkeit einer nochmaligen Analyse unterzöge. Was für die vorhergehende Königin bemerkt worden, gilt in derselben Weise auch für die jetzige. Nur zwei Punkte sind es, dic hicr noch besonders zu beachten sein dürften, cinmal der frühzeitige Eintritt eines Samenmangels*), der sich schon wenige Wochen nach Beginn der Eierlage bemerkbar machte, und sodann die temporäre Drohnenbrütigkeit, mit der unsere Königin ihre Eierlage cröffuete.

Was den ersten Punkt betrifft, so ist bei der Kürze der Legezeit kaum anzunchmen, dass der beobachtete Samenmangel, wic in den vorhergehenden Fällen, durch Verbrauch des vorher vorhandenen Sperma herbeigeführt wurde. Viel näher liegt die Annahme, dass der Grund desselben in einer unvollstiindigen Zufuhr von Sperma beruhe. Es hat also entweder dic Drohne, mit der sich unsere Königin begattete, nux eine geringe Menge von Sperma zur Disposition gehabt, oder es ist die der Begattung erst nachfolgende Uebertragung des Sperma in die Samentasche eine unvollstïndige gewesen. Ich gestehe, dass ich mich am meisten der letztern Annahme zuncige.

Wenn die Drohne eben erst ihre Verwandlung bestanden hat, dann findet man die IIoden derselben (Vgl. meine Darstellung in der Bienenzeitung 1855. S. 2)1) noch stark turgescirend und zum Theil noch mit unvollständig ausgebildeten Samenfiden gefüllt. Nachdem die Bildung dieser wichtigen Elemento beendet ist, sind die Iloden-

*) Aehnliche Fulle sind von Liebe beobachtet, Bienenzoitung 1857, \$. 83. 
röhren leer und zusammengeschrumpft. Der reife Samen ist dann Aufungs in den beiden Samenleitern und zwar den unten erweiterten Enden derselben zu finden. Bei noch ältern Drohnen trifft man die Samenmasse in dem unpaaren Leitungsapparate und zwar demjfnigen Theile, der durch seine zwiebelförmige Bildung und dic hier eingelagerten IIornschüppehen ausgezeichnet ist (Penis, nach Ratzeburg). An dieser Stelle ist die Samenmasse von dem Secrete der beiden beutelförmigen Anhangsdrüsen der Genitalien umhüllt und überlagert: es ist inzwischen die Bildung einer s. g. Spermatophore vor sich gegangen.

Ich vermuthe nun, dass bloss diese ältern mit einer Spermatophore in ihrem Geschlechtsgange versehenen Drohnen begattungsreif sind *), und bei diesen dürften wohl kaum solche Schwankungen in dem Samengehalte vorkommen, wie sie zur Erklärung des vorliegenden Falles angenommen werden müssten. Wenn freilich auch von jungen Drohnen, besonders solehen, die eben erst ihre Zelle verlassen haben, cine Begattung vollzogen würde, dann möchte immerhin auch mitunter eine bedeutend geringere Menge von Sperma in die weiblichen Theile eingeführt werden.

Das Sperma, welches bei der Begattung in die Königin übertragen wird, gelangt nun aber nicht sogleich in die Samentasche, sondern $\Lambda$ nfangs erst in dic Scheide (Fig. 14 und 15). Erst von da **) wird es durch den Samengang in das Receptaculum übertragen. Diese Uebertragung geschicht vorzugsweise dadurch, dass das Secret der münnlichen Anhangsdrüsen, welches mit dem Sperma zusammen die s. g. Spermatophore und besonders denjenigen

*) Dr. Dönh off scheint übrigens anzunehmen (Bienenzvitung 1855, S. 195), dass die Bildung einer solchen Spermatophore nicht bei allen Drohnen vor sich gehe.

**) Die Behauptung von Ebrard (Cpt. rend. 1855, p. 1012), dass dio Befruchtung der Bienenköniginnen auf dieselbo Weise, wio bei den Heuschrecken, d. h. durch eine Uusserlich den Geschlechtsorganen angehlingto spermatophore gescheho, dürfto wohl auf einer durch das sogenannte Begattungszeichon bedingten. Tuuschung berahen. 
Theil derselben bildet, der nach geschehener Begattung der weiblichen Geschlechtsöffnung zugekehrt ist, allmälig crhärtet und sich dabei immer melır zusammenzieht. Der Druck, der durch diese Zusammenzichung entsteht, und bei der Lage der Spermatophore hauptsiichlich nach vorn wirkt, treilt nun das Sperma gegen den Grund der Scheide und die hier befindliche Oeffinung des Samengangs. Freilich könnte das Sperma auf diesem Wege auch leicht in den unpaaren Eiergang getrieben werden, allein unsere Bienenkönigin besitzt dicht hinter der Einmündung des letzteren und zwar an der Bauchfläche der Schcide, der Einmündungsstelle des Samengangs gegenüber, cinen ganz ansehnlichen wulstigen Vorsprung (Fig. 14\%), der sich vor dem Andrange des Sperma aller Wahrscheinlichkeit nach in den Eicrgang einkeilt und dann die Communication desselben mit der Sehcide eine Zeitlang unterbricht.*)

Die Uebertragung des Sperma in das Receptaculum wird übrigens nur dann eine vollstïndige scin können, wenn dasselbe an keiner anderen Stelle dem Drucke der zusammenschrumpfenden Spermatophore ausweichen kann, oder wenn die Scheide, mit andern Worten, völlig ausgefüllt ist. Diese Ausfüllung ist nun in der Regel auch wirklich eine ganz vollstïndige, denn der Raun, den die Spermatophore noch übrig lässt, wird bei der Bienenkönigin bekanntlich (vgl. v. Sicbold in der Biencnzeitung 1854. S. 227) von dem Penis eingenommen, der nach oder vielmehr noch während $*$ ) der Begattung abreisst**a:) und in der Scheido stecken bleibt bis die Königin sich

*) Dieser Wulst, der wahrscheinlich auch bei der Befruchtung der Eicr cine Rollo spiolt, ist bisher überschen, wio denn üborhaupt dic ganze eigenthümlicho Bildung der Scheido bei der Bienenlönigin (Fig. 14 u. 15) früher nur sehr unvollstlindig bekannt war.

**) Unter solchen Umstanden erklirt sich auch dio kurzo Zoitdauer der Begattung bei den Bienen oder vielmehr, da dio Begattung selbst noch niemals beobachtet ist, des erfolgreichen Hochzeitsausfluges, dessen Llinge Vogel auf 10-15 Minuten scbulzt (Bienenzeitung 1857, 8. 229).

***) Dr. Dönhoff vermuthet, vielleicht nicht olne Grund, dass dio Königin den Penis ibres Gatten abbeisse. Biencnzeitung 1856, S. 179. 
nach der Rückkehr von dem IIochzeitsausfluge, vielleicht unter Beihülfe der Arbeiter, desselben entledigt. Geschicht dieses Hervorziehen des Penis nun viclleicht zu frühe, oder ist die Ausfüllung der Vagina sonst eine unvollständige, so wird nach aller Wahrscheinlichkeit statt der ganzen Samenmasse nur ein Theil derselben in das Receptaculum aufgenommen werden können. Und solch ein Fall scheint mir der hier vorliegende zu sein. *)

Aber die unvollständige Füllung der Samentasche ist nicht der einzige Umstand, der uns bei unserer Königin zu einer näheren Berücksichtigung aufforderte. Es war weiter auch noch dio durch von Berlepsch in dem Begleitschreiben besonders betonte Thatsache, dass die ersten Eier unserer Künigin ausschliesslich Drohneneier gewesen sind, dass diese Königinilıre Eierlagealso mit einer temporïreu Drohnenbrütigkeit eröffnetc. Scither ist diese Erscheinung cbensowohl von v. Berlepseh (Bienenzeitung 18:5). S. $205 \Lambda \mathrm{mm}$.), wie von Dzierzon (Ebendas. 1858. S. 44) auch bei sonst ganz normalen Königinnen öfters beobachtet; sio dürfte demnach eben nicht sehr'selten sein.

Ich glaube, dass die physiologische Erklïrung dieser Thatsachen nicht allzuschwer zu finden ist. Wir müssen zunüchst bedenken, dass die Samentasche der Königin vor der Begattung nicht etwa leer und zusammengefallen ist, wic bei andern jungfriulichen Insekten, sondern cine Flüssigkeit enthält, in die das Sperma durch den Samengang eindringt. Dieses Eindringen geschieht, wie wir oben sahen, unter einem continuirlichen Drucke und mit einer gewissen Kraft; die unmittelbare Folge davon ist die, dass sich die Samenfiden vorzugsweise in dem blinden, der Eintrittsöffnung gegenüberliegenden

*) Wenn die II uber'schen Beobachtungen über Drohnenbrütigkeit in Folge einer Vorzügerung der Begattung (s. oben S. 379) wirklich richtig sind, so können sio gleichfalls nur in einer solchen - viclleicht durch Verilnderungen der Scheide bedingten - Unvollstindigkeit in der Ucbertragung des Samens ihre physiologische Erklurung finden. 
Ende des Receptaculum ansammeln. Ist nun die Samenmasse vollstïndig eingeführt und der Ueberrest der Spermatophore mit sammt dem Penis aus der Scheide entfernt, so wird begreiflicher Weise zunächst eine Zusammenziehung der durch das eingetriebene Sperma übermässig ausgedchnten (elastischen) Samentasche stattfinden. Beschriankt sich diese Contraction nur auf die Spannkraft der Samentasche, so wird genau so viel Flüssigkeit aus derselben ausgetrieben, wie an Sperma früher eingefuhrt wurde. Diese ausgetriebene Flüssigkeit fliesst zunächst aus dem untern, mit dem Samengang communicirenden Raum ab; sie ist also kein Sperma, sondern ein grösserer oder geringerer Theil dea schon früher vorhandenen indifferenten Fluidums. Von der Mongo dieser ausgetriebenen Flïssigkeit, oder, was nach der vorhergehenden Bemerkung genau dasselbe sagt, von der Menge des vorher eingeführten Sperma wird es nun ablïngen, ob die Samenfäden jetzt dem Samengange so weit angenähert sind, dass die zum Zwecke der Eibefruchtung stattfindende active Zusammenzieluung der Samenblase eine $\Lambda$ nzahl derselben austreibt, oder nicht. Im andern Falle wird statt der Samenfiden cine kürnerlose helle Masse entleert, die natürlich zur Befruchtung unfiahig ist; die Eicr bleiben unbefruchtet und entwickeln sich dann zu Drohnen. Das dauert so lange, bis die Vertheilung der Samenfiden eine gleichmässigere geworden oder bis die immer fortdauernde Absonderung jener hellen Flüssigkeit die Samenfüden aus dem Grunde des Receptaculum dem Sanengange genugsam angenähert hat.

Wo cine selhr reichliche Menge von Sperma bei der Begattung aufgenommen wird, da werden dieso Erscheinungen der Drohnenbrütigkeit natürlich kaum jemals hervortreten, wälrend sie im andern Falle sehr gewöhnlich sein möchten. Dzierzon giebt an, dass or dieselben besonders häufig bei italienischen Müttern beobachtet habe; sollte man daraus vielleicht abnehmen dürfen, dass die italienischen Drohnen durchschnittlich eine geringere Menge von Sperma produciren? Vielleicht dass man durch Beobachtung von deutschen Bastardmüttern (die von italienischen Drohnen befruchtet sind) diese Vermuthung controlliren könnte. 
Die Erklïrung, die ich im Voranstehenden versucht habe, stützt sich auf zahlreiche anatomische Untersuchungen und cine möglicht unbefangene Erwägung der bei der Begattung und Befruchtung der Bienen in Betracht kommenden Factoren und Umstände. Sie knüpft zunächst an dic Anscliauungen an, dic sich mir im Laufe der Zeit über den Mlechanismus dieser Vorgänge allmälig gebildet haben. Dzierzon vermuthet den Grund dieser Frscheinung in einem ganz anderen Verhültnissc. Er verweist zur Erklärung derselben auf Beobachtungen Küchenmeister's, nach denen (Bienenzeitung 18.5. S. 14) die Samenfüden der Bienen nach der Ueberfihrung in das Receptaculum eine Formverïnderung erlitten, und glaubt, dass diese Veräuderung nothwendig sei, um die Samenfäden befruchtungsfühig zu machen. Die Bienenkönigin ist seiner Ansicht nach so lange drohnenbrütig, bis jene Formveränderung vollendet ist. Die Richtigkeit der Küchenmeister'chen Angabe vorausgesetzt, würde sich vielleicht nur wenig gegen eine derartige Deduction einwenden lassen.*) Allein diese Voraussetzung ist nichts weniger als crwiesen. Die einfache Angabe, dass die Samenfiden der Bienen im Receptaculum einen "vollkommen entwickelten, fast schaufel- oder spatenartigen Kopf" besïssen, der ihnen früher fehle, kann da wohl kaum grenügen, wo es sich um eine Thatsache handelt, die nicht bloss an sich neu ist, sondern auch mit allen unseren bisherigen Erfahrungen über die Samenfiden der Insekten im Widerspruch steht. Nit Recht darf man unter solchen Verhältnissen eine genaucre Beweisführung verlangen. Ich habe manch liebes Mal die Samenfiden der Drohnen und Bienenkönigin unter dem Mikroskope gehabt, aber niemals an denselben eine Verschiedenheit bemerkt und suche auch jetzt,

*) Was man in diescr Bezichung vielleicht geltend machen könnte, wïre etwa die Behauptung von $\vee$ Berlepsch, dass ganz dieselbo temporitro Drohnonbrütigkeit mitunter auch bei altern Müttern vorkommt, wenn dieso im Frühlinge ihro Eierlage wieder aufnehmen. Offenbar ist es in diesem Falle nur die übermissige Ansammlung des in die Samenblase abgeschiedenen Secretes, durch welche die Befruchtung gehindert wird. 
nachdem ich inzwischen die Küchenmeister'sche Angabe kennen gelernt habe, vergebens nach dem fraglichen Kopfe. Dio Samenfüden erscheinen mir beständig nur als cinfache und schwach spiralig gowundene, sehr lange Füden, deren eines Ende etwas dünner ausläuft als das andere. Unter solchen Umstanden trage ich kein Bedenken, die Richtigkeit der Küchenmeister'schen Angabe in Abrede zu stellen. Wer das Verhalten der haarförmigen Samenfiden gegen Wasser u. a. Reagentien nicht kennt, kann leicht durch die merkwürdigen (ron v. Siebold zuerst in gründlicher Weise, Müller's Arch. 1836. S. 30, erörterten) Erscheinungen der Oesenbildung in die Irre geführt werden und wirklich vermuthe ich hier den Grund des Küchenmeister'schen Irrthums, denn eine solche Oese hat allerdings eine gewisse Achnlichlseit mit einem, „schaufel- oder spatenartigen" Kopfe.

In den bisher betrachteten drei Fällen von secundärer Drohnenbrütigkeit war der Samenmangel im Receptaculum durch dessen mehr oder minder jungfräuliches Aussehen schon bei oberflïchlicher Betrachtung zu erkennen. $\Lambda$ ber so ist es nicht in allen Fällen. I ch habe auch eine Reihe von Beobachtungen über drohnenbrutige Königinnen, bei denen das Aussehen des Receptaculum ein vollkommen oderdoch wenigstens fast vollkommen normales war.

\section{Siebonter Fall.}

Den Uebergang zu dieser Reihe macht eine Bienenkönigin, dic ich der Freundlichkeit des Herrn Pfarrer D e ichert in Grüningen bei Giessen verdanke. Dieselbe wurde mir im Juli 1856 mit der Note übergeben, „dass sic theilweise drohnenbruitig sei und zuletzt das Legen gïnzlich eingestellt habe". Der letztere Umstand dürfte wohl schwerlich durch irgend welche anatomische $\Lambda$ bnormitiiten bedingt gewesen sein, zumal die Ovarien, wenn auch gerade nicht sonderlich entwickelt, doch ganz in gewöhnlicher Weise mit reifen und unreifen Eiern besetzt waren; die „theilweise" Drohnenbrütigkeit" aber wurde mir sogleich plausibel, als ich die Samentasche näher untersucht hatte. 
Die Anwesenheit von Sperma in derselben war nach Entfernung des peripherischen Tracheennetzes allerdings keinen Augenblick zu übersehen, allein die Fürbung des Receptaculum war mehr nilchglasartig, als weiss oder wolkig, wie es bei frisch begatteten Königinnen der Fall ist. Offenbar hatte die Menge des im Innern enthaltenen Samens bereits betrïchtlich abgenommen, obwohl lange noch nicht in dem Grade, wio wir dies in den beiden letzten Fällen zu bemerken hatten.

Die physiologiseho Beurtheilung dieses Falles dürfte genau diesclbe sein, wie früher. Dic Wahrscheinlichkeit ciner Befruchtung war bei der Füllung der Samentasche vielleicht nicht grösser als die Unwahrscheinlichkeit derselben; es dürfte also unnöthig sein, zur Erklïrung der Drohnenbrïtigkeit hier noch weitere Factoren zu Hülfe zu ziehen.

Achter bis zohnter Fall.

Aber anders in drcien mir zur Untersuchung gekommenen Fällen, in denen die Füllung der Samentasche ganz die normale schien, auch die Samenfiden (zwei Mal - der dritto Fall betraf cin Spiritusexemplar) ganz in gewöhnlicher Weise beweglich waren und überhaupt keinerlei Abnormititen erkennen liessen. Leider fehlen mir für zwei dieser Königinnen alle näheren Nachrichten; dieselben wurden einfach als „Drohnenküniginnen “ übersandt. In Betreff der dritten Königin schreibt Pastor Kleine, dem ich dieselbe verdanke, Folgendes: "Sie crhalten hierbei cine abstindige italienische Königin, deren Auflüsung ich seit etwa drei Wochen entgegenselıe. Dicselbo war im Frühjalr noch frisch und kräftig, beschränkte aber bald ihre Eierlage, legte Drohneneier in gewöhnliche Zellen und setzte schliesslich wohl 15-20 Eier in eine einzige Zelle ab. Diesen Nachmittag (d. 29. Mai 1856) fand ich sie verscheidend auf dem Bodenbrette und da ich sie noch mit cinigen Lebensresten eingepackt habe, so glaube ich, dass sie müglichor Weise noch untersucht werden kann. Ihr Sperma ist wohl schwerlich schon erschüpft, wohl aber vermuthe ich, dass ihro Zeugungsorgano wesentlich degenerirt scin müssen." Diose letzto Vermuthung erwies sich bei der 
Untersuchung als unrichtig; die Geschlechtsorgane der Königin waren eben so normal, wio die F'üllung der Samentasche.*) Die einzige Abnormität, dic ich bei der Königin fand, bestand in einer Unzahl kleiner scharf contourirter Körperelen von ovaler Gestalt, die den Chylusmagen und Mastdarm erfüllten und sogleich als Pilzsporen erkannt wurden. Es waren die Sporen des erst später von mir entdeckten Mucor melittophthorus Hoffm. (Hedwigia 1857. N. 19), der in dem Chylusmagen der Bienen vegetirt und die besonders durch Dönhoff's Experimente (Bienenzcitung 1857 S. 199 und 210) interessant gewordenene Pilzsucht hervorbringt. Ich vermuthete damals einen gewissen Zusammenhang zwischen dem Auftreten dieser Pilzsporen und der fehlerhaften Geschlechtsthätigkeit unserer Königin und balte solche anch heute noch nicht für unwahrscheinlich, obgleich es schwer sein dürfte, denselben im Speciellen nachzuweissen.

So viel ist jedenfalls sicher, dass wir es im vorliegenden Falle nicht mit den gewöhnlichen Erscheinungen einer Drohnenbrütigkeit aus Samenmangel zu thun haben. Eine Zusammenziehung des Receptaculum würde nothwendiger Weise ein Auspressen des Sperma zur Folge gehabt haben. Die Befruchtung unterblieb - es liegt nahe, daraus auch auf ein Unterbleiben der sonst stattfindenden Muskclthiitigkeit, a u f eine Störung der Innervation zu schliessen. Auf derartige Störungen wiesen auch die Unregelmïssigkeiten der Eierlage hin; cine Königin, die den Mechanismus ihres Legeapparates gehörig behcrrscht, wird wohl schwerlich 15-20 Eier in cine cinzelne Zelle legen. Ir̈̈chstens, dass eine solche einmal (zur Zeit der stärksten Eierlage) im Drange des Geschäftes statt des gewöhnlichen einen Eies deren zwei oder drei in derselben Zelle absetzt.

*) Die Künigin kam allerdings (den 31. Mai) todt an, hatto aber trotzdem, wie ich das mehrfach bcobachtet hatte, noch bewegliche Samenfiden. Die Bewegliclikeit der Bienensamenfllden erlischt überhaupt nur seliwer; man beobachtet sie mitunter noch bei Thieren, die einen Tag lang in schwachem Spiritus gelegen haben; 
Eilfter Fall.

In dieser Auffassung wurde ich noch weiter bestärkt, als ich gegen Ende Juli vergangenen Jahres von Dr. Dönhoff in Orsoy eine drohnenbrütige Königin mit folgendem höchst interessanten Schreiben crhiclt: ${ }_{n} \Lambda$ uf die Beobachtung von v. Berlepsch gestützt, dass eine zufüllig am Hinterleibe gequetschte Königin fortan nur Drohneneier legte, habe ich in diesem Sommer Versuche angestellt, um dureh absichtlichen Druck des Ilinterleibes normal fruchtbare Königinuen in Drohnenköniginnen zu verwandeln. Ich drückto $z u$ dem Ende die beiden letzten obern Hinterleibsringe einer Königin mit einer Pincette vou beiden Seiten melirere Male kräftig zusammen, so dass Alles, was zwischen diesen Ringen lag und nicht ausweichen konnte, gequetscht werden musste. Dic Königin legte Eicr, und es entwickelten sich aus ihr nur Drohnen! Ich habe die Königin secirt, durch Unvorsichtigkeit aber die Samenkapsel verloren, so dass ich Nichts von Verletzung fand. Eine zweite Königin, die übrigens erst nach Wiederholung des Quctschversuches drohnenbrütig wurde, sende ich Ihnen. Diesclbe legte nach dem Versuch schr unregelmässig; die Eier blicben ihr theils am Hintern hängen, theils wurden sie in Häufehen von drei und vier in eine Zelle und zwar meist an den Wünden, statt dem Boden festgeklebt. Die Folge davon war, dass sich nur die wenigsten derselben entwickelten, indem die meisten von den Bienen hinausgervorfen wurden. Sic werden bei Besichtigung der Königin sich überzeugen, dass der letzte Hinterleibstring durch den Druck der Pincette scine normale Form verloren hat. Es wäre nun interessant, zu erfahren, ob die Ursache der Drohnenbrütigkeit in einer Verletzung oder bloss in einer durch den Druck verursachten Lähmung besteht."

In Betreff des von Dönhoff angezogenen Falles von v. Berlepsch äusserte sich dieser (Bienenzeitung 1856, S. 78) folgendermassen: „Im Mai 1851 fing ich eine alte fruchtbare Königin aus, um sio Behufs Anfertigung eines gemischten Ablegers einstweilen in cinen Weiselkäfig zu sperren. Als ich das in einen Falz auslaufende Kläppchen zuschicben wollte, quetschte ich die Königin am Fnde 
des Hinterleibes so bedeutend, dass sic den ganzen Ilinterleib, wie eine gestochene Bione zusammenzog und nachschleppen liess. Ich hiclt sie anfinglich für verloren, gab sie jedoch, als sie nach einer Stunde noch lebte und wieder gestreckt und rüstig dasass, ihrem Volke zurück. Sie legte nach wie vor Tausende von Eiern, aber aus allen entwickelten sich von nun an nur Drohnen." Es unterliegt keinem Zweifel, dass dic Fälle von Dönhoff in der That genau mit diesem ältern Falle übereinstimmen.

Ueber die Causalitït der Erscheinung blieb v. Berlepsch, da cine Section nicht vorgenommen wurde, ungewiss. Lr theilte dieselbe dem Präsidenten Busch in Eisenach, dem Verfasser der "Honigbiene” (Gotha 1856), mit und bat um dessen Ansicht, da er damals noch nicht bestimnt wusste, dass die Bienen ein wirkliches Receptaculum scminis besässen. ${ }^{\mathrm{B}} \mathrm{B}$ sch war aber auch rathlos; mein (Bienenwart) Günther hingegen meinte, vielleicht sei das leceptaculum zerdrückt und vernichtet worden. Dies halte ich jedoch für höchst unwahrscheinlich, da cin Zerdrüeken des regelmässig schr festen Receptaculi zwischen den so wcichen, es umgebenden Theilen, ohne der Königin schnell den Tod „u bereiten, nicht wohl möglich sein dürfte. Ich glaube daher, dass nur Organe, die bein Schliessen und Oeffnen der Miundung oder beim Zurüekzichen und Vorbringen des Receptaculi thätig scin mögen, gelähmt, gestreift u. s. w. wurden." v. Siebold, der in seiner „wahren Parthenogenesis" (S. 86) denselben Fall anzicht, ist anderer Ansicht. Fr vermuthet, „dass durch jeno Quetschung des Hinterleibes das mit Samen gefüllte Receptaculum seminis der Königin an seiner Einmündungsstelle von dem Eileiter abgerissen wurde, wodurch die auf diese IVeise verletzte Königin nicht mehr im Stande war, ihre Eier bei dem Legen zu befruchten und also nur unbefruchtete, mithin -znännliche Eicr legen konnte."

Natürlich, dass ich mich mit grosser Spannumg an dio Untersuchung machte. Zuuaichst ergab die Obduction, dass die sechsto obere Hinterleibsschiene links in ihrer ganzen Länge ticf eingedrückt war. Der Druck der Pincette hatto offenbar von links und oben schrïg nach rechts und unten gewirkt, am letaten Orte aber keinen 
Eindruck ঈurückgelassen, vielleicht weil der untere Pincettenschenkel das IInterleibsskelet gerade an der Berührungsstelle der obern und untern Schienen getroffen hatte, an einer Stelle also, die sehr dünn und elastiseh ist. Dieser Eindruck des IIinterleibsskelets war nun aber überhaupt die einzige nachweisbare Verletzung unserer Königin. Ich überzeugte mich mit aller Genauigkeit, dass weder eine Quetschung der Samentasche, noch ein Abreissen des Samenganges *) stattgefunden hatte. Nicht einmal die an den Befruchtungsapparat hinantretenden Nerven waren gerissen. Auch die Muskulatur der Scheide und des Legapparats war in vollstïndiger Integritatt. Ls blieb mir unter solchen Umständen nichts $\Lambda$ nderes übrig, als eine theilweise Lahmung der beiden letzten Hinterleibsganglien anzunehmen, die mit ihren Nerven ausschliesslich die IIinterleibsspitze mit den daselbst vorhandenen Organen (Befruchtungs- und Legapparat, wie Mastdarm) versorgen und überdies durch ihre Lage im fünften $\Lambda$ bdominalringe (Fig. 15) zunïchst der Wirkung des Druckes ausgesetzt waren. Einen Beweis für die Richtigkeit dieser Vermuthung fand ich auch hier in den gleichzeitigen Unregelmïssigkeiten des Legegeschäftes **), die um so bestimmter auf eine Störung in dem Bewe-

*) Dass cino derartige Verletzung Drohnenbrütigkeit zur Folge haben würde, leidet keinen Zweifel. Ich habe diesen Nachweis auch auf experimentellem Wege liefern wollen und bei meiner Anwesenheit in Seebach eine Bienenkönigin mit der Nadel in der angedeuteten Weise zu operiren versucht. Indessen muss die Verletzung doch nicht den Samengang getroffen haben, denn die Königin legte nach einigen Tagen wieder Arbeitereier und setzte dieses Geschaft noch etwa zwei Wochen fort, wornuf sie starb. Eine Section konnte leider nicht gemacht werden.

**) Der Mechanismus der Eierlage ist freilich bis jetzt bei den Bienen noch sehr wenig gekannt, duch likst sich wohl so viel mit Sicherheit behaupten, dass dabei die Bewegungen des Stachelapparates eine grosso Rolle spiclen. Wahrscheinlich, dass das Ei, wenn es in dio Scheide eingetreten ist, von der Concavitut des Stachels, dio der Form des Eies entspricht, aufgenommen und dann durch ein Hervorstrecken desselben (natürlich des ganzen Apparates, nicht 
gungsmechanismus des Geschlechtsapparates zurückzuführen scin dürften, als unsere Königin sich nach der ausdrücklichen Bemerkung Dönhoff's nicht einmal vollständig ihrer Eier entledigen konnte. (Vergl. über diese Königin die Mittheilungen von Dönhoff und mir in der Bienenzeitung 1857, S. 220.)

Die Richtigkeit dieses Lrklïrungsversuches ist von $\mathrm{K} \ddot{\mathrm{ch}} \mathrm{hen-}$ meister (Moleschott's Untersuchungen zur Naturlehre III, S. 266) in Zweifel gezogen. Es wird mir von demselben zum Vorwurfe gemacht, dass ich nicht alle hier in Betracht kommenden Verhältnisse gehörig gewürdigt, und namentlich die Lagerungsverhältnisso der Samenblase keiner Berücksichtigung unterworfen hïtte. Verfasser scinerseits vermuthet, dass hier durch Jen Druck und die Deformitiat des Hinterleibsskelets wahrscheinlich cine Lagenveründerung des Receptaculım stattgefunden habe, die überhaupt, nach seiner Meinung, für die Erklärung der Drohnenbrütigkeit wichtiger sein dürfte, als eino hypothetisch angenommeno Paralyso.

Der Einwurf von $\mathrm{K}$ üchenmeister steht im innigen Zusammenhange mit den Ansichten, dio dieser Forscher von dem Mechanismus der Befruchtung bei den Bienen (und Verwandten) entwickelt hat (a a. O.).

Wir haben bei verschiedenen Gelegenheiten auf eine Contractilitit der Samentaschenwand hingewiesen und dicser für das Zustandekommen der Befruchtung eine grosse Bedeutung beigelegt. Von Küchenmeister wird eine solche Contractilitït geradezu geliiugnet „weil sich in den Wïnden der Samentasche keine Muskeln nachweisen liessen “. Es ist wahr, diese Muskeln sind bisher noch nicht aufgefunden, aber sie sind nichts desto weniger vorhanden. Freilich bedarf es einer gewissen Assiduität und einer sorgfältigen Untersuchung, um sich von ihror Anwesenheit zu überzeugen, nicht bloss weil sie sehr zart und blass sind, sondern namentlich auch des-

bloss der beim Stechen vortrotenden zwei Dolcho) nach Aussen abgesetzt wird. Die Analpalpen, dio nach dem Rücken zu gerichtet sind, dionen wahrschoinlich bloss als Fixationsapparat. 
halb, weil sio sich zwisehen den Tracheen des uns bekannten, peripherischen Luftgefïssnetzes, dem sie aufliegen, leicht verstecken. Ich habe gleichfalls lange Zeit diese Muskeln übersehen und dieselben erst dann mit Sicherheit erkannt, nachdem ich an der Samentasche von Vespa germanica unter dem Mikroskope mehrfach die deutlichsten Contractionen beobachtet hatte. Die Muskeln bilden (vgl. Fig. 17, wo dieselben in Durchschnitt auf der Drüsenschicht des Receptaculum gezeichnet sind) ein ziemlich weitmaschiges Netzwerk, das dic ganze Samenblase unspinnt und (besonders an Spirituspräparaten) hicr und da deutliche Querstreifen erkennen lässt*). Da aus dem benachbarten letzten Ganglion, das (mit dem dicht vorhergehenden vorletzten Ganglion, vgl. Fig. 18, bei Bombus) auf der Rückenflïche des unpaaren Eierganges aufliegt, auch ein paar kleine Nervenstämmchen an die Samenblase hinantreten, so zweifle ich nicht, dass die Zusammenziehung dieses Muskelüberzuges, die ein Zusammenpressen der eingeschlosscnen Sancnmasse zur Folge hat, unter dem directen Einflusse des betreffenden Ganglions steht. Dasselbe Ganglion giebt noch drei andere grössere Nervenpaare $a b$, ein obcres für die Muskeln der Scheide, ein mittleres für die Muskeln der Stachel- und Legeapparate und ein unteres für den Mastdarm, so wie für die Anhangsdrüse und den Samengang**:*). Denken wir uns also eine Lähmung des betreffenden Ganglions, so worden mit der Samenblase auch zugleich die Legapparate darunter lèiden müssen.

Wie dio Samentasche, so besitzt aber auch der Samengang einen besonderen bisher übersehenen MLuskel, und dieser dürfto für die Vor-

*) Dass solche Muskeln übrigens bei allen Insekten an der Samentascho vorkommen, scheint mir sehr zweifelhaft. Bei Coccus z. B. habe ich dieselben vermisst. Wahrscheinlich, dass in solchen Fullen das Secret der die Chitinhaut iiberall umgebenden Di ïsenzellen von besonderer Bedeutung ist.

**) Die von Kiichenmeister beschriebenen Levatores und Retractores, dio sich an das obero Ende des Samenganges ansetzen sollen, sind bestimmt mit dicsen Norvon, deren Ursprung und Verbreitung ich genau verfolgt habe, identisch. Wirkliche Mulskoln der ron Küchonmoister beschriobenen Art existiren nicht. 
giinge der Befruchtung nicht minder wichtig sein. Derselbe bildet (Fig. 18) eine ziemlich dichte und dicke Schicht von (besonders wicderum bei Spirituspräparaten) deutlich quergestreiften Ringmuskelfasern, die an der Insertionsstelle der Anhangsdrüse beginnen und bei der Biene fast bis in die Mitte des Samenganges (bei den Wespen noch weiter, weniger weit bei Bombus) sich verfolgen lassen. Die Function dieses Muskels kann begreiflicher Weise, je nach den Umständen, eine doppelte sein. Einmal kann derselbe dazu dienen, die Samenfïden, die durch die Zusammenzichungen des Receptrculum bis in den Anfangstheil des Samenganges gelangt sind, vollends in die Scheide hincinzutreiben. Ist aber die Contraction dieses Muskels nur cinigermassen krüftig, so wird die innere Chitinröhre des Samenganges, die sich in die Chitinbekleidung des Receptaculum fortsetzt, dadurch zusammengedrückt; der betreffende Muskel kann also zweitens auch dazu dienen, die Communication der Samentasche mit der Scheide je nach der Dauer seiner Contraction cine längere oder kurzere Zeit hindurch zu unterbrechen.

Die hier beschricbene Muskelcinrichtung erklärt es nach meiner Meinung zur Genüge, nicht bloss, wie überhaupt eine Befruchtung geschieht*), sondern auch weiter, wie es möglich ist, dass die Bienenkönigin, selbst bei normaler Füllung des Receptaculum, ihre Eier eventuell (Drohneneier) unbefruchtet lïsst.

Der voranstehende Excurs sollte nicht bloss dazu dienen, meine gelegentlichen Bemerkungen über den Mechanismus der Befruchtung bei don Bienen mit anatomischen Gründen zu rechtfortigen und im

*) Ich habe oben gelegentlich darauf aufmerksam gemacht, dass der an der Einmündungsstello des unpaaren Eileiters klappenförmig in die Scheido vorspringende Wulst bei der Befruchtung der Eier nicht ohno Werth sein möchte. Ein Blick auf die beigegebene Abbildung (Fig. 14) genügt, um zu zeigen, dass durch denselben das herabsteigende Ei mit seinem oberon (Micropyl-) Endo genau an die Oeffnung des Samenganges angedringt werden muss. Bei andern Insekten scheint diese Bildung zu fehlen; sie dürfte vielleicht nur da wioderkehren, wo, wie bei unserer Bienenkünigin, ein unnöthiger Samenverbeauch möglichst zu vermeiden war. 
Voraus gegen etwaige Einwürfe zu sichern, sondern ist namentlich auch dazu bestimmt, den Angaben Küchenmeister's einen Theil ihrer scheinbaren Berechtigung zu nelmen. Wo die Summe des Bekannten zur Erklärung einer Thatsache ausrcicht, da haben wir nicht nöthig, noch weitere Hypothesen aufzusuchen. Und mehr als Hypothesen sind es nicht, die uns $\mathrm{K} \ddot{\mathrm{c}} \mathrm{chenmeister}$ bietet, wenn er behauptet, dass es von der Lage der Samentasche und der Stellung des Samenganges gegen die Scheide abhünge, ob ein Ei beim IIerabgleiten durch die Scheide befruchtet werde oder nicht. Nach Küch en meister wird der Samen, der ein Ei befruchtet, nicht ausgepresst, sondern mach dem Gesetze des Falles in die Scheide ergossen; er fliesst gelegentlich ab - wie das Wasser aus einer Flasche, dic wir umstürzen.

Küchenmeister geht bei seiner Hypothese von der Annahme aus, dass die Samentasche der Königin nach binten von der Einmündungsstelle des Samenganges gelegen sei und dass dieser mit der Scheide einen spitzen Winkel bilde. In dieser Stellung, so wird nun weiter geschlossen, kann der Samen nicht ausfliessen. Sobald aber die Bienenkönigin ihr Abdomen in cine enge Arbeiterzelle hineinschiebt, wird auf die Samentasche cin Druck ausgeiibt, der dieselbe nach dem Kopfe zu emporhebt und dem Samengange eine mohr senkrechte Lage giebt. Der Samen fliesst ans, das Ei wird befruchtet. Aber so ist es nur, wenn die Königin ihr Ei in cine enge Arbeiterzelle ablegt; bei dem Besetzen einer weiten Drohnenzelle tritt dieser Druck nicht ein; die Samenblase behält ihre Lage, das Ei wird nicht befruchtet.

Ich will die zahlreichen Einwände, die sieh gegen diese Annahme machen lassen, hier nicht alle aufzählen*), es würde uns solches viel

*) Wie ist es z, B. mit Kü chenmeister's Hypothese in denjenigen Fullen, wo man ( $G$ undelach, Nachtrag zur Naturgeschichte der Honigbienen, S. 22) durch Hinwegnahme der Waben mit Arbeiterzellen, die Künigin schliesslich zwingt, befruchtete Eier in Drohnenzellen abzulegen? Küchenmeister sicht hier die Unzulunghtchkeit seiner IIypothese sclbst ein - er muss für 
zu woit abfübren. Aber das muss ich orwähnen, dass die Drohnenbrütigkeit bestimmt eine unendlich viel häufigere Erscheinung sein wilde, wenn Küchenmeister mit seiner Hypothese Recht hätte, denn Königinnen mit einem Abdomen, das ohne Zwang und Druck sich in cine Arbeiterzello einschicben lïsst, giebt es die IIülle und Füllc. Ausserdem ist die Lago des Samenbehälters sehr geschützt, (vgl. Fig. 15); derselbe wird an der Bauchfläche durch die Scheide, an der Rückenfläche*) durch den Mastdarm und auch zum Theil durch die Giftblase von den Chitindecken der Körper abgetrennt, so dass cin Druck, der sich bis zu ihr fortpflanzen sollte, bereits eine bedeutende Stärke besitzen müsste.

Doch wie gesagt, ich will diese theoretischen Einwände nicht weiter ausführen. Die Hypothese Küchenın e ister's fillt vor der T'hatsache, dass die Ruhelage der Samentasche überhaupt eine ganz andere ist, als behauptet wird $\left.{ }^{* *}\right)$. Freilich beruft sich unser Forscher bei seiner $\Lambda$ ngabo auf die Autorität Swammerdam's und dessen bekannto Darstellung in der Bibel der Natur (Tafel XIX). IIätte derselbe jedoch Gelegenheit gehabt, seine anatomischen Untersuchungen über eine grösserc Anzahl

diese Fulle eine Ueberfüllung der Samentasche (mit dem Secret der Anhanggdrüsen) und ein dadurch bedingtes Ueberfliesson zu IIülfo nehmen.

*) v. Siebold verlegt die Samenblase bei den? woiblichen Hymenopteren irriger Weise an dio untere Flicho der Scheide (Gormar's Archiv 1843, \$. 366), whhrend es überall bei den Insokten die obere oder dorsalo Flilche ist, dio dieselbe triggt.

**) Ich spreche hier zunßchst nur von der Bicnenkönigin und weiss schr wohl, dass die Verhaltnisso bei den Hummeln, Wespen (und sogar den Arveiterbienen) anders sind und mit Küchonmesstor's Voraussotzungen scheinbar melir übcroinstimmen. Allein auch für dieso halto ich die Annahmo einer Lagenveränderung bei einem tusseren Drucko für unzultssig, schon deshalb, weil hier die Befestigung der Samentasche viel vollstilndiger ist, wio bei den Bienenköniginnen, und (z. B. bei den Hummeln, Fig. 18) in einer Weise stattfindet, dass eine Erhobung des Samenganges geradezu unmöglich wird. Auch die Bildung des Samenganges ist oftmals (vergl. Fig. 17 von Vespa germanica) so complicirt, dass eine Verilnderung der Stellung allein noch keineswogs zum Austliessen des Samens gonügen würde. 
von Bienenköniginnen auszudehnen, so würde er wissen, dass die sonst so trefflicho Abbildung des berühmten Zootomen für die hintere Partie des Leitungsapparates ganz unzureichend ist. Swammerdam wusste nicht einmal, dass die Bienenkönigin eine eigene, von dem engeren Tiergange verschiedene und sogar sehr eigenthümlich gestaltete Scheide besitzt. Doch soll das natürlich kein Vorwurf sein - auch die späteren Beobachter (v. Siebold eingeschlossen) haben dieses Gebilde, das sich wegen der damit in Verbindung stehenden, zum Theil sehr complicirten Muskeln schwer präpariren lïsst, nur sehr unvollständig gekannt*).

Statt einer weitläufigen Auseinandersetzung dieser Verhältnisse verweise ich hier auf die beigegebenen $\Lambda$ bbildungen (Fig. 14 und 15), die die Lage der Samentasclie und die Stellung des Samengangs gegen die Scheide in naturgetreuer Weise wiedergeben. Ich will dabei nur erwähnen, dass die betreffenden Organe durch keinerlei von aussen herantretende Muskeln, sondern nur durch Tracheen und Nerven befestigt und in ihrer Lage erhalten werden, dass ferner der Spielraum ilurer Bewegungen bei der Verpackung zwischen den oben genannten Organen und der Anwesenheit des Fettkörpers in den Zwischenräumen kaum irgend bedeutend genug ist, um unter normalen Verhältnissen wesentliche Verseliedenheiten herbeizuführen. Wäre Küchenmeister's Hypothese in Wirklichkeit begründet, so müssten die Bienenköniginnen an beständiger Spermatorrhöe leiden.

Küchonmoister hat sich zu sciner Hypothese offenbar durch den Widerwillen verleiten lassen, den er gegen v. Siebold's u. A. Behauptung von der Willkür der männlichen oder weiblichen Eierlage empfand **). Ich muss gestehen, dass ich die Ansicht gleichfalls

*) Für eine vollstindigo und genauo Beschreibung dieses Apparates verweise ich auf die demnalchst von mir erscheinende nAnatomio und Physiologio dor Geschlechtsorgano bei den Bionen und übrigen gesellig lebenden Hymenopteren.

**) Schon vor Kü ch en m 0 i s tor hat Prilsident Is u s ch (Bienenzeitung 1857, S. 166) den Versuch gemacht, die mulnuliche und weibliche Eierlage durch dio Verschiedenheiten der münnlichen und weiblichen Zellen als nothwendig zu or- 
nicht theile, als wisse die Königin, wann und ob sie ihre Eier zu befruchten habo oder nicht. Die Thatsache, dass die Drohnenzellen mit unbefruchteten Eiern, die kibrigen Zellen des Bienenstockes aber mit befruchteten besetzt werden, erscheint mir vielmehr als ein specieller Fall jener wunderbaren Harmonie zwischen Leistung und Umständen, die, wenn auch in verschiedenen, bald mehr, bald minder auffallenden Zügen das Leben eines jeden Geschöpfes durchzicht. Diese harmonische Verknüpfung geschieht nicht zufüllig, sondern ïberall nach bestimmten pliysiologischen Gesetzen; sie geschieht nicht freiwillig, nach vorausgegangener Erkenntniss der Sachlage, sondern nothwendig, sobald gewisse Verhältnisse obwalten. Damit ist aber noch nicht gesagt, dass diese Nothwendigkeit in allen Fällen eine :iussere sei - sie kann eben so gut auch in der innern Einrichtung der thierischen Maschine ihre Begründung finden. Dass die Bienenkönigin ihre Eier bald befruchtet, bald auch nicht, dass sie mit andern Worten die Muskeln ihres Befruchtungsapparates bald in dieser, bald in jener Weise zusammenzieht, scheint mir nichts als eine sogenannte Reflexthätigkeit zu sein, die je nach den üussern Verhältnissen, hier also je nach dem Eindrucke, den die mit Eiern zu besetzenden Zellen auf die Gefühlsnerven erregen, in verschiedener Weise durch die motorischen Nerven vermittelt wird, ohne dass das betreffende Individuum der äussern Sachlage sich bewusst wird und ihre Thätigkeiten willkürlich beherrscht. -

Die bisher betrachteten Fälle von Drohnenbrütigkeit bei Bienenköniginnen möchten wohl in ziemlich erschöpfender Weise einen Ueberblick über die gewöhnlichen F'ormen dieser eben so sonderbaren, wie

kliben. Busch ging dabei von der Thatsacho aus, dass die mänulichen Zullen betritchtlich linger seien, als die weiblichen, und vermuthete, dass der Samengang durch die zum Besetzen einer solchen langen Zelle nothwondigo Streckung des Hinterleibes verschlossen werde. Durch v. Berlepsch erfahren wir jedoch (ebendas.), dass die milnnlichen Zellen nicht selten schon im halbfertigen Zustande mit Eiern besetat werden, also unter Unstlinden, welche die Yoraussetzung von Buseh als unzureichend erwoisen. 
interessanten Erscheinung bieten. Man könnte denselben vielleicht nur noch jene Fille hinzufügen, die durch ein etwaiges $A$ bsterben der im Innern des Receptaculum vorlandenen Samenfüden bedingt werden. $\mathrm{Ob}$ solche Fälle auch im Naturzustande existiren, muss ich dahin gestellt sein lassen, dass sie aber möglich sind und unter Beihülfo des Experimentators wirklich vorkommen, darüber können wir nach dem oben erwilhnten Versuche v. Berlepsch's (S. 29) nicht länger zweifoln *). In dieser Hinsicht sind mir auch cin Paar Beobachtungen interessant, die ich im Laufe des vergangenen Winters an Ameisen gemacht liabe. Unter acht und zwanzig A meisenköniginnen (Formica rufa), die ich aus zwei starken Nestern hervorsuchte **), fand ich nämlich drei Exemplare, deren Samenfaden alogestorben und in schwarze Stränge 'rerwandelt waren. Welche Ursache dieser lirscheinung zu Grunde lag, weiss ich nicht; ich muss es auch unentschieden lassen, ob dic von den betreffenden Thieren etwa abgelegten Eier sich entwickelt haben würden, obwohl solches mir um so wahrscheinlicher ist, als die Eierstöcke derselben ganz das Ausselsen der normal befruchteten Küniginnen besassen und mit unzähligen Eikeimen besetzt waren.

Wenn es erlaubt ist, die Verhältnisse der Bienenkönigin auf die Ameisen zu übertragen, dann war das Eirgebniss der hier erwähnten Untersuchungen auch noch in anderer Weise interessant. Ich will nicht hervorlheben, dass die Samenmenge im Receptaculum der einzelnen Ameisenköniginnen selır auffallende. Schwankungen zeigte da mit dem bei den Bienenköniginnen am Receptaculum vorkommenden elastischen Tracheenüberzuge müglicher Weise auch zugleich der

*) Dio Angabo Dönhoff's, dass die Samenfiden der dem Froste ausgesetzten Königin nicht bloss bowegungslos wïrden, sondern sich auch auflösen sollten (Bienenzeitung 1856, S. 15), dürfte wohl noch der weitern Bestitigung bedürfon.

**) Wenn de Geer angiebt, dass Winters in den Nestern von Formica rufa ko in $\theta$ Königinnen angetroffon würden (a. a. O. Th. II, S. 305), so ist das ein Irrthum. 
Grund einer unvollständigen Ausprossung des Spermas hinweggefallen sein könnte - aber auffallend war es mir, dass ich in beiden Stöcken auch einzelne Königinnen mit ganz leerem Samenbeutel antraf *). Schon im vorhergehenden Herbste hatte ich in zwei Nestern derselben Ameise die gleiche Beobachtung gemacht, obwoll der Flug schon längst beendigt war und die betreffenden Königinnen auch bereits ihre Flügel verloren hatten. Das eino Mal wurden damals zwei, das andere Mal nur eine solche unbefruchtete Königin aufgefunden, und zwar mit Geschlechtsdrüsen, deren Röhren den gleichen Entwickelungsgrad zeigten, wie or im Winter von mir bei allen Königinnen beobachtet wurde.

Nach diesen Erfahrungen scheint es mir fast, als wenn die Existenz von unbefruchteten oder doch wenigstens samenleeren Weibchen in den Ameisenstöcken mit zahlreichen Königinnen eine sehr gewöhnliche Erscleinung sei, eine Erscheinung, dio möglicher Weise anch für den Gesammthaushalt unserer Thiere von Bedeutung ist.

$\mathrm{Ob}$ auch bei den Hummeln und Wespen Erscheinungen rorkommen, die sich der Drohnenbrütigkeit dor Bienenkönigin vorgleichen lassen, weiss ich nicht. Die MIöglichkeit derselben müssen wir zugeben, obgleich die Stöcke dieser Thiere (auch die mancher, in kleineren Colonien lebender Ameisen) nach meinen Beobachtungen stets nur eine einzigo befruchtete Legekönigin besitzen **a). Ich sage, die Möglichkeit ciner Drohnenbrütigkeit müssen wir auch hier zugeben ${ }^{\prime \prime s}$ ), denn die Königin ist ja bekanntlich nicht bloss Gründerin, sondern $\Lambda$ nfangs auch Pflegerin des ganzen Volkes; sie würde also auch neben einem Volk von Männ-

*) Ein Nest mit 21 Küniginnon enthielt 3 mit loerem Samenbeutel, 2 mit abgestorbenen Samenfuden, das zweite mit 7 Königinnen je eine unit dieser $\mathbf{A b}$ normitut.

*) Allerdings finden sich im Uerbst auch noch andere befruchtoto Woibchon im Stock, allein diese beginnen bestłndig erst im nłklısten Frühjahr ihr Eierlegen.

***) Vielleicht liesse sich diese Frage leicht durch kinstliche Einrinterung unbefruchteter Weibchen lösen. 
chen existiren können, zumal diese ja, besonders bei den Hummeln, sich an den Geschaften des innorn Iaushaltes in melrfacher Weise betheiligen.

\section{Lierlegende Arbeiter.}

Wir haben bisher bloss die sogenaunten Königinnen, das heisst die vollstïndig entwickelten Weibchen der Bienen und verwandten Insekten im Auge gehabt. In den Gesellschaften dieser Thiere giebt es nun aber bekanntlich auch noch zahlreiche weibliche Individuen mit melır oder weniger verkümmerten Geschlechtsorganen, die sogewannten Arbeiter*). Auch diese sind uns hier in der Frage nach der Parthenogenesis von hohem Interesse.

Es ist eine den Bienenzüchtern schon seit lange (seit Riem) bekannte Thatsache, dass unter diesen Arbeitern hin und wieder auch eierlegende Individuen vorkommen. Nachdem es Huber gelungen war, durch anatomische Untersuchung solcher Arbeiter die Eier im Innern der Eierstocksröhren nachzuweisen (a. a. O. fünfter Brief), durfte diese T'liatsache als ausgemacht gelten ${ }^{*}$ ), obwohl manche

*) Dio hier und da (auch von bedeutenden Entomologen, wie z. B. Newman) ausgesprochenc Vermuthung, dass die Arbeiter der Hymenopteren, besonders der Ameisen, theilwcise auch mulunlichen Geschlechtes seien, muss ich nach meinen Untersuchungen als völlig unbegründet bezeichnon. Dio Grössenunterschiedo der Arbeiter, die allerdings in ihren Extremen oftmals sehr bedeutend sind, dürfen keineswegs als Geschlechtsunterschiede betrachtet werden. Bei den Termi'en ist das freilich anders; nach den anatomischen Untersuchungen von Lospòs (Aun. des se. nat. 1856, T. V, p. 234 ff, bestehen die Arbeiter, wie auch die den Arbeitern sehr nahe verwandten sogenannten Soldaten, hier nicht bloss aus weiblichen, sondern auch aus männlichen Individuon mit verkümmerten Geschlechtsorganen.

*5) Lón Dufour bezweifelt froilich die Existenz von eiorlegendon Arbeitorbienen; er fand die (10-12) Eiröhren derselben beständig leer und behauptete Bogar, dass der unparo Eiergang olnne Oeffnung nach Aussen sei und sich an der Bauchschieno dos vorletzten Abdominalsegments fixire. Rech, anat, et physiol. in den Mém prés. de l'Inst. T. VII, 1841, p. 497. 
Bienenzüchter noch immer der Ansicht waren, dass die eierlegenden Arbeiter, trotz ihrer scheinbaren Uebereinstimmung mit den gewöhnlichen Arbeitern, eine besondere Individuengruppe in dem Bienenstate repräsentirten („Drolnenmütterchen”).

Ist diese Thatsache nun schon an und für sich interessant, so wird sie es in einem noch höhern Grade dadurch, dass die Eier dieser Arbeiter sich unter allen Umständen, wie die Eicr ciner drohnenbrütigen Königin, zu männlichen Individuen entwickeln. Diese Entwickelungsweise ist so constant, dass bedeutendo Bienenzüchter, wie z. B. Gundelach (Naturgeschichte der Honigbienen S. 56), die Drohnen überhaupt nur als Abkömmlinge solcher eierlegenden Arbeiter betrachten konnten und der Königin nur das Geschäft der weib. lichen Eierlage überwiesen; eine Ansicht, die erst in neuester Zeit, durch die von Dzierzon und v. Berlepseh mit italienischen Müttern (in deutschen Stöcken) angestellten Experimente, ihre gründliche Widerlegung gefunden hat.

Solche eierlegende Arbeitsbienen finden sich vorzugsweise in weisellosen Stöcken, in denen dann nach, wie vor, Eier abgesetzt werden, aber Eier, die blosse Buckelbrut liefern *), meist auch an den Seitenwänden der Zellen, nicht auf dem Boden derselben befestigt sind ***), und überdies gewöhnlich nur unregelmässig und in geringer Menge über die Waben vertheilt werden. Nach Beobachtungen von Gundelach u. A. scheinen diese Drohnenmiitterchen jedoch keinesweg's ausschliesslich auf weisellose Stöcke beschränkt zu sein, sondern gelegentlich auch neben einer normalen Königin vor-

*) Dass Drohnen auch noch in weisellosen Stöcken erbrütet werden künnten, wusste bereits Aris to telos, hist. animal. Lib. V, Cap. 18.

**) Dieser letztere Umstand erklürt sich theils durch die Kürze des Abdomen bei den Arbeitern, theils auch durch dio gerade Form ihres Stachels, der, wio wir oben gesehen, fiir das Legegeschlift sehr wichtig ist. Offenbar but das Abdomen der eierlegenden Bienen in der Zelle koino ganz axillare, sondern vielmehr eine diagonale Stellung, durch die cine Krümmung des Legestachels nothwendig wird, wenn das $\mathrm{Ei}$ auf den Boden gelangen soll. 
zukommen und ihr Legegeschät zu treiben, nur dass es begreiflicher Weise viel schwieriger ist, die Anwesenheit derselben unter solchen Umständen zu constatiren*).

Dass vrir es hier mit einem neuen Falle von Parthenogeneso zu thun haben, ist nach den frühern Auseinandersetzungen über die Drohnenbrutigkeit gewiss von vorn herein schon glaublich und muss noch an Wahrscheinlichkeit gewinnen, wenn wir die Beschaffenheit der Geschlechtswege bei den $\Lambda$ rbeitern in das Auge fassen, die so eng sind, dass eine $\Lambda$ ufnahme der so müchtig entwickelten münnlichen Begattungsorgane kaum möglich erscheint. Schon Dzierzon hat diesen Umstand geltend gemacht, als or die Arbeitereier für unbefruchtete erkliirte und die Drohnenbrütigkeit derselben als einen gewichtigen Grund für die Richtigkeit seiner Hypothese in Anschlag brachte.

Doch solche indirecten Beweise sind begreiflich nicht ausreichend, da sie dem Z weifel immer noch Thor und Thüre geöfnet halten. Es gilt auch hier durch unmittelbare Untersuchung die Jungfräulichkeit der Eierlegerinnen festzustellen.

Schon im Jahro 1855, während meines $\Lambda$ ufenthaltes in Seebach, habe ich zwei solcher eierlegenden Arbeitcrinnen, die Herr v. Berlepsch in flagranti ertappt und in Spiritus aufbewahrt batte, zergliedert, dabei aber nur so viel constatiren künnen, dass dieselben der königlichen Samentasche entbehrten und überhaupt wirkliche Arbeiter waren, also keine Zwischenformen zwischen Arbeitern und Königinnen darstellten, wie man wohl behauptet hatte. Es war mir daher äusserst willkommen, als ich Anfangs September vergangenen Jahres durch IIrn. Dr. Dönh off Gelegenheit zu neuen Untersuchungen fand.

*) Dönhoff gab im Spitherbst einem woisellosen Stocko mit eiorlegenden Arbeitern oino Königin und sah, wio die erstern trotz der Eierlago der Königin zu legen fortfuhron (Bienonzeitung 1857, S. 230). In andern Fullen ( $r o n$ Scholz, ebendas. S. 183) dauerte dio Drobnencierlago der Arbeiter nur so lange, bis die (hier freilich von den Bienen selbst aus einer Arbeiterlarve erbrütete) Königin ihrerseits: die Eierlage begann. 
Derselbo übersendete mir eine ganzo Anzalal von Arbeitern aus zwei weisellosen Stïcken, deren Zellen mit fortwïhrend neuer Drohnenbrut besetzt wurden und auch dann noch besetzt blieben, als diese Stöeke mehrfach gethellt waren. Mit Recht schloss Dönhoff aus diesem Umstande, dass die Zahl der cierlegenden Arbeiter, die man früher auf einen oder höehstens einige wenige beschränkt glaubte, im vorliegenden Falle cine viel beträchtlichere sein müsse. (Vergl. Bienenzeitung 18577; S. 229.)

Ich untersuchte im Ganzen 24 Stück dieser Arbeiter und fand bei mindestens 18 derselben Eiröhren mit deutliehen, mehr oder minder weit entwickelten Eikeimen. Viclleicht die Ḧ̈lfte enthielt auch völlig ausgetragene Eier, meist aber nur cinige wenige, wie denn überhaupt die ganze Beschaffenheit der Eiröhren dafür sprach, dass die Entwickelung dieser Gebilde viel langsamer und spärlicher vor sich gehe, als bei den Königinnen. Die Eier selbst hatten übrigens genau die Grösse und Bildung der gewöhnlichen Eier; sie zeigteu auch genau den Micropylapparat, den ich schon früher (Bienenzeitung 1855, S. 99) an den Eiern der Königinnen beobachtet hatte *).

Die Zahl der Eiröhren schwankte in den Ovarien dieser Bienen, wie in denen der gewöhnlichen Arbeiter, von 2-12, wïhrend eine nor-

*) v. Sicbold kann sich mit meincr Auffassung des Micropylapparates bei den Bieneneiern nicht ganz einverstanden exklitren und hillt namentlich dio von mir beschriebenen, fächerförmig gestellten Micropylkanäle für etwas Auderes, ohne jedoch seine abweichende Meinung nther zu begrïnden (wahro Parthenogenese u. s. w. S. 106). Eine sichere Entscheidung ïber die Natur der von mir als Kanale betrachteten Streifen dürfte vielleicht sehr schwer sein; so viol aber ist ausgemacht, dass jeno Streifen existiren und dass dio Micropylen in mehrfacher Anzahl vorhanden sind. So ist os auch bei den Wespen, Ameisen und Irumeln, bei denen allen ich jetzt eine zum Theil (wio z. B. bei den Hummeln) ausserordentlich zicrliche Micropyleinrichtung gefunden habe. Was ich an den Iornisseneiern beobachtete, macht mich in der That an der Kanalnatur jener oben erwilhnten Stroifen etwas zweifelhaft. Eine speciolle Erörterung dieser Verhliltnisse gehört jedoch nicht hierher; ich bohalte mir dieselbe für eine spätere Gelegenheit vor. 
male Königin deren etwa 150-180 jederseits enthält*). Meistens betrug dieselbe 5 oder 6 , doch finden sich nicht selten an beiden Seiten beträchtliche Unterschiede, mitunter um mehr als das Doppelte. Die Länge der Röhren, die bei den Königinnen während der schärfsten Eierlage bis zu $8 \mathrm{Mm}$. heranwachsen, war hier - nach Entfernung des Poritonealübcrzugs - höchstens nux $4 \mathrm{MIm}$, meist aber geringer, etwa bis $3 \mathrm{Mm}$., je nach der Zabl und Entwickelung der im Innern entlhaltenen Eikcime. Mitunter waren es nur einzelne wenige Eiröhren eines Ovariums, die solche Likeime in sich einschlossen und auch vielleicht dieses nicht cinmal in ganzer Länge, sondern bloss an gewissen Stellen, in der Mitte, oder an untern Ende, vielleicht anch mit Unterbrechungen hier und dort. Indessen will es mir seheinen, als wenn solche unregelmässig sich entwickelnden Eikeime nur selten ihre volle Ausbildung erlangten, denn oftmals waren dieselben wie in Rückbildung begriffen und in fettartige gelbliche Massen verwandelt, dic ihro genuine Bildung kaum noch zu erkennen gaben. Namentlich galt solches von den Dotterfächern, deren Bildungszellen mitunter völlig zerfallen und aufgelöst zu sein schienen.

Doch daneben fehlte es auch nicht an Eiröhren mit ganz normal und regelmässig entwickelten Eikeimen, ja es gab selbst Fialle, in denen das ganze Ovarium mit allen seinen Röhren vollstindig besetzt war, wie bei eincr Legekönigin, nur dass die Zahl der Eikeime hier natürlich an Menge zurückstand. Mit blossen Augen unterschied man in solchen Fällen viclleicht 3-4 Eikcine oder, da jeder derselven bis zur völligen Entwickelung aus Dotter- und Keimfach bestand, 6-7 einzelne Anschwellungen, während die Königin deren mehr als die doppelto Zahl erkennen lïsst. Auf diese $\Lambda$ nschwellungen folgte dann nach oben noch eine vielleicht eben so grosse oder auch etwas grössere Menge von jungen Keimen, die sich

*) Die geringate Zabl der von mir bei einer Königin beobachteten Eiröhren ist etwa 100 jederseits. Ich fand sio bei einer von v. Berlepsch mir übersendeten nMiniatarkönigin". 
erst bei mikroskopischer Untersuchung zu erkennen gaben, ganz wie bei den Königinnen *).

Natürlich war das Ausselıen der Ovarien bei der geringen Menge der Eiröhren ganz anders, als das bei den ausgebildeten Weibchen der Fall ist. Doch das gehört am Ende nicht hierher; wie ich denn überhaupt cine ausfuhrliche Beschreibung vom Bau der $\Lambda$ rbeitergenitalien für eine andere Gelegenheit mir vorbehalte. Das Einzigc, was uns hier noch interessirt, und für die Beurtheilung des vorliegenden Falls allein massgebend orscheint, ist die Bildung und Beschaffenheit der Samentasche.

Wenn ich bemerke, dass dieses Organ in jeder Beziehung mit der Samentasche der Arbeiter ibereinstiment, so ist damit der Beweis für die Jungfrüulichkeit unserer Drohnenmütter geliefert.

Das Receptaculum der Königin ist bekanntlich ein kugelrundes Blïschen, das jederzeit, wihrend des jungfrïulichen Zustandes, wie auch später, etwa 1,5 Mn. im Durchmesser hat und auf einem etwa eben so langen Sticle aufsitzt, der in umberleutender Entfernung von seinem obern Ende die beiden Anhangshrüsen aufnimmt. Statt dieses ansehnlichen Gebildes besitzen unsere Arbeiter ein sehr kleines, kaum mit blossem Auge sichtbares Receptaculum von keulenförmiger Gestalt, dessen kolbig aufgetriebenes Ende 0,25 Mm. in Länge und 0,17 Mm. im Querdurehmesser misst. v. Sicbold, der die Existenz dieses verkümmerten Organs zuerst nachwies (Ge r m ar's Zeitschrift fuir die Entomologie IV, S. 375), hielt die kolbige Endanschwellung desselben für dic zusammengefallene Samentasche; ich habe mich indessen davon überzengt, dass dasselbe (Fig. 16) nur das Ende des Samenganges darstellt und dass das eigentliche Receptaculum nur

*) Ich habe auf der Natuforscher-Versammlung in Bonn (wiederum durch Dr. Dönhoff) Gelegenheit gehabt, solche Bienenarbeiter mit Eiern und Eikeimen der zoologischen Section unter dem Mikroskope zu demonstriren und viclo bedeutende Autoritaten (wio z. B. van Bonoden, van der Hooven, Krohn, Troschel, Vrolik u. A.) von der Richtigkeit der obigen Bemerkungen überzeugen können. 
durch einen sehr unbedeutenden kegelförmigen Anhang reprësentirt wird, durch ein Gebilde, das sich äusserlich nicht einmal abzeichnet (Fig. 16a). Zum Beweise für die Richtigkeit meiner Auffassung hebe ich hier besonders den Umstand hervor, dass die beiden kleinen Anhangsdrüsen mit ihrem gemeinschaftlichen Ausführungsgang in das Ende dieser Anschwellung neben dem oben erwähnten Züpfehen sich inseriren. Die kolbige Anschwellung des Samenganges, die sich ganz in derselben Weise auch an dem Befruchtungsapparate der Königin auffinden lïsst, rührt theils von ciner Erweiterung der innern Chitinroblure her, theils aber auch und vorzugsweise von einer stäkern Zntwirkelung der diese Chitinröhre umgebenten drusigen Zellenschicht und der Anwesenheit des oben bei der Königin beschriebenen Muskelapparates, der hier natürlich höchstens dazu dienen kann, das Secret der Anhangsdrüsen in die Scheide zu überführen*).

Es bedarf unter solchen Unstinden keiner weitern Ausführung, dass eine Arbeitsbiene - und das sind ja dic eierlegenden s. g. Drohnenmütter - zu ciner Aufnahme von Sperma untauglich ist und es selbst dann auch blicbe, wenn eine Begattung derselben möglich wäre.

Wenn es nun aber erwiesen ist, dass diese Drohnenmitter blosso cierlegende Arbeiter sind, so entstelit die Frage, durch welche eigenthümliche Combination der Umstande diese Individuen zur Legreife sich entwickeln konnten. Die Eiröhren der gewöhnlichen $\Lambda$ rbeiter sind leer, d. h. ohne Eier und Eikeime, deren Stello durch gewöhnliche helle Zellen vertreten wird, wie man es während der ersten Hälfte des Puppenlebens auch bei den Königुmuinen findet. Nur in sehr seltenen Fällen fand ich in diesen Eiröhren auch die allerèsicen Anfünge der Eibildung, grössere helle Bläschen, dic in ziemlich regelmässignan Abständen hinter einander lagen und sich durch cine Umlagerung mit Etiveiss als Keimblïschen zu erkennen gaben. Ob diese Arbeiter vielleicht s] äterhin vollstïndige Eier ent-

*) Und auch das nichit einmal in allen Fillen, denn nicht selten sucht its?n bei den Arbeitsbienen vergeblich nach einem Zusammenhango zwischen den Ausfïhrungsgingen der Anlangsdrüsen und dem Duct. seminalis. 
wickelt haben würden, weiss ich nicht, doch scheint mir der Umstand hier beachtenswerth, dass ich (in denselben Stöcken) niemals weitero Entwicklungsstufen auffand:

Man hat die Existenz solcher Drohnenmütter wohl durch die Annahme erklären wollen (II uber), dass dieselben in der Nähe der Weiselwiegen erbrütet wïrden und gelegentlich einen Brocken königlichen Futterbreics erhielten. Auch v. Siebold hat sich diesem Erklärungsversuch angeschlossen (a. a. O. S. 76), obwohl ich schon früher darauf aufmerksam gemacht hatte (Bienenzeitung 1856 S. 210), dass derselbe unzureichend sei, da sich die Drolnemeütter, wie man weiss, gelegentlich noch in sulchem Stocleou entricleclı, in denen bei dem Abgang der Königin bereits alle Brutzellen bedeckelt sind, oder auch in $\Lambda$ blegern solcher Stöcke, die gar nicht geschwärmt, also auch keine jungen Königinnen erzogen haben (Scholz, Bienenzeitung 1857. S. 183). Auch würde man in solchem Falle vielleicht cher eine Zwischenform zwischen den Königinnen und Arbeitern erwarten können*), als eine gewöhnlicho Biene.

*) Es ist bekanntlich eine der interessantesten Entdeckungen in der Bienenkundo (von Schirach), dass sich bis zu einem bestimmten Termine eine jedo Arbeiterharve zu ciner Königin crzichen lasst. ( $\mathrm{I} u \mathbf{b} \in \mathbf{r}$ a. a. O. Vierter Bricf.) Diese Thatsache findet ihr wissenschaftliches Verstzndniss in dom Umstande, dass (nach meinen Beobachtungen, a. a. O.) anfunglich eine jedo Arbeiterlarvo dieselbe Nahrung (Futterbrei $=$ Chymus) bekommt, wio die Königintarve. Erst etwa am sechsten Tage ibres Lebens tritt hierin eine Aenderung e dem dio Arbeiterlarve dann statt des frühern Futterbreies dic Rolisto hult, aus denen dieser im Magen der Arbeitsbienen bereitot wurde, an und Pollen), wlhrend dic Königinlarve bis : ihrer Verpupnoung init Futterbrui und zwar sehr reichlich ernkhrt rirci Ist liese Antulerung dor Nahrungswolse einmal eingotreteu, daun entwiekslt gint. die Arbeiterlarvo unwiedorbringlich zu

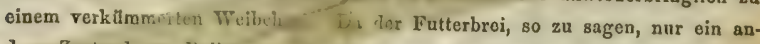
derer Zustand vol Pollen und Honig ist, so reducirt sich der hier vorliegendo Untersebied in wirn Lihlıungsweise der Arbeiter- und Königinlarven im Wer.iticben auf ein Plus und Minus, wio das auch experimentell nachzuweisen ist, wenn man einem Bienenvolke die Pollennahrung abschneidet und die Bienen dann $z$ wingt, ihre ganze Brut mit Honig und Futterbrei aufau- 
Im Gegensatze zu dieser fruheren Erklärungsweise habe ich (a. a. O.) die Vermuthung aufgestellt, dass es zur Entwicklung der Arbeitereier überhaupt nur gewisser günstiger Ernährungsverhältnisse bedürfe. Wenn eine $\Lambda$ rbeitsbiene und besonders eine jüngere, wio ich damals vermuthete, bei geringer Ausgabe eine reichliche und kräftige (eiweisshaltige) Nahrung genösse, vielleicht auch von den iibrigen Bienen nach Art einer Königin gefüttert würde, wenn also die nutritiven Ersparnisse über das individuelle Bedürfniss hinausgingen, dann sollten meiner Meinung nach die physiologischen Bedingungen für die Bildung und Entwickelung der Eikeime erfült sein. Was ich hiermit aussprach, war im Grunde genommen nichts Neues, sondern bloss die Uebertragung gewisser allgemeiner, zum Theil auch lïngst erkannter Gesetze (vgl. meinen Artikel Zeugung a. a. 0. S. 719) auf einen speciellen Fall, eine Uebertragung, die um so näher liegen musste, als dieselben Verhältnisse offenbar auch auf die Fruchtbarkeit und selbst den Eintritt der Eierlage (die s. g. Brunst) bei den Königinen bestimmend influiren.

Die Richtigkcit meiner Schlussfolgerung sollte bald bewiesen werden. Gegen Ende October 1856 erbielt ich wiederum von Herrn Dr. Donhöff, unserm modernen Huber, eine Sendung ron Arbeitsbienen, die zu einer Zeit, in der die Ausflüge bereits aufgehört hatten, 14 Tage lang mit Eiern (in Honig) gefüttert waren. Zu meiner freudigen Ueberraschung fanden sich (Bienenzeitung 1857. S. 4) unter etwa 18 Bienen vier Exemplare mit deutlich entwickelten, zum Theil sogar ganz ansehnlichen Anschwellungen an den Eiröhren, ganz ïhnlich, wie ich es später bei manchen der oben erwähnten Drohnenmütter fand. Ausgebildete Eier wurden freilich nicht angetroffen, allein das erklärt sich wohl aus der geringen Zcitdauer des Versuches, so wie der vielleicht nicht ganz passenden Nahrung.

riehen. Vergl. Dönhoff, a. a. O. 1856, S. 172. (Das Eiweiss des Futterbreies stammt in solchen Fullon begreiflicher Weise aus dem Bienenkörper, wo es sich im Innern des Magens noch wochenlang nach vorhergegangener Pollennahrung nachweisen lilast. D ön hoff ebendas. 1855, S. 287.) 
Unter solchen Umständen wird es denn auch physiologisch verständlich, wenn wir derartige Drohnenmütter häufiger und vielleicht zahlreicher in weisellosen Stöcken finden, als in solchen mit einer fruchtbaren Königin, die täglich (viele hundert bis tausend) Eier legt *). Was in solehen Fällen die Brut an Futterbrei und Rohstoffen verzelirt, wird in weisellosen Stücken zum Theil auf die Production von Eiern verwandt, oder kann wenigstens in dieser Weise seine Verwendung finden. Wenn das nicht überall, bei jeder Biene und in jedem Stocke geschicht, so düfte das wohl nur cin Beweis scin, dass ausser dieser einen Hauptbedingung noch eine Anzahl weiterer Momente hier in Betracht kommen.

Was nun aber in solcher Weise bei der Biene nur eine Ausnahme ist, die Existenz von eierlegenden Arbeitern, das erscheint in don Colonien unserer Wespen, Hummeln und $\Lambda$ meisen als eine ganz constante Erscheinung. Es ist unrichtig, wenn v. Siebold in sciner oben erwähnten Abhandlung über das Receptaculum der Hymenopteren (a. a. O. S. 377) von den Wespen behauptet, dass die Eiröhren derselben beständig leer seien, wie die Samentasche. Man kann von allen den genannten Thieren - ich untersuchte drei Arten Bombus und etwa eben so

7) Die Fruchtbarkeit der Bienenkönigin ist eine ungeheure und beträt oftmals im Jahro woit tiber 100000 Eier. Diese Eicr reprilsentiren ein Gewicht von mehr als $16 \mathrm{Gr}$, wahrend dio Königin selbst nur etwa 0,15 Gr. Reingewicht hat. $100 \mathrm{Gr}$. Bienenkönigin produciren also des Jahres $11000 \mathrm{Gr}$. Eisubstanz, d. b. ungefuhr so viel, wie ein Woib, das tllglich 3-4 Kinder geburen würde! (Noch weit botrlichtlicher ist aber dio Fruchtbarkeit der Termitenzönigin, die - Tormes bellicosus - nach Smoathman in 24 Stunden 80000 Eier, in cinem Jahro also, sechs Monato Legezcit vorausgesetzt, mindestens 12 Millionen Eier legt. Obgleich die Tormitenoier nicht unbetrilchtlich kleiner sind, als Bieneneier, so mögen dieso 12 Millionen doch immerhin gegen $400 \mathrm{Gr}$. wiegen, wllhrend das Reingewicht der Termitenkönigin - ohno Koth und Eier - vielleicht das Doppelte der Bienenkünigin betrïgt. Auf dicse Woise bekommen wir $0,3: 400=100: 130000$, eine Productivitlt also, dio noch etwa $12 \mathrm{Mal}$ grösser ist, als die der Biencnküniginl) 
vicle Wespen, von Ameisen besonders die Formica rufa - kaum ein Dutzend Arbeiter untersuchen, ohne mehrere darunter mit Eikeimen und selbst mit entwickelten Fiern in den Ovarien anzutreffen. Mitunter trifft man auch Völker, in denen diese Erscheinung noch häufiger ist, wie ich denn z. B. gegen Ende September ein starkes Volk von Vespa germanica aushob, in dem fast die IIälfte der Arbeiter Eier und Eikeime enthielt. Auch die Jahreszeit scheint hier von Einfluss; ich glaube wenigstens beobachtet zu haben, dass (bei IIummeln und Wespen) im Herbst mehr eierlegende Arbeiter vorkommen, als im Sommer.

Ich nenne diese Arbeiter eierlegend, obwohl ich bis jetzt erst die Anwesenbeit von Eiern oder Eikeimen in den Ovarien derselben hervorgehoben habe. Dass sie diese Bezeichnung verdienen, darüber kann kein Zweifel sein. Nieht nur, dass man bei ihnen nicht selten auch in den Oviducten und selbst in der Scheide reife Eier antrifft, das Eierlegen derselben ist auch - wenigstens bei Iummeln und Wespen -, wie wir später noch besonders zu erwähnen haben, durch unmittelbare Beobachtung festgestellt.

Was die Art und Weise betrifft, wie sich diese Arbeitereier entwickeln, so gilt dafür dassolbe, was oben für die eierlegenden Arbeitsbienen hervorgehoben worden. Auch hier sind es bald nur einzelne, bald alle Eiröhren, die Keime enthalten; bald sind dieso Keime über die ganze Lünge der Eiröhren verbreitet, bald auch mit Unterbrechungen und Spriingen über dieselben vertheilt. Doch scheint es im Ganzen, als wenn diese Unregelmïssigkeiten, viclleicht mit Ausnahme der Ameise, weniger häufig scien, als das bei den Arbeitsbienen der Fall ist.

Die Ameisen sind unter den hier in Betraclit kommenden Arbeitorn auch diejenigen, die sich durch dio Bildung ihrer Goschlechtsorgane am auffallendstc , von den königinnen unterscheiden. Während letztero (F. rutı) jederseits vielleicht 100-120 Eiröhren erkennen lassen - $\mathrm{F}$. nigra besitzt deren nur $30-40-{ }^{*}$ ),

*) Lóon Dufour fand bei Formica nur 5-7 zweikammerigo Eiroblren (1. c. p. 482) - sollto derselbe viclleicht Arbeiter untersucht baben? Uebrigens sind 
die zur Zeit der schärsten Eierlago bis zu $18 \mathrm{Mm}$. Länge heranwachsen, haben dio Arbeiter, wie die Bienenarbeiter, meist nur 5 Liröhren, selten mehr (bis 11), häufig aber weniger, mitunter nur 2 oder gar nur 1, und zwar Eiröhren, die allerhöchstens $4 \mathrm{Mm}$. messen. Eine Samentasche scheint diesen Arbeitern (Formica rufa) in der Regel vollstïndig zu fehlen; ich habe dieselben nur in einigen Fällon als ein helles und pralles Chitinblisschen von $0,08 \mathrm{Mm}$. im Durchmesser, das durch einen äusserst dünnen Gang in die Scheide einmündete und von einer einfachen Zellenlage umhüllt war (Fig. 19), aufgefunden.

Ganz anders verhält sich das bei den Arbeitern der Wespen und Hummeln, die nicht bloss durch die Zahl der Firöhren (meist 4 jederseits bei Bombus, $6-8$ bei Vespa), sondern auch durch die Bildung ihrer Scheide und ilhres Receptaculum (Fig. 17 von Vespa germanica) sich unmittelbar an die Königinnen anschliessen. Nur in der Länge der Eiröhren, sowie in der Existenz und Menge der Eikeime findet sich ein Unterschied. Während erstere bei der Legekönigin im Sommer bis zu $53 \mathrm{Mm}$. (Bombus subterraneus) und selbst bis zu $78 \mathrm{Mm}$. (Vespa Crabro) heranwächst, misst dieselbe bei den $\Lambda$ rbeitern selten melır als etwa $4 \mathrm{Mm}$., kaum die Hïlfte der Lünge, welche die Eiröhren der noch jungfrüulichen Königin besitzen.

Bei der Biene haben wir die Enge der Geschlechtsorgane und die rudimentiare Bildung der Samentasche als cinen Grund gegen die Möglichkeit einer Begattung und Befruchtung geltend gemacht. Für die Ameise künnte man mit Rücksicht auf die oben erwälnten analogen Verhältnisse ganz dasselbe behaupten und viellcicht mit eirem noch augenfülligeren Rechte. Aber nicht so für die Wespen und Hummeln, dercn Arbeiter sich viclmehr vom anatomischen Standpunkto aus als völlig begattungs- und befruchtungsfähig erweisen. Trotzdem aber habe ich unter mehreren Hunderten dieser Insekten niemals ein befruchtetes Individuum angetroffen. Wie sich diese

die Untersuchungen L. Dufour's meines Wissens dis einzigen, dio wir über den Bau der Geschlechtsorgano bei den Ameisen besitzon. 
Erscheinung physiologisch erklärcn lässt, weiss ich niclit; vielleicht, dass sio in einer Abneigung der männlichen Individuen begründet ist.

Trotz dieser Jungfiäulichkeit aber legen die Arbeiter aller der genannten Insekten Eier, und zwar Eier, die sich, wie die der $\Lambda$ rbeiterbienen, in Nichts von denen der befruchteten Königin unterscheiden; es entsteht nun die weitere Frage nach dem Schicksale dieser Eier.

In October des vergangenen Jahres sah ich in einem kleinen Stock von Vespa germanica, den ich unter einem Glaskasten hielt, einen $\Lambda$ rbeiter ein Ei legen. Er legte dasselbe in cino Wabe mit grossen Zellen, die zur Lirbrütung der Königinnen und Männchen bestimmt war und auch schon Brut enthielt. Die Arbeiterin wurde ergriffen und anatomisch untersucht. Sie erwies sich als Jungfrau und enthielt noch mehrere ziemlich weit entwickelte Eikeime. Am fünften Tage war das Ei ausgesclllüpft und eine junge Larve nalın dessen Stelle ein. Die Larve wurde mehrere 'Inge gefüttert; sie wuchs zusehends, bis plötzlieh ein kaltes und regnerisches Wetter eintrat und dicselbe mit der noch übrigen Brut zu Grunde richtete.

So unvollstïndig dic Bcobachtung ist, so beweist sie doch, dass die unbefruchteten Eier der Wespenarbeiter sich entwickeln, wie die der Arbeitsbieno - ob zu Männchen oder nicht, das bleibt freilich noch zu untersuchen.

Diese Beobachtung ist aber nicht die einzigo ihrer Art; wir haben ganz ähnliche und noch viel vollstindigere Beobachtungen auch für die IIummeln. Dieselben sind von dem Solhne des berühmten A pisten If ubor angestellt und in den Transact. Linn. soc, vom Jahro 1802 (Vol. VI. p. 288 ff.) publicirf worden, aber wie es scheint ziemlich unbekannt geblieben, obwohl sic auch in der bekannten Einleitung in die Entomologie von Kirby und Spence (Uebersetzung von Oken Th. II. S. 139) eine gebuihrende Stelle gefunden haben.

II uber sah nicht bloss zu verschiedenen Malen Arbeiter Eier legen und diese sich entwickeln; er überzeugte sich auch weiter davon, dass es ausschliesslich männliche Individuen waren, die aus diesen 
Arbeitereiern hervorgingen und zwar völlig ausgebildete Männchen, die sich nach einiger Zcit mit den im Stocke vorhandenen Königinnen begatteten。*)

Dass P. Huber diese drohnenbrütigen Hummeln von den übrigen Arbeitern unterscheidet und im Gegensatz zu der Königin ("grandes femelles") als "petites femelles" bezeichnet, kann uns in der Deutung seiner Beobachtıngen nicht irre machen, denn er erklärt ausdrücklich (p. 290), dass die Fähigkeit des Eierlegens der einzige Grund sei, der ihn zu dieser Bezcichnung veranlasse.**) Im $\Lambda$ eussern seien diese kleinen Königinnen in Nichts von den gewöhnlichen Arbeitern verschieden. Auch auf den Umstand kann ich kcin grosses Gewicht legen, dass $\mathrm{H}$ uber für diese kleinen Königinnen, ebenso wie für die grossen, die Nothwendigkeit einer vorhergegangenen Begattung in Anspruch nimmt. Allerdings klingt es ziemlich apodictisch, wenn er z. 13.1.c. p. 285 sagt: "Toutes les ouvrières qui naissent au printemps ne sont pas neutres, comme on l'a cru jusqu'à présent; il en est des fécondes; on en voit plusieurs dans chaque nid. Ces mouches font toutes les fonctions des mìres; elles sont quelques fois très-petites, et a cause de cela lo nom de petites femellos peut servir a les distinguer. Elles sont entourées dès leur naissance d'un petit nombre de mâles provenus des oeufs de la mèro commune; ces mâles les fécondent dès le mois de Juin; elles pondent bientôt après; et ce qui est bien remarquable, c'est qu'elles n'engendrent que des mâles, comme les ouvricres que l'on observe quelque fois dans les ruches d'abeilles, et qui ne pondent que des oeufs des faux bourdons. Mais si l'utilité de ces dernières est problematique, il me parait évident, que les petites femelles des bourdons sont destinées à fournir un plus grand nombre de mâles aux jeunes et grandes femelles, puisqu'après les avoir pondus et soignés, elles périssent cornme les ouvrières au commencement de l'automne."

*) Wegen der ausschliesslichen Drohnenbrütigkeit uennt II uber dicse cicrlegenden Arbeiter meist ndemi-fécondes".

**) Auch bezeichnet Verfasser dio eicrlogenden $\Lambda$ rbeitsbienen mit demselbon Namen "petites reines ou femelles", L. c. p. 283. 
Wenn ich trutz dieser apodictischen Behauptung eine Begattung bei den eierlegenden Arbeitern der Hummeln in $\Lambda$ brede stelle, so geschicht das nicht bloss deshalb, weil ich niemals $\Lambda$ rbeiter mit gefüllter Samentasche gefunden habe, sondern namentlich auch deshalb, weil das von $\mathrm{Huber}$ uns gleichfalls mitgetheilte Beobachtungsjournal, das seiner Darstellung zu Grunde liegt, nirgends einer solchen Begattung Erwähnung thut. Offenbar ist dic Annahme dieses Vorganges eine blosse Voraussetzung, ohne die sich Huber die Erscheinungen der Eierlage und der Drohnenbrütigkeit bei den $\Lambda$ rbeitern nicht erkliiren zu können glaubte, wie denn auch wciter die Behauptung von der frülızeitigen Drohnenbrütung aus den Eiern der Stammmutter meines Wissens durch keine einzige Beobachtung gestützt wird.*) Von besonderem Interesse ist es übrigens, aus den Angaben II uber's zu ersehen, dass das Vorkommen solcher eierlegenden Arbeiter, wie ich das auch dureh meine Untersuchungen bestïtigt finde, in den Nestern der IIummeln (und Wespen) ganz constant ist. Da nun auch zugleich die Menge der männlichen Individuen bei diesen Insekten nicht eben sehr gross ist, so könnte man hier vielleicht mit mehr Grund als bei den Bienen vermuthen, dass die männlichen Individuen überhaupt nur durch die Eierlage der Arbeiter ihren Ursprung nähmen.

Ob sich diese Beobachtungen und Annahmen ohne Weiteres auch auf die eierlegenden Arbeiter der Wespen und Ameisen ïbertragen lassen, muss ich leider unentschieden lassen. Ich wciss nicht einmal, ob die von den Amcisenarbeitern gelegten Eier - dass die Eier von diesen Thieren abgelegt werden, ist mir nicht zweifelhaft, da ich dieselben mehrmals in der Scheide vorfand **) - sich entwickeln. Jedoch dürfte solche Annahmo nach anderweitigen Erfahrungen im

*) An einer andern Stollo giebt Uubor selbst an, dass dio Mänuchen der Ifummoln erst im Splltsommer mit den Weibchen erbrütet würden. L. c. p. 264.

**) Ich will hier übrigens nicht verschweigen, dass P. II uber, derselbe, dem wir die interessanten Beobachtungen über die eierlegenden Hummelarbeiter verdankon, ausdrücklich angicbt, dass er niemals einen Ameisenarbeiter habe Eicr legen sehen. Rech. sur les mocurs des fourmis, 1810 , p. 88. 
höchsten Grade wahrscheinlich sein. Für die Wespen kann ich einstweilen nur so viel behaupten, dass eine Parthenogenese denselben nicht fehlt - ob sie sich glcichfalls, wie bei den IIummeln und Bicnen, als Drohnenbrütigkeit äussert, bleibt noch zu untersuchen. Durch die oben von mir mitgetheilte Beobachtung wird dic Vermuthung eines solchen Verhältnisses allerdings bis zu einem gewissen Grade wahrscheinlich. Dic damals crwilhnte Arbeiterin legte in eine grosse Zelle; es beweist das wenigstens so viel, dass dio aus diesem Li hervorgehende Larro sich in ein geschlechtlich entwickeltes Thier metamorphosirt haben würde. (Die Weiselzellen der Wespen sind weder durch Stellung, noch dureh Grösse und Ausschen vor den männlichen Zellen besonders ausgezeichnet.)

Ich darf es ïbrigens nicht unterlassen, hier auf eine Beobachtung Gundelach's (Nachtrag zur Naturgesch. der Honigbiene S.2) hinzuweisen, die mit der so eben von mir ausgesprochenen Vermuthung viclleicht nicht ganz übereinstimmt. Gundelach beobachtete nüimlich ein kleines, nur ans wenigen Arbeitern bestehendes IIornissenrölkchen, das, trotz der $A$ bwesenheit einer Königin, Eier absetzte. Die Eier entwickelten sich auch; aber sic entwickelten sich - zu $\Lambda$ rbeitern, von denen $G$. es jedoch zweifelhaft lässt, „ob es Männchen oder Weibchen waren". Dieser letzte Zusatz zeigt zur Evidenz, dass Gundelach von den Geschlechtsverhältnisser der Wespen keine genaue Kenntniss hatte, nicht wusste, dass die Arbeiter derselben beständig weiblichen Geschlechtes sind, also auch wahrscheinlicher Weise Arbeiter und Männchen nicht zu unterscheiden verstand. Die Beweiskraft der Gundelach'schen Beobachtung reducirt sich hiernach auf dio Thatsache, dass die Hornissenarbeiter entwickeJungsfähige Eier legen und zwar Eier, aus denen keine ngrossen Weibchen", sondern bloss kleinere Individuen hervorkamen. Hält man nun diese Thatsache mit meiner Beobachtung zusammen, nach der (allerdings in einem ausgebauten Neste) die Arbeitereier in eino Tafel für ausgebildete Geschlechtsthiere abgesetzt werden, so gewinnen wir einen neuen Wahrscheinlichkeitsgrund für die Annahme, dass die unbefruchteten (Arbeiter-)Eier auch der Wespe sich zu 
männlichen Individuen entwickeln. Und damit müssen wir uns einstweilen begnügen - das Weitere einer zukünftigen Beobachtung überlassend.

Die Thatsache, dass es nicht bloss die Bienen sind, bei denen unter den gesellig lebenden Hymenopteren eine Parthenogenese vorkommt, dass diese vielmehr auch bei den übrigen verwandten Coloniethieren ihre Rolle spiclt und in einer, vielleicht noch viel bedeutungsvolleren Weise, - diese Thatsache dürfen wir, glaube ich, fortan als bewiesen und gesichert für alle Zukunft anselsen. Aehnliches werden wir in Zu. kunft auch gewiss noch für den Maushalt der Termiten kennen lernen, wie denn schon jetzt eine Reihe von Thatsachen (z. B. die $\Lambda \mathrm{u}$ wesenheit s. g. II ̈̈lfsweibchen und Anderes) für die Ausbreitung der Parthenogenese auch auf diese Thiere zu sprechen scheint.

\section{Schlussbetrachtungen.}

Es unterliegt kcincm Zwcifel, dass die Parthenogenesis unter den Insekten eine sehr viel weitere Verbreitung hat, als wir das bis jetzt wissen und alınen können. Ich habe so eben erst auf die Termiten hingewiesen und sie als Geschöpto bezeichnet, deren Haushalt uns aller Wahrscheinlichkeit nach ein neues, vielleicht noch auffallenderes Beispiel von Parthenogenesis kennen lehren wird. Auch die Gallwespen dürften wohl in Betracht kommen, wenn es sich darum handelt, das Gebiet dieser Erscheinung im Voraus zu bezeichnen; die Fortpflanzungsgeschichte dieser Insekten scheint, so weit wir sie bis jetzt kennen, mit der der Sacktrïger und Schildläuse eine grosse Aebnlichkeit zu besitzen.

Ebenso finden sich unter den Crustaceen Fïlle von Parthenogencsis, wie bei den Daphnien, deren spontane Entwickelung durch Lievin und Zouker bercits vor 10 Jahren auf experimentellem Wege nachgewiesen wurde und durch die neuen Beobachtungen $L u b$ bock's ihre volle Bestätigung gefunden hat. $\Lambda$ pus, Limnadia und andere verwandte Formen dürften sich wohl ähnlich verhalten, wie denn auch in der Gruppe der Arachnoiden, bei Milben u. a. die Annahme einer spontanen Eientwickelung ihre Berechtigung finden möchte. 
Ob die Parthenogenesis auch in weitern Kreisen über die niederen Geschöpfe verbreitet sei, wissen wir einstweilen noch so wenig, dass eine jede Vermuthung hier nur verfriiht sein würde*), v. Sie bold weist allerdings auf die Beobachtung $V o g t$ 's hin, nach der sich bei einer unbefuchteten Firola die abgelegten Eier zerklüfteten und mit Flimmerchen bedeckten, allein diese Beobachtung sprieht eben so wenig für eine wirkliche Parthenogenese, wie die von $B$ isch off beobachtete Furchung der Menstrualcier bei Süugethieren oder die Furchung unbefruchteter Frosch- und Fischeier. Ich kann daraus auch noch heute nicht melır entnelnmen, als fruher, wo ich diese beiden Beobachtungen (Art. Zeugung a. a. O. S. 958) dahin deutete, ndass die crsten Schritte für dic Embryonalentwicklung nicht selten auch in unbefruchteton Eiern stattfinden." Diese Schritte führen verschieden weit - sie führen bei gewissen Arthropoden bis zur Parthenogenese, d. h. bis zum vollstiindigen $\Lambda$ bschluss der Embryonalentwicklung.

Uebrigens geht schon aus den bis jetzt uns bekannten Fällen von Parthenogenesis herror, dass diese Erscheinung in der Lebensgeschichte der verschiedenen Arten auch eine verschiedene Bedeutung hat. In manchen Insekten, wie z. B. den Seidenspinnern, ist dieselle so selten oder vielmehr so wenig constant, dass sie mehr den Charakter einer zufïlligen Erscheinung trïgt, als einer solchen, die ein integrirendes Gliel in der planmässig combinirten Reihe der cinzelnen Lebensvorgïnge darstellt. Weit wichtiger erscheint uns die

*) Am eliesten künnto man bier noch an die Rotiferen denken, deren gewöhnliche Sommereier sich nach Cohn ohne Befruchtung entwickeln sollen. Zcitschrift für wiszenschaftliche Zoologio VIII, S. 431. (Cohn glaubt freilich, dass diese Eier nur als nungeschlcchtliche Fortpflanzungskörper" betrachtet werden dürften, allein Bau und Entwickelung charakterisiren dieselben doch als genuine Eicr. Sind Cohn's Angaben richtig, so kann es sich hier nicht, wio Verfasser meint, un einen Generationswechsel, sondern nur um einen Fall von Parthenogenesis handeln, wio ich das auch bereits in der hollisndischen Uebersetzung meiner Nachtrilge und Berichtigungen zu van dor Hooren's Zoologie, p. 117, herrorgehoben habe.) 
Parthenogenese bereits bei den Psychiden, Coccinen und in andern ahnlichen Fälen, wihrend sie ihre ganze volle Bedeutung erst in den so wunderbar geordneten Thierstaaten der gesellig lebenden Insokten entfalten dürfte.

Suchen wir uns den physiologischen Werth dieser Parthenogenese oder mit andern Worten die Vortheile klar zu machen, die dem Uaushalte der betreffenden Insekten aus derselben orwachsen, so dürten diese wohl zunächst und vorzugsweise in der Umstande zu finden sein, dass durch die spontane Entwicklung der Eier die Zahl der producirten Nachkommen um ein Betrïchtliches zunimmt. Es ist also die Vergrösserung der Nachkommenschaft, die wir als unmittelbare Folge der Parthenogenese in Anschlag zu bringen haben. Die Bedeutung dieser Erscheinung ist sicherlich koine geringe, wie wir schon aus dem Umstande entnchmen können, dass zahlreiche andere Einrichtungen des Fortpflanzungslebens genau auf dasselbe Ziel hinauslaufen. Als besonders verwandt unter diesen weitern Einrichtungen dürfen wir wohl die ungeschlechtliche Vermehrung der Parthenogenese an die Seite stellen. Namentlich ist es die ungeschlechtliche Vermehrung durch Keimkörner oder Sporen, die sich der Parthenogenese verwandt zeigt und zwar in einem so hohen Grade, dass sich beide, wie wir das oben bei den Blatt- und Schildläusen gesehen haben, dureh ihr Vorkommen bei nahe verwandten Thieren vertreten können. Nichts desto weniger aber existiren Unterschiede zwischen der Parthenogenese und der spontanen Entwicklung der Keimkörner und zwar nicht bloss in der anatomischen Eigenthiumlichkeit des sich entwickelnden Substrates, sondern namentlich auch darin, dass das $\mathrm{Ei}$, das die Parthenogenese vermittelt, nicht bloss der spontanen Entwicklung fähig ist, wie cine Spore, sondern auch zugleich die Möglichkeit einer Befruchtung zulässt und nach aller Wahrscheinlichkeit auch wirklich von Zeit zu Zeit befruchtet wird.

In manchen Fällen wird durch den Eintritt der Samenfüden in das sonst sich parthenogenetisch entwickelnde Ei das Product der Entwicklung ein anderes, wio z. B. bei den Bienen und Hummeln (vielleicht auch bei den Sacktrïgern u. a., nur dass bei diesen dann 
gerade in ungekehrter Weise die Befruchtung zu der Entwicklung männlicher Individuen hinführen würde), allein das ist eine mehr beiläufige Erscheinung, die keineswegs, wie wir uns bei den Scidenspinnern überzeugen konnten, für alle Thiere mit Parthenogenese Geltung hat.

Man könnte vielleicht vermuthen, dass die Befruchtung der Eier l,ei den Insekten mit Parthenogenese in bestimmten gesetzlich festgestellten Zwischenräumen stattfinde oder stattfinden müsse, allein das ist eine Annahme, die bis jetzt noch durch keine einzige Thatsache unterstützt wird*). Was wir in dieser Bezichung kennen, spricht vielmehr für eine völlige Unregelmässigkeit in dem Eintreten und der Wiederholung dieses Vorgangs. Es scheint mir - doch das ist eino vielleicht bloss individuelle $\Lambda$ nsicht - eben die jedesmalige Möglichkeit einer Befruchtung mit den wesentlichen Charakteren der Parthenogenese auf das Innigste zusammenzuhängen. Wenn die Befruchtung der Eier bei den Thieren mit Parthenogenese nur in bestimmten Intervallen oder auch nur zu gewissen Zeiten stattfinde, dann ist nicht abzuschen, wozu die Zwischengenerationen durch vollstündige weibliche Individuen vertreten und durch befruchtungsfahige, mit besonderer Micropyleinrichtung verschene Eier vermittelt würden, warum also die Individuen dieser Zwischengenerationen keine Ammen sind, wio bei dem Generationswechsel.

Der Unterschied zwischen diesen beiden Formen der Fortpflanzung besteht nach meiner Meinung eben darin, dass das eine Mal (Parthenogenese) bei jedem Fortpflanzungsacte eine Befruchtung intercurriren kann, während eine solche Befruchtung das andere Mal (Gonera tionswechsel) von Zeit zu Zeit bei bestimmten Fortpflanzungsacten intercurriren mus8.

Mit der Feststellung der Thatsache von der spontanen Entwicklung gewisser Eier ist die Physiologie um ein scheinbares Gesetz ärmer

*) Bei den Chermesarten, deren Fortpflanzung vielleicht noch am ersten solcher Auffassung Vorschub leisten künnte (S. 44), ist die Zusammensetzung der Sommergeneration aus munnlichen und weiblichen Individuen noch keineswegs zweifellos nachgewiogen. Bei Ch. laricis finde ich schon im Frühjahro zweierlei verschiedene Individuen, flügellose und geflügelte, dio aber beido jungfräulicho Weibchen sind. 
geworden. Es galt bisher als ziemlich ausgemacht, dass das Ei zu seiner Entwickelung einer Befruchtung bedürfe - wir sehen jetzt, dass es sich auch ohne Befruchtung entwickelt, freilich nur bei bestimmten Thieren und unter bestimmten Verhältnissen. Worin die Bedingungen einer solchen spontanen Entwickelung bestehen, wissen wir nicht; wir wissen aber auch Nichts über die Momente, durch welche sonst die Nothwendigkeit der Befruchtung herbeigefuhrt wird. Jenes scheinbare Gesetz ist nur ein Erfahrungssatz; wir sehen, dass für gewöhnlich die Eier ohne Befruchtung unentwickelt bleiben - und daraus schliessen wir auf die Nothwendigkeit ejier Befruchtung. Wissenschaftlich ist diese Nothwendigkeit nienlials erkannt, noch im Einzelnen nachgewiesen.

Die Geschichte der Zeugungslehre zeigt in deutlicher Weise, wie dfie Rolle, welche die Samenkörperchen bei der Befruchtung zu spie1 n scheinen, durch die Fortschritte der Wissenschaft immer mehr fond mehr beschränkt ist. Anfänglich war das Samenkörperchen der junge Keim, der das Ei nur als Wiege und den Dotter nur als Nah-

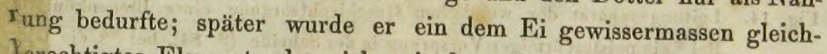
rerechtigtes Element, das sich mit demselben verbinden und durch Cese Verbindung den Keim erst erzeugen sollte; jetzt ist das Ei zum Keim geworden, wenn auch vielleicht nicht ohne Weiteres zum entwickelungsfähigen Keime. Das Ei repräsentirt nach dem heutigen Stande unserer Wissenschaft (vergl. Art. Zeugung a. a. O. S.957) ein System von Massen und Kräften, das sich unter gewissen Verhältnissen und Bedingungen durch eine fortlaufende Reihe von Veränderungen zu einem Embryo entwickelt. Zu der Erfullung dieser Bedingungen bedarf es in der Regel auch einer Befruchtung d. h. eines Contactes mit den Samenfäden; wo die Befruchtung unnöthig wird (bei der Parthenogenese), da ist der Kreis der Entwickelungsbedingungen entweder schon von vorn herein geschlossen oder er wird es durch Hinzufugung gewisser anderer, uns einstweilen noch unbekannter Factoren, die dann in gewisser Beziehung an die Stelle des befruchtenden Contactes zwischen Ei und Samenkörperchen treten. 


\section{Erklärung der Abbildungen.}

Fig. 1. Munnliche Geschlechtsorgane ron Aphis padi (8. 8),

Fig. 2. Weibliche Geschlechtsorgane derselben Art (S. 9)

Fig. 3. Eiröhren ohne, Eikeime aus einem weiblichen Embryo von Aphis padi (8. 11).

Fig. 4. Keimstöcke von A phis padi (S. 16).

Vig. 5-7. Junge Keimzellen von Aphis rosae, auf verschiedenen Entwickelongsstufen (S. 17), theils frei (Fig. 6), theils noch eingeschlossen in den Keimröbren.

Fig. 8. Weibliche Geschlechtsorgane von Lecamium hesperidum (S. 38).

Fig. 9 u, 10. Verschiedene Entwickelungszustände der Eiröhren von Coccus ado nidum (S. 40).

Fig. 11. Oberes Eiröhrenende von Coccus adonidum, nach vollendeter Eutwick lung (S, 41).

Fig. 12. Weibliche Geschlechtвorgane von Solenobia lichenella mit leeren Eirührea zusammengefallener Begattungstasche $\left(^{*}\right)$ und Samentasche $(* *)$.

Fig. 13. Eiröhrenstück einer ausgewachsenen Raupe von Solenobia lichenella, $m$ t ¿woi Eikeimen.

Fig. 14. Leitungsapparat der weiblichen Geschlechtsorgane einer BienenköniginBei * ein polsterförmiger Vorsprung in der Scheide (S. 84), bei ** die Gifblase.

Fig. 15. Durchschnitt durch den Hinterleib einer Bienenkënigin mit den Einge weiden in situ. Man sieht ausser den innern und Hussern Geschlechtsorganen mit den Anhangsgebilden (Samentasche, Giftapparat, Schmierdrüse) dio Bauchganglienkette, den Vor- oder Honigmagen, den Chylusmagen und Mastdarm, sowie unterhalb des Ovariums die grosse Tracheenblase. Bei * Vulra.

Fig. 16. Befruchtungsapparat einer weiblichen Arbeitsbiene. Bei * die rudimentäre Samentasche (S, 94).

Fig. 17. Vollstlundig entwickelter Befruchtungsapparat einer Arbeiterin von Vespa germanica. Unterhalb der üussern Peritonealhülle sieht man an Samentasche und Ausführungsgang die Durchschnitte der Muskelhaut.

Fig. 18. Scheide yon Bombus subterraneus, vom Rücken aus gesehen. Die Samentasche wird durch einen starken Tracheenstamm in ihrer Lago erhalten (8. 86).

Fig. 19. Rudimentürer Befruchtungsapparat einer Arbeiterin von Formica rufa (S,102). 


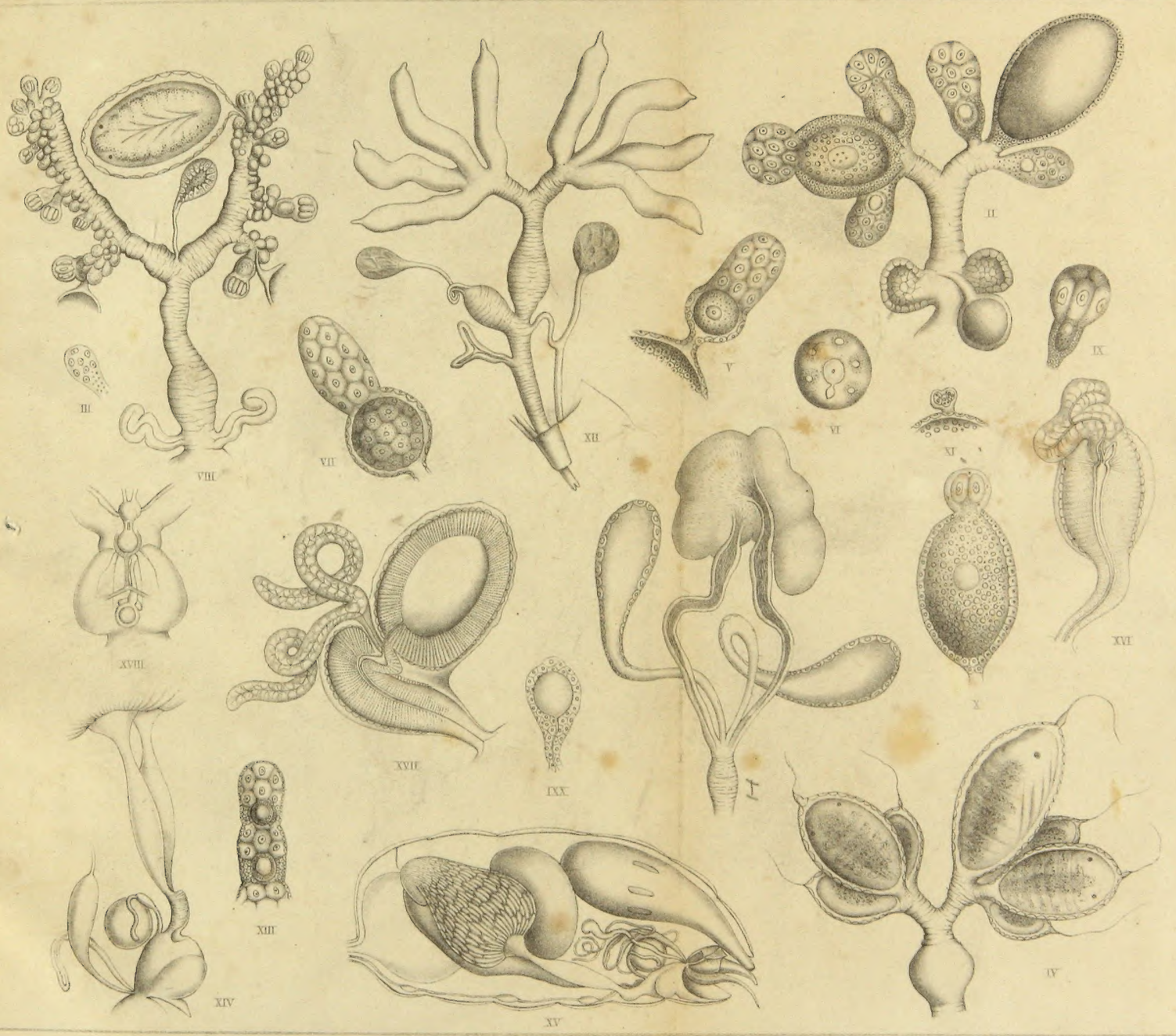


